Empowerment: What can nurse leaders do to encourage an empowering environment for nurses working in the mental health area?

\title{
By
}

\section{Heather Casey}

\begin{abstract}
A thesis submitted to the Victoria University of Wellington in the partial fulfilment of the requirements for the degree of Master of Arts

(Applied) in Nursing
\end{abstract}

Victoria University of Wellington

2000 


\begin{abstract}
Nurses, as the majority of the mental health workforce have a valuable contribution to make at a policy development level. The 1998 report from the Ministerial Taskforce on Nursing supports this statement but also indicates that there is a general reluctance by nurses to participate in policy development. For nurses to have control over their practice they need to have input into policy development.
\end{abstract}

Nurses having control over their practice has been linked to nursing empowerment. Therefore the question explored in this research project is: What can nurse leaders do to encourage an empowering environment for nurses working in the mental health area? The literature reviewed for this project includes empowerment, power, the history of nursing in relation to women's role in society, oppression and resistance, and literature on Critical Social Theory as the underlying theoretical and philosophical position which informs the research process.

In order to answer the research question a single focus group was used to gather data from a group of registered nurses practising in mental health. Focus groups as a data collection method produce data and insights that would be less accessible without the interaction found in the group. The key themes to emerge from the data analysis were; power is an important component of empowerment and power relationships; and at a systems level, professional, organisational, and political influences impact on feelings of empowerment and/or disempowerment. These key themes are discussed in relation to the literature and the broader social and cultural context of the mental health care environment. The contribution this research makes to nursing includes a list of recommendations for nurse leaders who aim to provide an empowering environment for nurses practising in mental health. 


\section{Acknowledgements}

There are a number of people who I would like to acknowledge who have contributed both directly and indirectly to the development of this thesis. Their support and assistance was invaluable.

Thank you to my thesis supervisor Rose McEldowney, who provided constant encouragement as well as guidance and feedback on the research content and process.

Thank you to the focus group participants for giving up their time to assist with the research and for sharing their thoughts and feelings within the group setting. Your generosity is acknowledged.

Thank you to the focus group assistant who also provided support and encouragement throughout the research project.

Thank you to the mental health service within the healthcare organisation supporting this research.

Thank you to the nurses I work with, their interest in my research and pride in my achievement often made the difference between writing and not writing.

Finally a huge thank you to my husband Greg, our children Shaun and Amanda, and, my father George - their patience with a wife, mother and daughter who was inclined to only ever hear half of a conversation and spent evenings and weekends working on the computer has resulted in the development of this thesis.

I would also like to acknowledge the Victoria University of Wellington Graduate School of Nursing and Midwifery who offered a Psychiatric/Mental Health Nurse Scholarship in 2000. I applied and was successful in obtaining a financial contribution toward the cost of this course of study. 


\section{Table of Contents}

Page

Abstract

ii

Acknowledgements

iii

Table of Contents

iv

List of Tables

viii

Chapter One: Introduction to the Research Project

Chapter Two: Context and Focus of the Research Project 11

Introduction 11

The Early Years 12

The Professional Years 15

$\begin{array}{ll}\text { Conclusion } & 22\end{array}$

Chapter Three: Literature Review on Empowerment 23

Introduction 23

Empowerment 24

Nursing History in relation to Women's Role in Society 29

Nurses as an Oppressed Group $\quad 30$

Nursing and Resistance to Domination 32

Oppression and Resistance Related to the Research Context 34

Conclusion $\quad 35$

Chapter Four: Critical Social Theory — Informing the Research Process 37

Introduction $\quad 37$

Critical Social Theory - Key Assumptions 38 
Critical Social Theorists — Jurgan Habermas and Paulo Freire $\quad 42$

Conclusion 46

Chapter Five: Research Method and Process 48

Introduction $\quad 48$

Focus Groups $\quad 49$

Rationale for Selecting the Focus Group Method 51

Analysing and Interpreting the Focus Group Data 53

Ethical Considerations $\quad 55$

Promoting Rigour in this Research Project 58

$\begin{array}{ll}\text { Conclusion } & 62\end{array}$

Chapter Six: The Focus Group 63

Introduction 63

Planning the Focus Group $\quad 64$

Facilitating the Focus Group Process 65

Selecting the Focus Group Participants 67

Implementing the Focus Group Process 68

Reflecting on the Focus Group Process 71

$\begin{array}{ll}\text { Conclusion } & 73\end{array}$

Chapter Seven: Analysing and Interpreting the Data from the Focus Group 74 Introduction 74

Data Analysis - Mechanical Stage 74

Data Analysis - Interpretive Stage 77

$\begin{array}{ll}\text { Conclusion } & 88\end{array}$

$\begin{array}{ll}\text { Chapter Eight: Discussion } & 90\end{array}$

Introduction $\quad 90$

Nursing Participation at a Decision-Making Level 91

Power is an Important Component of Empowerment

and Power Relationships 93

Analysis of Social Consciousness 98 
Professional, Organisational, and Political Empowerment

Chapter Nine: Conclusion to the Research

103

Recommendations for Nurse Leaders

103

Reflections: Answering the Research Question/Importance and

Contribution of this Research to Nursing 106

Benefits of Participating in the Research Project 108

Limitations of the Research Project 109

Suggestions for Further Research 111

Dissemination of Findings/Feedback to Participants 112

Concluding Statement 112 


\section{Appendices}

Appendix 1 Letter: Invitation to Participate in a Research Project

Appendix 2 Participant Information Sheet

Appendix 3 Consent Form to Participate in a Research Project

Appendix 4 Application for Ethical Approval to Undertake a Research Project with Registered Nurse Employees of the Healthcare Organisation

Appendix 5 Letter: Regional Ethics Committee Full Ethical Approval

Appendix 6 Letter: Request for Access to Registered Nurse Employees

of the Healthcare Organisation

Appendix 7 Letter: Healthcare Organisation Approval to Approach Registered Nurse Employees of the Healthcare Organisation

Appendix 8 Letters: Confidentiality Agreements

Focus Group Assistant

Transcriber

Appendix 9 Letter: Thank You for Participating in the Focus Group and Accuracy Check with Focus Group Participants

Appendix 10 Key Ideas to Emerge from the Focus Group Discussion with Supporting Quotes 


\section{List of Tables}

Table 1: Key ideas that emerged and examples of the associated words/phrases of similar meaning. 


\section{Chapter One: Introduction to the Research Project}

I have worked as a registered nurse in the area of Mental Health for the past nine years. My current position involves working as a team leader with managerial responsibility for inpatient beds. I also have the responsibility for service development activities that include; setting and maintaining standards of nursing practice, developing policies and procedures to support nursing practice, and providing leadership and direction in professional development activities. Nurses practising in mental health are expected to use organisational and service-based policies and procedures to guide their practice and therefore I believe that nurses should be part of the policy development.

In a booklet entitled 'Nursing leadership development', the Ministry of Health (1996) identifies the importance of nurses participating in health service decision-making and developing policy and planning skills. The booklet was collated by a group of nurse leaders in New Zealand as a framework for the development of leadership skills in nursing. The Ministry of Health also suggests that "While nurses are encouraged to be self-directed, nurse leaders at all levels can establish processes for feedback to be provided to colleagues and for the easy access of resources necessary to achieve their [nurses] goals" (1996, p.10).

As a nurse leader, I am constantly looking for ways in which I can involve nurses in policy development and decision-making processes. In general my experiences indicate reluctance by nurses to develop or contribute to policy/procedure development. The usual explanation given for the lack of participation in service development activities is the 'lack of time available'. A recent example is the development of a policy to guide practice when illicit substances, e.g. marijuana, are found in the inpatient units. One of the main problems has been a lack of a consistent approach to managing this issue and differing views on the legal requirements about notifying the police and/or disposing of the substances. The nurses were asking for clear guidelines for practice when these incidents occur. After talking to nurses about their current management of these situations, I produced a draft policy and circulated 
it via a staff meeting, requesting feedback over a two-week period. At the end of the two weeks the only feedback was from the medical staff. The finalised policy is one that nurses will be expected to follow as a guide for nursing practice, and despite the opportunity to have input into the content of the policy, they did not contribute. According to Manias and Street (2000), policies are developed to guide clinical activities and to promote quality patient care. Their research examines how nurses use policies to their advantage, to legitimise their knowledge, assert power, and demonstrate resistance when working with other health professionals. Their research supports the policy example I used. The nurses were clearly asking for a policy to guide clinical activities or practice related to illicit drugs in the inpatient units but were not prepared to contribute.

In 1998, the Ministry of Health (MOH) established a Ministerial Taskforce on Nursing to undertake a review of nursing in New Zealand. While supporting the valuable contribution nurses have to make to policy development, the final report identifies there is a general lack of participation by nurses in decision-making at a service level.

The taskforce believes that the lack of nursing involvement in policy and health-care strategy has exacerbated the fragmentation of nursing. Nurses - with their focus on continuity and co-ordination - have an invaluable contribution to make at a senior management level in providing a balanced picture of the continuum of care that leads to positive health outcomes (MOH, 1998, p.66-67).

There is little written about the level of nurses' participation in decisionmaking/service development activities. What has been written about nurses and their participation has related to nurses being involved in change processes and professional organisations. Lack of participation in professional organisations/activities and a willingness to provide care prescribed by others has been described in literature focusing on power/empowerment and oppressed group behaviours (Chopoorian, 1986; Du Plat-Jones, 1999; Hedin, 1986; Roberts, 1983; 
Sines, 1993). Roberts (1983) in her discussion on nurses as an oppressed group suggests that nurses do not participate in change because they fear change or moving away from the status quo, and that as a group they have poor self esteem and do not value their own input. It is also suggested that the only time nurses do get interested and involved in contributing to health policy is at times of crisis, such as diminishing pay equity and nursing shortages (Lange \& Cheek, 1997; Robinson, 1991). An Australian study that explores nursing participation at a health policy level suggests that;

If nurses are seeking more autonomy and control of their practice, and provide better care for their clients, more participation in decision-making, and a desire to be regarded as having professional status equivalent to other health workers, then they need to be active in the development of health policy (Lange \& Cheek, 1997, p.5).

My experience suggests that there are always a number of nurses in each area who will participate but that generally there is reluctance. Lange and Cheek (1997) suggest that lack of participation by nurses in policy development may be related to political or organisational structures discouraging the involvement of nurses. Whereas Roberts (1983) suggests that the lack of participation may be related to nurses' behaving as an oppressed group and being controlled by other more dominant groups.

In light of what has been written I often reflect on why nurses are reluctant to participate in policy development activities. Is it because they think their input will not be valued or be ignored and therefore they do not bother? Is it that they are quite happy for other people to tell them what to do and to define how they practice? Is their reluctance to participate related to feelings of disempowerment?

If people are to feel empowered within a setting they need to feel able to make choices and decisions about their life (Fulton, 1997). Within the nursing practice setting nurses need to believe they have control over the content and the context of 
their practice (Laschinger \& Havens, 1996). In the area of mental health I think it is particularly important that nurses feel empowered as a group. Horsfall (1997, p.61) identifies that;

People who experience psychiatric disturbances require trust, support, and care. None of these will be inevitably forthcoming if the nurse is rendered powerless by organisational practices and medical epistemologies and is therapeutically (along with the consumer) at the mercy of unpredictable medication. A cycle of impotence is perpetuated whereby the agency of both the client and the nurse is diminished, and the service user, as the more vulnerable and least powerful of the two, is likely to remain in a desperate state.

This concept of agency identified by Horsfall (1997) refers to the ability the nurse has to act as a change agent. Agency will be explored further in the literature review related to empowerment and power in Chapter three. The important point that Horsfall (1997) makes relates to 'impotence being perpetuated', which is also described by Sines (1994) who identifies that nurses dominated by managers may in turn dominant the patients requiring care.

I suggest that if nurses feel supported in a caring and trusting practice environment, they in turn will create this environment for the users of mental health services. As a nurse it is important to me that the users of mental health services feel supported in a caring and trusting environment. It is in my position as a nurse leader that I aim to provide an environment in which nurses feel valued, have opportunities for development and input into decision-making, have access to resources and support, and have access to information. It is these factors which have been identified in the literature as necessary if nurses are to feel empowered by having control over the content and the context of their practice (Barker \& Ritter, 1996; Cahill, 1997; Gaitskell, 1998; Jenkins, 1997; Laschinger \& Havens, 1996; Rodwell, 1996; Yarling \& McElmurry, 1986). The lack of input into decision-making or practice guidelines by nurses, and their apparent willingness to have the structure of nursing practice 
dictated by others, suggests I may not have created an environment that is empowering.

Therefore I am interested in exploring 'What can nurse leaders do to encourage an empowering environment for nurses working in the mental health area?' The aims of this research are to identify how nurses feel about participating at a decision-making level, and to identify what needs to change in the work environment for nurses to feel they can participate and therefore have control over the content and the context of their practice and thus feel empowered. In order to answer the research question I have undertaken this research project which uses an exploratory descriptive research method to generate data. The research data will be gathered from a focus group of registered nurses working within the mental health service. Focus groups are similar to a group interview; the significant difference being the discussion is generated from the interaction of participants within the group in response to the researcher's questions. Morgan (1988, p.12), describes the hallmark of focus groups as "the explicit use of the group interaction to produce data and insights that would be less accessible without the interaction found in the group". The questions asked during the focus group are designed to stimulate discussion, explore the concept of empowerment, and identify what it takes for nurses to feel empowered in the workplace. The four main questions are:

1. Describe what the term empowerment means to you as a mental health nurse within your current practice environment?

2. Describe the aspects of your present working environment, which encourage you to feel empowered?

3. Describe the barriers in your working environment, which discourage you from feeling empowered?

4. Describe the changes you would like to see in your working environment that would assist in increasing your own feelings of empowerment?

The mental health nurses participating in the study will be identifying, describing and sharing their experiences of clinical practice in relation to the factors they believe are necessary to create an empowering environment - an environment in which they feel 
they have control over the content and the context of their practice. The focus group data will be analysed in two stages as described by Morgan (1993). The first stage is the mechanical stage where the raw data from the focus group transcripts is examined until the key ideas emerge. Meaning is ascribed to the data in the second stage, the interpretive stage. In this stage the key ideas are examined within the context of the broader discussion and information available from the literature. The research process and data analysis will be informed by a Critical Social Theory perspective, as power relationships are central to both Critical Social Theory and exploration of empowerment as a concept.

Also in keeping with the Critical Social Theory perspective I will use credibility, transferability and dependability as the criteria to measure the trustworthiness of this research rather than using the traditional criteria of validity and reliability which are associated with quantitative or scientific research (Guba \& Lincoln, 1989; Koch \& Harrington, 1998).

Although I am interested in exploring what nurse leaders can do to encourage an empowering environment for nurses working in the mental health area, I will not be exploring 'leadership styles' within the scope of this research project but the term 'nurse leader' does require clarification. Within the New Zealand healthcare setting there are no consistent models of nursing leadership. Nurse leaders may be in generic management positions; specific nursing leadership positions such as Senior Nursing Officers, Nurse Advisors; or they may be practising nurses with leadership skills. Cook (2001) explores the literature on nursing leadership from the United Kingdom, the United States, and Australia. He finds that the terms 'nursing leadership' and 'nursing management' are used interchangeably and that the literature generally focuses on nursing leaders in positions of power within the healthcare hierarchy. Cook (2001, p.41) identifies "the need for leaders to be more political and to have greater influence over healthcare policy", and that professional equality is important if nurses are to have an 'equal voice' when developing health policy. Cook (2001) suggests that the nurse leaders' experience, understanding of what they do, and their internal beliefs and values are important elements of leadership along with the 
healthcare organisation structure and culture. I write from the perspective of a nurse in a mental health generic management position. The focus of this research is to identify what I can do as a nurse leader to encourage an empowering practice environment for nurses working within the mental health area. I agree that the nursing practice environment is influenced by the healthcare organisational structure, and culture. I also suggest that the organisational culture include the beliefs and values of nursing as a professional group. The strategies I identify as part of this research, may be useful for nurse managers/leaders in mental health to consider as part of developing the nursing practice environment within healthcare organisations.

There are various terms used in the literature to refer to nurses participating at a decision-making level. Examples include; policy development, health policy, practice development and service development - the key feature is about nurses participating at a decision-making level. I will use the term 'policy development' throughout this research project in a generic way to indicate participation by nurses at a decision-making level in the areas of service, strategy, policy and practice development.

I have organised the thesis document into nine chapters. This introductory chapter gives an overview of the research project as well as explaining how I decided on the topic, why I decided to explore the lack of nursing participation in policy development in relation to empowerment, and justifying why the research is important to nurses and nursing, and specifically in mental health services.

In Chapter two, I will explore in more detail the context and focus of the research project. My own experiences as a nurse working with other nurses indicates reluctance by nurses to participate at a policy development level. Some of these experiences are also reflected nationally in the 1998 Report on the Ministerial Taskforce on Nursing. Participation by nurses (who comprise the majority of the health workforce) in policy development is identified as essential but I consider it is not currently occurring. A Critical Social Theory perspective acknowledges the impact the researcher has on the research and therefore I locate my own position, by 
describing my own journey related to empowerment, providing an overview from a personal, professional, and educational perspective.

I begin Chapter three by exploring the literature on empowerment, providing definitions and discussion from dictionaries and literature from the areas of management, social science, nursing and other health-related disciplines, and from a mental health perspective. This leads into the literature which examines the history of nursing as a traditionally women's profession which has been dominated by more powerful groups such as doctors and managers. The literature identifying nurses as an oppressed group and the associated concept of resistance is explored as well as linking it to the practice environment.

Chapter four outlines the underlying theoretical and philosophical positioning of this research. The assumptions about reality which are inherent in Critical Social Theory are identified and linked to this research topic, including the reasons why I chose Critical Social Theory to inform this research. I briefly describe the work of two critical theorists, Jurgan Habermas and Paulo Freire, who have specifically informed my thinking in relation to this project. I conclude this chapter by introducing and discussing the four levels in the analysis of social consciousness identified by Freire (1987) as assessment of where individuals/groups are in terms of their social consciousness is an important aspect of social reform.

The research method is identified in Chapter five. Initially I will discuss the characteristics and origin of the focus group as a research method, its strengths and weaknesses as a data collection tool as well as how I will analyse the data that is generated from the focus group discussion. I state the reasons why I consider the focus group is an appropriate data collection tool both in terms of the information I am seeking and also to ensure that the research process is empowering and therefore consistent with the Critical Social Theoretical underpinnings of the research project. I discuss the process I use to gain ethical approval for this project as any research using human subjects raises ethical issues. I identify the ethical issues that arose as a result of the use of the focus group and also from choosing to use participants from 
within the service where I hold a management position. I conclude this chapter with a discussion on promoting rigour within this research project and how I plan to ensure the trustworthiness of the research process.

In Chapter six, I discuss the focus group process, which was used as part of this research project. Specifically the planning, the facilitation, and the selection of participants, the implementation of the focus group, and my reflections on the group process.

I analyse and interpret the data collected from the focus group discussion in Chapter seven. I initially outline the two stage mechanical and interpretative process as described by Morgan (1993) that I will use to inform the data analysis process. The key ideas that emerge from the mechanical stage of the data analysis are further developed during the interpretive stage when I link the key ideas to the wider mental health nursing practice environment. I use quotes from the focus group discussion to support the support the data analysis process.

In Chapter eight, I discuss the key themes that emerged from the data analysis in relation to the broader social and cultural context, and identify historically formed contradictions, which exist in the nursing practice environment. The key themes identified are; power is an important component of empowerment and power relationships; and at a systems level, how professional, organisational, and political influences impact on feelings of empowerment and/or disempowerment. I discuss what the focus group participants considered needed to change in the work environment for nurses to feel they can participate, and therefore have control over the content and the context of their practice. In this chapter, I will also suggest that nurses may not participate in policy development for different reasons and suggest a method for analysing where nurses are positioned in relation to social consciousness.

Chapter nine is the concluding chapter. I make a number of recommendations for nurse leaders who aim to provide an empowering environment for nurses practising in mental health. I reflect on the research process to identify if $I$ have answered the 
research question, why the topic is important and what contribution I consider the research makes to nurses practising in mental health. I identify how I have benefited from participating as a researcher and also how the participants may have benefited from the process. I outline the limitations of the research and identify areas that might benefit from further investigation. I conclude by identifying how the research report will be disseminated and specifically how the focus group participants will receive the final research report. 


\section{Chapter Two: Context and Focus of the Research Project}

\section{Introduction}

In Chapter one $I$ have introduced the research question and aims, and the reasons why I believe the lack of input by nurses at a policy development level requires exploration. As part of establishing the context in which this research is being undertaken I will begin this chapter by expanding on the report produced by the Ministry of Health (MOH) in 1998 and introduced briefly in Chapter one.

In the foreword to the 1998 Report on the Ministerial Taskforce on Nursing, The Hon Bill English (the then Minister of Health) stated that the Taskforce was established in response to nurses and nursing organisations repeatedly saying that there were obstacles to the nursing profession realising its full potential with respect to health service delivery. He thought it was important to make sure that the health sector effectively used what nurses had to offer and also stressed the importance of the need for the nursing profession to continue to adapt to meet the challenge of radically changing healthcare delivery. Within the public hospital setting, nurses remain the majority of the health workforce (MOH, 1998). Nurses are in the privileged position of providing healthcare to patients 24 hours a day and are in the ideal situation to make comment on the needs of clients and communities (MOH, 1998). The time they spend with users of healthcare services and the nature of the relationship they from with individuals and groups is the reason why they are ideally placed to contribute to policy development, concerning the individual patient, patient care in general, systems of care delivery within services, and within the healthcare organisation. Although the Ministerial Taskforce on Nursing identifies that nurses are in an ideal position to make a meaningful contribution to healthcare decisionmaking, they also identify that there is a current lack of nursing involvement in policy and health-care strategy (MOH, 1998). This lack of input by nurses into policy development supports my own experiences within the practice environment. If nurses are ideally placed to contribute to policy development in healthcare, then research into the reasons they are not participating is required, and as already identified, this has not been previously explored. 
I will be asking nurses for their views on empowerment and participation (or lack of) into policy development in the healthcare or practice setting. I will also explore the wider socio-political climate of nursing, including the history of the nursing profession in relation to the women's role within society and healthcare settings. A New Zealand nurse academic Marie Crowe (1997, p.59), writes specifically about mental health nursing and states that "nursing is a political activity which takes place within a particular socio-cultural context". She also suggests that "contemporary nursing practice has been shaped by its history," (Crowe, 2000, p.963). The historical aspect is considered fundamental to understanding reality as it acknowledges that history extends to the construction of social forms and knowledge (Held, 1980).

Critical social theory informs my thinking and writing for this research, therefore I will initially reflect on my own journey from a critical perspective. Critical social theory identifies that knowledge can only be understood by examining the social and cultural conditions that exist from an historical perspective, and also acknowledges the impact that one's position as a researcher has on the subjects and the research process (Held, 1980). At this point I will locate myself within this research as my experiences have culminated in my unique view of the world with the inherent assumptions that underpin my interactions with those around me and the way I interpret the world. I will consider the social and cultural factors that have shaped me into the person I am today and have also influenced my perception of empowerment. I reflect on my own journey related to empowerment - examining my own values and beliefs around empowerment and/or disempowerment. Do I as a nurse feel empowered within the practice setting to make choices and decisions and do I perceive that I have control over the content and the context of my practice? Do I feel I have the power to act, to make choices about my life and work practice? The answer is yes but in a limited way - have I always felt that way - no.

\section{The Early Years}

My own journey begins as the eldest of two children raised on a farm within the typical nuclear family. The life path anticipated was schooling until reaching the legal leaving age or 15 years; working for a few years until marriage, home 
ownership and children came along. A career was not planned, as motherhood for many years would not allow time for work. Continuing my education was never considered, as only really bright people went to University and pursued professional careers. On reflection I could have continued my education if I had considered this as a realistic option. Having a my future life path mapped out suited me fine, having choices was not important to me, as at that time I did not know that there were alternatives to choose from.

When I left school at 15 I worked in an unskilled position until marriage; home ownership and the children came along as expected. At this point I started to think about the years ahead, I had no particular plan in mind but did start thinking that if I wanted to have options in later years I needed to prepare myself. I had a number of free evenings each week with small children who went to bed early and my husband who worked a number of night shifts. I restarted my education through the Correspondence School - completing school certificate and university entrance subjects. I passed year after year and what was most surprising was that I passed well. I was also involved in the usual pre-school children's activities and was sought after for many committees. I worked my way through Plunket, playgroup and kindergarten committees with roles of secretary, treasurer and president. I was developing skills and abilities that would prove to be invaluable in the future without realising it at the time. It was at this point that I started to consider that there were alternatives to my life path and that in order to choose I had to think about the various options available to me.

As the children settled into school I started to become disenchanted with housework being my priority during the day and thought about where my life was heading. I started working part-time, again in an unskilled job. It did not take me long to realise that I would always be working at least part-time and that I needed to enjoy and find a challenge in what I was doing. My husband was supportive of the way I was feeling and the decisions I was making. I had thought about undertaking nursing training but always thought it was beyond my reach as I considered nursing was a profession that required intellectual ability. With very little confidence of being 
accepted, I tentatively applied and attended the interview. I was accepted first time around which was unusual from the stories I had heard. I realised that the years when the children were small, working through school certificate and university entrance subjects were paying off even though at the time I was unclear why I was doing it. I started my nursing training with great trepidation, thinking I would soon be 'caught out' for the fraud I was, that is - not having the intellectual ability to complete the first year, and then the second year, and finally the third year and state examinations. It took me all of three years of being an 'A' student to realise I did have the intellectual ability to succeed and finally coming to the realisation that I could probably succeed at anything I took on. This was a wonderful feeling - the 'world was my oyster' as the popular saying goes. The power to succeed and to make choices was located within me. It was not something that I had no control over; my life path was not as 'mapped out' as I thought it was.

Barker and Ritter (1996) suggest gaining control over oneself and one's reactions to the world is empowerment and that empowerment is about personal power, the power that comes from within. Empowerment is not omnipotence - just because one believes one has the power to change things, change does not necessarily occur. Barker and Ritter (1996) also argue that true empowerment is impossible, as any political system prohibits an individual or an organisation gaining total control of their environment. It was my perception that had altered rather than anyone giving me or sharing their power with me. I had finally come to the realisation that the power to make choices and to make changes was located within me while also acknowledging that factors and systems outside my control would also limit this ability.

One of the factors outside my control at the time of graduation in 1991, was the shortage of nursing positions within the public health service. As a new nursing graduate I was eager 'to get out there' and practise. My preference at this time was for medical and/or surgical nursing as it was portrayed as 'real nursing' throughout my training by the majority of the teaching staff. However, even though I felt empowered to make choices, in reality the lack of nursing positions available to new 
graduate nurses provided limited choice. It is interesting that I entered mental health 'by default' rather than choosing it as an area of practice. I applied for a position in mental health because there were vacancies and I wanted to start work - my thinking at the time was to get a position in the mental health area and then move into my area of preference.

\section{The Professional Years}

In 1992 I was successful in obtaining a position within the mental health service. Nine years later I continue to work there through choice. I choose to practice as a nurse in mental health because I believe that nursing practice makes a significant difference to the experience a person has when using mental health services. As nurses we are in the privileged position of sharing some of the most difficult times in a person's life either because of mental illness or because of a situation in which a person's mental health is compromised. This may also be the experience of nurses working within medical/surgical environments but my perception of the 'worthwhileness' of nursing in mental health keeps me there.

When I started work I was aware of the power imbalances that exist between nurses and the patient within any healthcare setting, but I was developing an increased awareness of the complexity of the issues of power within mental health. There is the potential for the abuse of power when working in an area where compulsory assessment and treatment are supported through legislation, namely the Mental Health (Compulsory Assessment and Treatment) Act 1992. I was continually reflecting on ways in which this power imbalance could be minimised. I also reflected on the nursing role within the ward and within the healthcare setting and I listened to nurses talking about the power of the medical staff and the managers.

A significant moment within the practice setting and within my professional life occurred within my second year of practice and illustrates the location of power. I was lamenting the lack of clear information to give patients about their medication. I clearly recall saying 'you think they would provide information which everyone could understand'. I was challenged by the charge nurse at the time who said, "who 
are they?" I had to think about this and realised that who 'they' were, was not clear but that 'they' were external to me. The charge nurse then invited me to come up with an information package that met the needs of the patients on the ward. I took up this challenge while on six weeks of night shift. I initially developed an information sheet for each type of medication used routinely on the ward, in non-medical language which patients and families would understand. I also completed a corresponding information sheet for nursing staff to ensure they understood the information they were providing to patients and families. I recently used this same technique when a registered nurse was complaining about the way the patient group had to line up to receive their medications. She also laid the onus of change externally by saying 'why don't they change it'. I was well prepared from my own experience and challenged her to explain who 'they' were. She, as I had been, was baffled and has since identified an alternative way of administering medication. She worked through a change process with staff and now the medications are administered in a manner that respects the patient's dignity and privacy. Also, as with my experience she now recognises that she has the power to change things within her practice environment and knows the process to use which ensures changes are acceptable, evidence based, appropriate, and well planned. In both these examples there was a shift in the perception of where the power to change things was located, and an environment conducive to individuals facilitating change.

As a manager within the mental health care setting I attempt to provide an empowering environment. Reading on the topic of empowerment has reinforced my belief that access to educational opportunities is essential, as is access to information. Over the past six years in a variety of management positions I have role modelled and actively encouraged nurses to further their education. The increased availability over the last five years of undergraduate and postgraduate programmes and the opportunity to attend and have fees paid or partially paid at an organisational level, has led to what I would describe as a 'groundswell' of nurses applying to study undergraduate and postgraduate papers. Nurses who have not studied since graduating are applying, as are nurses who have continually updated their education. I have also sought to ensure that nurses have access to the information they need to 
make informed decisions and that they are fully informed about all aspects of the organisation and wider systems in general.

There is a level to which we have the ability to directly influence and then there is a wider level at which our power may only be partly influential. I do not always feel empowered to act as a change agent when wider systems are involved. Within my immediate environment I can act as a change agent but within the wider organisation, community and political arena, my input may or may not have an impact. For example in my current position I have a high level of influence into the direction of individual inpatient mental health services and a medium level of influence into the overall direction of the mental health service. I sometimes consider that I influence the direction of mental health care at a national level through participation in policy development and feedback on specific consultation documents, whereas I do not consider that I influence the overall direction of health policy at a national level. I have noticed an increase in the areas I perceive I have the power to influence, mainly at a local service level.

Postgraduate education combined with ongoing clinical practice have increased my ability to critique the socio-political implications or influences on mental health care and hence increase my ability to understand what is going on. With this understanding often comes the knowledge of how to change, influence or impact on existing situations. The saying 'knowledge is power' is true when considering how one can have an impact outside the immediate environment. Having a broad understanding of issues and systems is required before one can act to influence policy development. Being politically and socially aware is important while also having an understanding of the historical context. This is one of the reasons why Critical Social Theory appeals to me as an approach to examining issues. Guba (1990) and Held (1980), purport that it is through identifying the historically formed contradictions and eliminating the false consciousness of people, that understanding and emancipation occurs and leads to empowerment and transformative action. 
Another reason for my interest in Critical Social Theory is the focus on power relationships and where power resides within the relationship. The concept of power and power relationships has interested me throughout my years of study. I recollect the first time I read about oppression while completing my undergraduate nursing programme. The focus was nursing history but the readings explored the role of women in society. It was at this point that I realised that my view of the world was related to the knowledge and experiences to which I had access. Education at an undergraduate and postgraduate level has impacted on my choice of research topic and the research process.

There are a number of key authors around the topics of nursing (the profession and practice), oppression and Critical Social Theory which I recall as making a significant and lasting impact on my thinking. These authors include Jurgen Habermas (1972), Sally Hutchinson (1990), Susan Reverby (1987), Susan Roberts (1983), Sandra Speedy (1987), Annette Street (1992), and Roland Yarling and Beverly McElmurry (1986).

As previously stated, the initial reading when completing the Diploma of Nursing, focused on nursing history and its relationship to women. I subsequently bridged from the diploma to the undergraduate degree after commencing practice in mental health. Further reading when completing anthropology papers as part of the undergraduate degree introduced me to the concepts of epistemology, ontology and methodology. I realised that there were different realities and that how reality was constructed impacted on one's perception of the world. I came to realise that there were alternative ways of viewing reality.

The authors I have identified as significant in my thinking contributed in a number of different ways and most relate to the years after commencing practice while completing the degree in nursing. The timing is significant as it was only after commencing practice that I was able to fully integrate the theoretical and practical knowledge. 
Yarling and McElmurry (1986) made me think about nurses not being able to act in morally/ethically responsible ways because of employer expectations. "Nurses are not able to actualise their commitment to patients in the practice setting when the freedom and well being of the patient is in conflict with the interests of the hospital" (Yarling \& McElmurry, 1986, p.67). A classic example from my own practice area is when a patient discharge is determined by demand for inpatient beds rather than the readiness of the patient for discharge.

The first time I read the term 'responsible subversion' was in an article by Sally Hutchinson (1990). I found myself thinking about the frequency of responsibly subversive acts in my own and other nurses' practice on a daily basis and the reasons why nurses felt they had to act covertly rather than overtly to meet the patients needs. An example, again related to discharge, is when the nurse slows the discharge process until the patient is ready to leave - thereby meeting the needs of the patient while being seen to facilitate the discharge process.

Susan Roberts (1983) introduced me to the idea of nurses as an oppressed group and this was further developed by Sandra Speedy (1987) who examined the history of nursing as a profession and as an oppressed group. Speedy (1987) concluded that feminism has something to offer nursing, namely striving for power through increased consciousness or understanding the present by exploring the past. Susan Reverby (1987) explored the development of nursing training and education, identifying the historical relationship between nursing and a woman's duty to care. This article was based on Susan Reverby's seminal work in 1987; a book entitled Ordered to care. Annette Street (1992) also examined how power relationships have developed and how they are maintained within nursing. These authors have had a significant influence on my thinking in relation to the current position of the nurse within the healthcare setting. The history of nursing and the power relationships that exist were evolving into an area of interest as I could relate the importance of power relationships to my everyday practice. 
The history that I am influenced by as a nurse is the history of nursing in general and not just the history of psychiatric nursing. The nursing literature I read is mainly across nursing and not necessarily specific to nursing within mental health. I do not consider myself a mental health nurse - I am a comprehensively trained nurse practising in the area of mental health.

The institution where I studied at an undergraduate level used Critical Social Theory to inform the development of their curriculum framework and therefore it is not surprising that I was exposed to the concepts of oppression and power, the location of power and its impact within a relationship. Strangely $I$ was not introduced in a meaningful way to the writings of Jurgen Habermas until near the end of my undergraduate studies. I found the language he used difficult to grasp; power relationships were easier to understand when related to the nursing practice environment by nurse authors rather than by reading Habermas's writings. However, I have included him as significant because of his writing around the area of how different types of authority and expertise contribute to the development of knowledge (Habermas, 1972). His ideas on the development of knowledge through technical, practical and emancipatory interests increased my understanding of how knowledge is generated and maintained and also encouraged me to read further on the topic of emancipatory knowledge. It is in this area that I found Paulo Freire's (1970) writing assisted in understanding the idea of emancipation being a process which included raising the consciousness of people (conscientisation) to the point where they understood enough about what they were experiencing to take action and change the situation (praxis).

And so my interest in power relationships has evolved over the years and has become more meaningful as I apply the principles to everyday situations. More recently I have been reading articles by nurse academic Marie Crowe (1996, 1997, 2000). She writes about nurses practising in mental health and she challenges the taken-forgranted ways nurses practice and encourages the reader to take a different view. Nursing in the area of mental health with legislation such as the Mental Health (Compulsory Assessment and Treatment) Act 1992 that compels people to accept 
treatment, has the potential for vulnerable people to feel powerless. Within this context I have observed examples of excellent nursing practice but I have also observed nurses abusing their power. Sines (1994) examines nursing and the power nurses have within the mental health services in the UK. She suggests that;

Clients may still be expected to conform to the dominant themes of time, order, control and regimentation. Sanctions such as the removal to other care environments and threats of seclusion or denial of privileges continue to be part of the repertoire of some nurses...

And when discussing the institutional model of care;

...some of our present hospitals continue to appear to be characterised by a world divided in two, where managers dominate the front line workers and where staff dominate their clients in turn (Sines, 1994, p.895).

One of the reasons I initially moved into management/leadership positions was because of my interest in power relationships. As a manager of services I could be part of ensuring people who were in a less powerful position because of their hospitalisation through illness and/or the requirement that they accept compulsory treatment, were treated with respect and that the power of dominant groups and individuals within the healthcare setting was not abused.

This discussion on mental health nursing practice does not always paint a good picture of the 'caring' nurse and from my experience the reality is that nurses can and do abuse their power, some knowingly and others without realising it. It is interesting that Sines (1994) identifies that nurses dominated by managers may in turn dominant the patients requiring care, and that Horsfall (1997) suggests that the agency of the nurse and the patient may be diminished in disempowering environments. This is where my research project started - with the idea that what I role modelled as a nurse leader was in turn role modelled by nurses within the practice environment. I have narrowed the scope of this research project to look specifically at what nurse leaders can do to create an empowering environment for 
nurses because I consider that if nurses feel empowered they will also provide an environment where the people they work with will also feel empowered.

\section{Conclusion}

As part of discussing the context and focus of this research project I have referred to the Report of the Ministerial Taskforce of Nursing ( $\mathrm{MOH}, 1998)$. The report identifies that in New Zealand there is a lack of involvement in policy and healthcare strategy by nurses even though they provide patient care 24 hours a day and are in an ideal position to participate in a meaningful way. The New Zealand healthcare environment provides the context within which this research is being undertaken. I introduce Critical Social Theory, as the underlying theoretical and philosophical position that informs this research. I highlight two fundamental aspects of Critical Social Theory and relate these aspects to this research. First, the importance of understanding the historical context of nursing in relation to the current practice environment, and second, the impact the researcher has on the research process and content. As an acknowledgement of the impact the researcher has on the research process I have reflected on my journey related to empowerment, through the early years and more latterly in my professional and academic life. I have described how my understanding of the term empowerment has evolved and continues to evolve as I explore the empowerment literature and relate this knowledge to my own experiences, values and beliefs. I refer to a number of the authors who have made a significant contribution as I explore the literature related to this research topic in the next chapter. 


\section{Chapter Three: Literature Review on Empowerment}

\section{Introduction}

The books and articles I have read and used in the development of this chapter on empowerment have come from a variety of sources. For the purposes of this research I have sought books and articles through CINAHL and MEDLINE database searches and used the reference lists from articles I have read relating to my research topic. The other source of articles has been nursing colleagues. As my research topic has become known, articles on focus groups, empowerment and related topics, have steadily arrived through the mail. I have also collected many of the articles relating to the history of nursing, Critical Social Theory and oppression over the past ten years. An interesting theme around the issues of power has evolved, as evidenced by undergraduate and postgraduate assignment topics over this period and my choice of literature. The origins of power, where and how it resides within relationships, and the impact this has on thinking, behaviours and attitudes at an individual and group level, are all areas explored during this decade of study. My interest in power and power relationships has been maintained because power is a real issue when working as a nurse within mental health services, particularly the inpatient service. Lange and Cheek (1997) linked participation in policy development to nursing empowerment. Therefore, it is fitting then that I explore the concept of empowerment.

I have chosen to start the literature review by exploring the concept of empowerment, including what it means to be empowered and barriers to empowerment at an individual, professional, organisation and political level. The definitions and discussion arise from dictionaries and literature from the areas of management, nursing and other health-related disciplines, and from a mental health perspective. I will continue the discussion on empowerment by exploring the history of the nursing profession and its relationship to women's role in society, to oppression and the subsequent impact on nurses and nursing within contemporary practice environments. I will also raise the concept of resistance and discuss how acts of resistance maintain oppressive structures but also indicate nurses are rebelling against oppressive forces that dominate their practice. This concept of rebellion will be further explored in 
Chapter four when I provide an overview of the underlying theoretical and philosophical position of this research, Critical Social Theory.

But first what is empowerment?

\section{Empowerment}

Empowerment is an important concept in mental health and is one of the guiding principles for consideration in mental health service delivery and planning (Mental Health Commission, 1998; Ministry of Health, 1997). Jenkins (1997) and Rodwell (1996) suggest that before embarking on the process of empowering others, health professionals need to feel empowered themselves. Rapp, Shera and Kisthardt (1993) in their examination of empowering research strategies for mental health consumers, identify that empowerment is about increasing personal, interpersonal, or political power so that an individual or group can take action to improve their situation. I will now discuss the various definitions of empowerment, what it means to individuals and groups to feel empowered and the barriers to empowerment at various levels of society that emerge from the literature reviewed.

\section{Definitions of Empowerment}

There is a wide range of definitions of empowerment in the literature and also numerous research articles, which attempt to describe what it means for people or groups to feel empowered. Gilbert (1995) suggests using the word 'empowerment' with caution because its popularity has led to a considerable degree of ambiguity. This ambiguity is because popular or 'politically correct' terms are often used indiscriminately and have so many meanings to different people that they have come to mean little (Chamberlin, 1997; Walker, 1998).

The Collins Concise Dictionary (1999) defines the word 'empower' as to 'authorise' and 'to give power and authority to'. In the New Merriam - Webster Thesaurus (1989) 'authorise', 'entitle' and 'sanction' are synonyms for the word 'empower'. These words all suggest that power is given from one person to another rather than individuals having a right to power. To understand the concept of empowerment, the concept of power must first be explored (Ekeberg, Lagerstrom \& Lutzen, 1997). 
Power is explored in terms of individual power and organisational power. Within social science literature, agency and locus of control are terms used to describe the location of power. Weary, Gleicher and Marsh (1993, p.177) define power as "having an impact on the environment, being an agent of change and affecting reality". Agency then is the ability one has to act as a change agent within one's environment. Locus of control relates to how people think about their ability to control or change outcomes. People who are identified as having an internal locus of control believe that it is their behaviour which influences the outcomes and that they are in control of their own life whereas people with an external locus of control believe that it is factors external to themselves that control their lives or specific outcomes (Weary et al., 1993).

'Power from within' and 'power over' are the terms Starhawk (1982) uses to differentiate the location of power. She calls 'power from within' 'immanence' which she defines as "the awareness of the world and everything in it as alive, dynamic, interdependent, interacting and infusing with moving energies..." (p.9). Using this 'power from within' an individual can "choose to co-operate or to withdraw co-operation from any system" (Starhawk, 1982, p.12). 'Power over' Starhawk (1987) calls 'estrangement', as it is external to the individual and is often only recognisable in its extreme form as it is the dominating power inherent in all societies' institutions.

In studies of workplace empowerment, power according to Kanter $(1977$, p.166) is the "ability to get things done, to mobilise resources, to get and to use whatever it is that a person needs for the goals he or she is attempting to meet."

No discussion on power would be complete without reference to modern French philosopher Michel Foucault who links power with relationships and with knowledge (Du Plat-Jones, 1999; Foucault, 1980; McHoul \& Grace, 1998; Kuokkanen \& LeinoKilpi, 2000). "Those who are able to lay claim to legitimate areas of knowledge, also have the power to shape the form of enquiries and who, or what is, included in the discussion" (Du Plat-Jones, 1999, p.39). According to Foucault (1980), power does 
not reside within people (individual, group, institution or wider society), but rather to the degree of power in relation to other more or less powerful people. The degree of power is linked to the body of knowledge people have and the value society places on the type of knowledge (Foucault, 1980; McHoul \& Grace, 1998). An example within the healthcare setting is of institutional power being maintained through the disciplines which exist within the institution. The discipline of medicine in relation to other health professionals has traditionally dominated and impacted on the power of the healthcare institution and within the healthcare institution (Street, 1992).

The literature related to empowerment reveals a dichotomy about the giving and taking of power. One view is that nurses cannot empower others, as people can only empower themselves by gaining control over their reactions to the world (Barker \& Ritter, 1996). The alternate view is that an individual, group or organisation that has power has the ability to share this power with others. Within nursing it is suggested that it is the nurse sharing their power with the patient that results in the patient feeling empowered. Within organisations power sharing can be achieved by people in authority ensuring access to resources and encouraging others to act autonomously and be involved in decision-making (Kanter, 1977; Turrell, 1996). Whether power comes from within the individual or group, or is something than can be bestowed on others, is an important distinction when discussing what empowerment means.

A number of research studies seek to identify what empowerment means to nurses within the practice setting (Fulton, 1997; Laschinger, Sabiston \& Kutszcher, 1997; Morrison, Jones \& Fuller, 1997). The findings suggest that having control over the context and content of practice; having the freedom to make choices and decisions; and feeling their jobs are relevant, flexible and visible; are important concepts for nurses if they are to feel empowered in the practice setting.

Literature that explores experiences of empowerment also identifies perceived barriers to empowerment (Barker \& Ritter, 1996; Gaitskell, 1998; Laschinger et al., 1997 and 2000; Laschinger \& Havens, 1996; Laschinger \& Wong, 1999; Morrison et al., 1997; Opie, 1998; Rodwell, 1996; Yarling \& McElmurry, 1986). Barriers to 
empowerment or factors that influence feelings of empowerment are identified at a political, organisation, professional and individual level. Barker and Ritter (1996) argue that true empowerment is impossible, as any political system prohibits an individual or an organisation gaining total control of their environment.

Factors that impact on nurses feeling empowered are frequently related to organisational characteristics of the practice setting. Kanter's (1977) studies on workplace empowerment structures within the business setting have been used as a basis to examine the organisational structures in which nurses practice (cited in Laschinger et al., 1997; Laschinger, Finegan, Shamian \& Casier, 2000; Laschinger \& Havens, 1996; Laschinger \& Wong, 1999; Rodwell, 1996). Organisational characteristics found to increase feelings of empowerment include; access to work empowerment structures through high levels of formal and informal power, positive relationships with management and peers, active leadership, involvement in workplace decision-making, and access to information and education.

Barriers at a professional level within the healthcare setting have also been identified as contributing to feelings of disempowerment. Gaitskell (1998) found professional structures encourage hierarchical leadership and strict role definition, and that professional accountability and scope of practice are defined by codes of conduct, resource limitation and internal/external policies or legislation. Social workers identify the empowering aspect of their role is disappearing and relate this to an increasingly restrictive and regulatory healthcare environment (Opie, 1998). The same could be said of nurses and nursing, as the healthcare system becomes more regulated, and the ability of the nurse to practise autonomously and control the context and content of their practice decreases.

At a professional level, how a group perceives themselves in terms of power is also important and Morrison et al. (1997) use the term 'psychological empowerment' to describe individual or group feelings of effectiveness or competence. Opie (1998) suggests that perceptions of empowerment are located within the individual or group and also within the structure of society and its institutions. The perception of nursing 
from both within and outside the profession is an important determinant of how nursing is viewed in terms of empowerment. One perspective is that the political and organisational environment may provide options and the authority to make choices, but the person or group also needs to perceive these options and the authority to make choices (Rapp, 1998). Another perspective is suggested by Yarling and McElmurry (1986) who question whether 'nurses are free to be moral'. They conclude that the structures that nurses work within result in nurses not being free from forced choice as the interests of the patient may conflict with the interests of the hospital. Cahill (1997) supports this argument and discusses how nurses are encouraged to be consumer focused and to empower patients but often organisations expect nurses to put the needs of the organisation before the needs of patients.

There is much written on empowerment and empowerment within nursing. However, for the purposes of this research project I have formed my own views on what empowerment is and what it means for nursing from the literature I have read and from my own experiences which I have described in Chapter two. At this point I will state my position or perception of empowerment as it exists at this point in time. I believe that empowerment is about power and where an individual, group or community perceive the power resides. I do not believe power can be given to another person, or within nursing - that nurses can empower others. Empowerment is about 'power within', how one thinks about the world and their position in the world in relation to others. I support Fulton (1997) and Laschinger and Havens (1996) who suggest if people are to feel empowered within a setting they need to feel able to make choices and decisions about their life and within the nursing practice setting nurses need to believe they have control over the content and the context of their practice.

This literature also raises questions about how nurses perceive themselves and how others perceive nurses as a group. The history of nursing is important when considering how nursing is perceived in the current practice environment (Crowe, 2000). The history of nursing has been written about extensively, however, I will 
continue the discussion on empowerment by specifically exploring the history of the nursing profession and its relationship to women's role in society.

\section{Nursing History in Relation to Women's Role in Society}

Understanding the historical, social and political position of nurses within the healthcare system assists in understanding the issues of empowerment within nursing. The history of nursing impacts on individual nurses and their practice (Crowe, 2000). This history is complex and has been heavily influenced by the role of women in society and the valuing of the scientific/medical knowledge.

The domination (or colonisation) of nursing by physicians and administrators occurred early in nursing history when medicine became a dominant force and hospitals proliferated. Few nurses recognised their oppression since they were acculturated to the existing structure, and had also been socialised to the woman's role behaviours (Speedy, 1987, p.23).

McEldowney (1995) identifies subordination and domination as characteristics of Western patriarchal societal views of woman and that since nursing is predominantly a woman's profession these characteristics may also apply to nursing. She suggests that the oppression of women and by association nurses (because the majority of nurses are woman), is linked historically, politically, socially and economically. Oppressed groups are controlled by outside forces that have greater prestige, power and status which identify and enforce the dominant norms and values (Freire, 1970). Characteristics of oppressed groups include; individual rather than collective action, horizontal violence, taking on the values of the oppressor and fear of freedom or change (Freire, 1970). Horsfall (1997) specifically identifies that nurses practising in the area of mental health are dominated by contemporary psychiatry and that this domination is reinforced and maintained through political and organisational power and scientific credibility. 


\section{Nurses as an Oppressed Group}

A number of research articles identify nurses as behaving in ways that suggest they are an oppressed group (Hedin, 1986; Horsfall, 1997; McEldowney, 1995; Roberts, 1983; Street, 1992). Roberts (1983, p.21) describes nurses as an oppressed group, who are "controlled by forces outside themselves that have greater prestige, power, and status...". One of these forces is the medical profession who have been identified as having prestige, power and status which largely goes unchallenged and dominates in health care settings and hierarchies (Street, 1992).

Hedin (1986) explored the oppressed group behaviour of nurses in West Germany and identified that nurses were divided into many groups and fought amongst themselves. They were more likely to act individually rather than collectively - such as nurses choosing to leave the profession due to dissatisfaction rather than acting collectively to change unsatisfactory conditions. Street (1992) uses the term 'touristy nurse' to describe the way in which nurses move from job to job searching for better conditions rather than stay in a job and promote a change in conditions. Roberts (1983) also suggests that nurses do not participate in change because they fear change or moving away from the status quo, and they also do not participate because nurses as a group have poor self esteem and do not value their own input.

Horizontal violence, another characteristic of oppressed groups, is conflict within a group which develops when oppressed groups are unable to challenge the oppressor or dominant groups (Roberts, 1983; Street, 1992). 'Housing the oppressor within' is another characteristic also identified, where nurses believe that they are powerless to change their situation and this belief is maintained through socialisation and education. Hedin (1986) also found that nurses value the technical rather than the caring aspects of the nursing role, which indicates that they have adopted the values of the dominant group in order to become more like them (Freire, 1970). Horsfall (1997, p.59) identifies that;

Psychiatric nursing, more than other mental health professions, has been in the thrall of mainstream medical theory and practice. As the importance of objectivity, the mind-body split, and a 
material understanding of the person increases, the values of caring, interactivity, holism and self-expertise (of patients and nurses) diminishes.

Medical domination results in (and is maintained by) a valuing of the technical rather than the caring aspects of nursing. Nurses who also value the technical rather than the caring aspect of their role, are more likely to lose confidence in their ability to connect at an interpersonal level and therefore the valuing of technical knowledge is maintained.

One of the reasons given by nurses for not participating in policy development activities is a lack of time available as they are usually 'too busy looking after the patients'. Roberts (1983) discusses how oppressive behaviours are maintained with positive reinforcement being given for behaviour preferred by the oppressor. The changes in economic policy in the last decade have led to a high value being placed on efficiency in health care. Organisational culture may reflect this value - for example, nurses are expected to work harder and harder, managing higher caseloads of higher acuity, leaving little time for input into developing policies which impact on their practice (McEldowney, 1995). In the example I gave in Chapter one related to nurses not participating in the development of a policy around the use of illicit drugs on the inpatient units, the only feedback I received was from the medical staff. The issue of nurses not 'having the time' may be valid; it could also be viewed as a method of the healthcare organisation maintaining the oppressive/dominant structures. As Lewis (1990, p.477) suggests in her discussions on increasing the consciousness of women regarding their role within society "The dominant forms of discourse are aimed hegemonically at preventing women from engaging in discussions that lead toward consciousness raising...". There could be a risk for the dominant groups if nurses did have the time to discuss and reflect on their position within the healthcare setting. Within the public hospital setting, nurses remain the majority of the health workforce (MOH, 1998) and consciousness raising may lead to dissatisfaction and a change to the existing power structures. As Foucault (1980) suggests, it is the powerful or dominating groups who decide what groups get 
included in discussions. An alternative interpretation of why nurses do not participle in policy development might be that the nurses wish to resist change or that they wish to resist the dominant forces. They may not participate in policy development when the dominant group sets the terms and conditions of the policy. I will now explore the concept of resistance to domination within nursing.

\section{Nursing and Resistance to Domination}

To this point I have provided supporting evidence and examples from the literature which identify nurses as an oppressed group and how nurses behave in ways, which indicate they are oppressed. The dominating forces in the nursing practice environment have been identified as the medical profession and the organisational structures. I have painted a picture of nurses as an oppressed group who are dominated by the medical profession and organisational hierarchical structures. Nurses could be viewed as not having the ability to stand up to the dominating forces but it is at this point that I would like to introduce the concept of resistance. Yarling and McElmurry (1986) question whether 'nurses are free to be moral'. They discuss the organisational structures in which nurses work that result in nurses not being free from forced choice, and how the interests of the patient can conflict with the interests of the hospital. It makes nurses seem a pitiful and weak group, who are so fearful of authority that they do as they are told.

I consider nurses generally work in the best interests of the patient while being seen to adhere to the values of the employing organisation. Hutchinson (1990) in her research article, Responsible subversion: A study of rule bending among nurses, explores how nurses bend the rules for the sake of the patient and describes this behaviour as 'responsible subversion'. Her findings identify that nurses consider that institutional and medical rules conflicted with their own beliefs about what is the best outcome for the patient. They resisted the dominant forces in a subversive manner, but labelled the rule bending as 'responsible' as it was done in the best interests of the patient. Freire (1970) identifies that as people or groups become aware of oppressive forces they will 'test the waters' with rebellious acts. Street (1992) provides an example of nurses behaving in a way that suggests they might be an oppressed group 
but is more an act of resistance. She looked at the issue of nursing rosters as part of her study into clinical nursing practice and found that an attempt by the organisation to empower nurses by using a self-rostering technique encountered resistance from nurses. On the surface it appeared that nurses were apathetic, would prefer to have others tell them what to do and complain about the rosters rather than decide on their own rosters. The group was acting in a way that suggested they were an oppressed group - a fear of freedom, preferring the security of the present system rather than taking the risks required to make a change. The study revealed that what the nurses were resisting was the way the change was introduced rather than the change itself, the change was developed 'for' them from the organisational hierarchy, rather than 'with' them. Although resistance as described in this example can be viewed as a rebellious act, this type of resistance is also passive and supports the status quo or dominant ideology (McEldowney, 1995; Speedy, 1987; Street, 1992). Responsible subversion is a similar type of resistance as nurses who are fearful of speaking out, meet the needs of the patient in a subversive manner which is not empowering to the nurse or the patient. The power of oppressive forces is maintained through oppressed people not speaking out or as Freire (1970) suggests, maintaining a culture of silence.

However, the consequences of speaking out against oppressive forces can be devastating and put the individual or group at risk.

Nurses who openly challenge established authority structures or powerful physicians in a hospital bureaucracy most often put their jobs, their economic welfare, and their professional careers on the line, even if they are acting on behalf of the patient and have strong justification for doing so (Yarling \& McElmurry, 1986, p.70).

An example in the New Zealand mental health practice environment is Neil Pugmire who in 1994 publicly criticised the release of a patient from the Lake Alice Forensic Psychiatric Unit (Hubbard, 1994). He believed the patient would reoffend and should not be released. He was dismissed by his employer and publicly criticised for speaking out. There was a high personal cost as a result of 'speaking out' but his 
actions resulted in a Ministerial Inquiry with subsequent changes to legislation. An article in the Listener magazine states "Here he is, winner of two political victories: the government has plugged the gap in the mental health legislation, and also promises a whistle blowers' law to protect future Neil Pugmires" (Hubbard, 1994, p.16). Rebellious acts are described as part of the process of individuals and groups becoming aware of oppressive forces and I will explore this process further in Chapter four as part of the discussion on Critical Social Theory.

\section{Oppression and Resistance Related to the Research Context}

I now return to the example I used in Chapter one - that of nurses not having input into a policy document that would be used to guide their practice in relation to the presence of illicit drugs, i.e. marijuana, on the inpatient unit. If I consider this group of nurses as an oppressed group there could be a number of reasons why they are reluctant to participate. They may be 'touristy nurses' in that they do not have a commitment to the area but move from job to job searching for better conditions rather than staying in a job and promoting a change in conditions (Street, 1992). They may fear freedom and prefer acting in the ways prescribed by the oppressor rather than acting independently and choosing a course of action for themselves (Freire, 1970). They may believe that they are powerless to change their situation, a belief maintained through socialisation and education or they may not participate because nurses as a group have poor self esteem and do not value their own input (Roberts, 1983). Another explanation could be that the nurses are resisting in a passive way. As they become aware of oppressive forces they will test the waters with rebellious acts or they may fear speaking out against oppressive forces as the results can be devastating and put the individual or group at risk (Yarling \& McElmurry, 1986). The reason for the reluctance to participate may be one or a combination of the identified characteristics of oppressed groups or it may not be any of them. The nurses may simply not have the time, as healthcare organisations attempt to increase efficiency while maintaining effectiveness, often resulting in reduction of the nursing workforce. 
The concept of control appears frequently in the literature related to the nursing profession both in terms of empowerment and when describing nurses as an oppressed group. Speedy (1987) identifies that it is the lack of autonomy, accountability and control over their profession that indicates that nurses are an oppressed group. Laschinger et al. (1997) found that for nurses' empowerment means having control over the context and content of their practice. McEldowney (1995), who links oppression and empowerment when discussing nurses as an oppressed group states “ nurses experience patriarchal domination and control in relation to education and practice that denies them autonomy and control over their own sphere of practice" (p.10). My experiences indicate that nurses are often reluctant to participate in policy development activities, and indicate a willingness to have the structure of nursing practice dictated by others. While this behaviour suggests the work environment may not be empowering, it may also suggest that it is a work environment that supports and maintains oppressed group behaviours (Speedy, 1987).

\section{Conclusion}

As part of examining empowerment and/or barriers to empowerment in nursing, the history of nursing and its links with woman's role in society and oppression have been considered. It is only by exploring the historical position of nursing that the current social and political position of nurses within the healthcare system can be understood (Crowe, 2000).

I started this research by asking questions about why nurses are reluctant to participate in policy development. I have searched for reasons in the literature relating to empowerment, power, and the history of nursing in relation to women's role in society, oppression and resistance. My search has been guided by the assumptions I make about the nature of reality. In order to assist the reader of this research to understand the assumptions I make about the world, that is my worldview, I outline the theoretical basis for my work and am clear about the factors that guide my thinking. Assumptions about what reality is, shape what I research, how I go about it, what I consider to be important and also not important. Gilboe, Campbell 
and Berman (1995) discuss the assumptions researchers make in terms of the power of the paradigm or the model the researcher uses. They suggest that

Paradigms are based on a set of assumptions that help shape the form and purpose of any inquiry and provide the lens through which the results of the investigation are viewed and interpreted (1995, p.15).

In the next chapter I will discuss how Critical Social Theory informs this research project. 


\section{Chapter Four: Critical Social Theory - Informing the Research Process}

\section{Introduction}

In this chapter I will explore the underlying theoretical and philosophical position which informs the research process. I describe the Critical Social Theory approach to interpreting reality and where the approach originated. Key assumptions underlying Critical Social Theory are explored and related to this research. The work of two modern Critical Social Theorists specifically inform my thinking, Jurgan Habermas and Paulo Freire, and I will discuss a number of key points from their work.

Critical Theory originated from the Frankfurt School in Germany in the 1920s. Stevens $(1989$, p.57) identifies that

$$
\begin{aligned}
& \text { Critical theorists were concerned about interpreting the } 20^{\text {th }} \\
& \text { century history, especially the effects of World War } 1 \text {, the } \\
& \text { defeat of the left-wing working class movements, the rise of } \\
& \text { fascism and Nazism and the degeneration of the Russian } \\
& \text { revolution into Stalinism. }
\end{aligned}
$$

The major contributors to critical theory include, Marx, Kant, Hegel, Weber, Horkheimer, Adorno, Marcuse, Foucault, Habermas, Derrida, Freire, Irigaray, Kristeva and Cixous (Denzin \& Lincoln, 1994; Guba, 1990; Held, 1980). Critical theory was inspired by the Marxism and Hegelian movements and in more recent times has influenced the post modern/structural movements of feminism and cultural theories (Denzin \& Lincoln, 1994; Held, 1980; Kuokkanen \& Leino-Kilpi, 2000; Stevens, 1989).

Critical theory focuses on a critical approach toward social institutions and how reality is constructed through the linking of ideas, thoughts and language to the social and historical conditions (Held, 1980). Longres and McLeod (1980, p.267) define social structure as "...the way in which particular societies are organised, their norms and their institutions...". They also identify that social structures are taken for granted or internalised, being reinforced and maintained through socialisation 
processes which may result in individuals or groups not recognising that the structures are made by people interacting with each other and that the structures can be changed by the same process. Therefore reality for people is the 'taken for granted' of every day life. Hegemony is the term used within Critical Social Theory to describe how reality is shaped and maintained and I will explore this concept in this chapter. Horsfall (1997, p.63) states that "it is essential that psychiatric nurses explore and critique hegemonic psychiatric beliefs and critically reflect on their own practice". She is referring to the dominance of the medical model and the assumptions made about mental illness and therefore the treatment of people with a mental illness.

\section{Critical Social Theory - Key Assumptions}

Within any philosophical framework it is important to identify the epistemological, ontological and methodological elements (Denzin \& Lincoln, 1994; Held, 1980). Held (1980, p.241) expands on this point by stating "the assumptions, value dispositions, and methodologies of each tradition coherently interrelate to generate its definition of what counts as legitimate scientific knowledge". Epistemology relates to how we know the world and what the relationship is between the researcher and what is known. Ontology is about the nature of reality and methodology seeks to determine how we gain knowledge. If Critical Social Theory is to inform this research project, then the assumptions about how we come to know the world, the nature of reality and how knowledge is gained, need to be explicit. I will expand on the six key assumptions of Critical Social Theory as outlined by Stevens (1989) identifying and discussing terms which appear frequently in the literature and which are central to the understanding of Critical Social Theory.

The first assumption identifies that all research is political. Within critical theory the interaction between the researcher and the known is acknowledged, as is the fact that the values of the researcher impact on what is inquired into and what is known (Held, 1980). This is an important point when undertaking research and is a major difference between critical social theory and positivist paradigms. Critical social theory acknowledges the impact the researcher has on the subjects whereas positivist 
paradigms claim value and bias free research in which the researcher is an 'objective outsider' (Held, 1980). Within this research, I have made assumptions about the nature of reality, which has shaped the questions I ask, who I ask, the literature I read and the research process I use.

The second assumption identifies that oppressive structures exist and are usually taken for granted. In any society certain groups are identified as privileged over others. Guba (1990) suggests power relations are socially and historically constructed and fundamentally mediate all thought and that the reasons for this vary but the oppression evident in modern societies is most forcefully reproduced when subordinates accept their social status as natural, necessary or inevitable. Hegemony is a term used to describe how the dominant group maintain their power through society's institutions. They in turn shape the thinking and subsequent behaviour of the dominant group and the oppressed groups within a society (Gramsci, 1971). Reality is therefore the 'taken for granted', taught and reinforced in a way that is embedded in the consciousness of people and it is only by analysing society's structures that hegemonic ideas can be explored. Within the New Zealand setting, health care delivery shifted from a focus on public service to a focus on market values and individuality with an emphasis on efficiency and standardised measurements (Crowe, 2000). Crowe (1997, p.60) also gives an excellent example of the power of hegemonic processes in structural and social change;

Existing power structures, in this case government, preserve their position by ensuring that general awareness of alternatives and other possibilities are limited, thus ensuring the continuation of the established order. The media, particularly television, acts to naturalise neo-liberal economic theory as the only possible way that New Zealand can go. The models constructed in accordance with this are taken to be the only way of doing things - they are perceived as 'reality' and the only 'reality'. Social structures constructed by the government to ensure the continuance of the neo- 
liberal ethos become internalised as mental structures by the individuals living within them.

Crowe wrote this article in 1997 when the National Government was in power; since then there has been a change to a Labour Government in 1999. It is interesting to note that since this time and the introduction of District Health Boards, the practice environment has not changed significantly. A recent article by Dara McNaught (2001) in the Metro magazine discusses the mental health practice environment in New Zealand. She states that "There has been no indication that the latest change of funding structures, from former Health Funding Authority (HFA) to the new district health boards, signal any change in political policy" (2001, p.40).

Power relations are identified and reinforced by the dominant groups. Gramsci (1971) discusses how order is maintained through the dominant groups use of coercive power. The legal system enforces discipline on groups or individuals that do not conform or consent to the dominant thinking of the time. The dominance of the scientific model is evident within society and the healthcare setting. For example people who act and think outside the acceptable range of 'normal behaviours' are diagnosed as mentally unwell. The tool for psychiatric diagnosis is commonly known as DSM-IV (The Diagnostic and Statistical Manual of Mental Disorders), an authoritative interpretation of behaviours that do not fit within the range identified as 'normal' (Crowe, 1996). The medical model on which a diagnosis is based is the dominant discursive explanation of all forms of behaviour in all settings where diagnoses are made. Its influence is so pervasive that it has been taken for granted as an authoritative and therefore expert position;

Medical staff are sanctioned to diagnose and are therefore identified as a dominant group within healthcare. Within the mental health setting the legal system through the Mental Health (Compulsory Assessment and Treatment) Act 1992 also supports the dominant thinking, reinforcing that people who meet the DSM-IV criteria need to accept treatment to return them to 'normal' (Crowe, 1996, p.106). 
Nursing practice is heavily influenced by powerful groups in the current health care environment. These groups include; the medical profession because of their 'authoritative/expert' knowledge, and management because of the market driven economy (Crowe, 2000). Hegemonic influences or the 'taken for granted' assumptions are what shape reality. The thinking and subsequent behaviour of dominant and oppressed groups need to be identified as they impact on the 'reality' of nursing.

The third assumption reinforces that all types of knowledge are a form of interpretation and therefore need to be open to critique. Facts cannot be separated from values or the wider context, as they are able to be within traditional positivist models. "The positivist paradigm focuses on the discovery of reality characterised by patterns and regularities that may be used to describe, explain, and predict phenomena" (Gilboe et al., 1995, p.16). To assist in understanding the different realities or multiple positions I will be seeking the views of a number of nurses to ensure that different knowledges are sought and explored.

The fourth and fifth assumptions suggest that social conditions and the change in social conditions over time can not be viewed as natural and constant but must be viewed as having been created by specific historical conditions. In critical theory, reality is evolved over time and influenced by socio/political, cultural/ethnic, economic and gender factors. Therefore, in exploring the nature of reality it is important to explore how the 'taken for granted' ideas which constitute reality have developed historically. Starhawk (1987, p.8) suggests "the way we define reality shapes reality" and that it is "only when we know how we have been shaped by the structures of power in which we live can we become the shapers". Within this research I have explored the relationship of women and power within the context of the history of nursing as a profession. It is this history which impacts on the reality of contemporary nursing practice and the practice environment (Crowe, 2000).

The sixth assumption identifies that people must be liberated from oppressive structures. Rationality is the term used to describe the process when people are freed 
from conscious or unconscious constraints (Allen, Benner \& Diekelmann, 1986). Autonomy and responsibility are viewed as components of rationality, specifically being free of constraints necessary to make autonomous decisions and responsible for creating an environment in which others can be autonomous. The term 'rational autonomy', is the process of people understanding themselves, their histories and how they contribute to maintaining oppressive structures. It is this process that is emancipatory and empowering by promoting change at an individual and societal level (Habermas, 1972; Street, 1992).

All people are capable of self-reflection and have a need for independent action (Kuokkanen \& Leino-Kilpi, 2000). Reflexivity or 'self-reflection' is a person's or group's ability to reflect on their history and gain insight into their situation that may change the course of history (Skinner, 1985). This ability to reflect and gain insight is an essential aspect of critical theory as the sciences based on positivism attempt to define the social within the parameters of the natural sciences.

Consciousness raising is described by Longres and McLeod (1980, p.268) as "reflection in search of understanding dehumanising social structures" and is "aimed at altering social conditions" while Habermas (1972, p.197) defines autonomy and responsibility as prerequisites for enlightenment and says, "knowledge for the sake of knowledge comes to coincide with the interest in autonomy and responsibility". Given these assumptions I will now draw on the work of critical theorists Jurgan Habermas and Paulo Freire, who specifically inform my thinking about the content and process of this research project.

\section{Critical Social Theorists - Jurgan Habermas and Paulo Freire}

In Chapter two I describe my initial introduction to both of these theorists while participating in undergraduate and postgraduate education and the aspects of their work that have influenced my thinking. To recap, Habermas's writing became significant when I started to understand how different types of knowledge shaped reality. His explanation on the development of knowledge through technical, practical and emancipatory interests increased my understanding of how knowledge 
is generated and maintained and also encouraged me to read further on the topic of emancipatory knowledge. It is in this area that I found Paulo Freire's (1970) writing assisted in understanding the idea of emancipation being a process which included raising the consciousness of people to the point where they understood enough about what they were experiencing to take action and change the situation. Campbell and Bunting (1991) identify Habermas and Freire as modern critical theorists Habermas with an emphasis on communication, and Freire with an emphasis on political action through education.

\section{Jurgan Habermas}

Habermas has influenced my thinking to a lesser extent than Freire but I will provide a brief description of his work. It is his ideas around dialogical and dialectical approaches that have influenced the research process I have used, and how the research process can facilitate emancipation.

Habermas draws heavily on the original ideas of the Frankfurt School; he also regards himself as a Marxist but relates the key concepts of Marxism to the current environment (Skinner, 1985; Habermas 1972). Marxist ideology focuses on social regulation, and unequal distribution of resources and power (Holter, 1988). Stevens (1989) discusses Habermas and Critical Social Theory. She describes her interpretation of Habermas's intention with the use of critical social theory as "to understand how people communicate and develop symbolic meaning, and by means of this process to uncover distortions and constraints that impede free, equal and uncoerced participation in society" $(1989$, p.58). Language is identified as central to the formation of subjectivity (conscious and unconscious awareness) as it is through language that people develop and share meaning (Habermas, 1972). In critical theory, knowledge is only gained by interaction between the researcher and the participants. The terms dialogic and dialectical are associated with a critical methodology. A dialogic approach is the term used to describe the interactions that occurs between the researcher and the participants, the dialectical approach aims to eliminate the false consciousness of participants to reveal the true reality, facilitating understanding and therefore transformative action (Guba, 1990; Held, 1980). It is 
through this interaction that the consciousness of the participants is raised about the historical factors that have influenced reality, as it is known. Skinner (1985, p.126) illustrates this point by stating;

The more human beings understand about the springs of their own behaviour, and the social institutions in which that behaviour is involved, the more they are likely to be able to escape from constraints to which previously they were subject.

While the influential aspects of Habermas's work on knowledge development, and the role of language in developing shared meaning is significant, it is his work on the importance of discussion in facilitating understanding and transformative action that was particularly significant for me in this research project. It is Paulo Freire who expands on the concept of facilitating understanding (conscientisation) through transformative action and reflection (praxis).

\section{Paulo Freire}

I will provide a brief description of Paulo Freire's early life, as it is an important part of who he is and what he believes (Freire, 1970, 1983, 1987; Lythgoe, 1977). Freire was born in 1921 and grew up in Brazil. When he was eight years of age his family became destitute because of an economic depression. His poor nutritional status impacted on his ability to learn, he fell behind in his schoolwork and was diagnosed as mentally retarded. These early years were significant as they had a profound effect and led to his commitment to improving the life of people who live in an underprivileged environment. After graduating from Law School he worked among the poor and became aware of the need for literacy training. He worked as a literacy educator from 1947 to 1959 . His radical ideas about education, namely that social reform could be brought about through education, were seen as subversive and led to imprisonment and subsequent exile in 1964. Lythgoe (1977, p.21) provides an example of why Freire thought literacy was essential "Only as the illiterate was to become conscious of the complexity of the dynamic of his/her situation would he/she be able to understand his/her place and begin to consider how to change those circumstances". 
Freire (1970) has made a significant contribution in terms of his work with underprivileged and dispossessed people. His work focuses on oppression, how oppression is maintained through the education system and how consciousness raising (or conscientisation) through learning can assist people to take action against oppressive forces. He identifies that the education system can teach people what is known or the current reality and therefore maintain the status quo, or the education system can teach people how to question and critically examine what is known to help them promote freedom and transform or change their reality (Freire, 1970). Transformation is a word used frequently by critical theorists. Lewis (1990, p.469) provides a definition of transformation from a Critical Social Theory perspective;

Transformation is the development of a critical perspective through which individuals can begin to see how social practices are organised to support certain interests, and the process whereby this understanding is then used as the basis for active political intervention directed toward social change with the intent to disempower relations of inequality.

Whereas other Critical Social Theorists with their origins firmly rooted in the Marxist tradition believed change could only come about by a total rejection of the (dominating) system, Freire promoted social reform from within the system (Lythgoe, 1977). One aspect of social reform was the assessment of where individuals/groups were in terms of their social consciousness. Freire (1987) identifies four levels in the analysis of social consciousness. The most primitive level, intransitive consciousness is evident when individuals or a group are preoccupied with basic survival with little interest in asking questions about their life situations. The next level, semi-intrasitivity is evident when there is an absence of critical questioning about 'the way things are', a culture of dependency exists, as people do not have the confidence or ability to be self-sufficient. The next level naive or semi-transitive consciousness is when people start to question 'the way things are', and will 'test the waters' with rebellious acts. The final level, critical consciousness, occurs when consciousness is informed by in-depth questioning, interpretation and analysis. Alschuler (1986) when discussing counselling makes 
reference to the levels of social consciousness described by Freire (1987). He describes three stages, the magical conforming stage, the naive reforming stage, and the critical transforming stage. The magical conforming stage exists when people are passive and conform, as they do not recognise their oppression. The naive reforming stage exists where problems lie with the individual rather than the system, and the critical transforming stage is where people realise they are victims of the systems they live within. The stages move from total ignorance of the need to or the ability to change the way things are, to a time of questioning where people or groups look toward themselves and their own deficiencies. In the final and more critical stage/s the whole of society is viewed and critiqued including the interface between various aspects of a society.

As I reflect on my own journey I can identify points in my life when I was at each of these stages. Using Alschuler (1986) stages, the magical conforming stage was when I was moving along on the expected life path without questioning it. The naïve reforming stage was when I started to identify that there were choices but that I lacked the confidence in my own ability to actually succeed (therefore I was the problem). The critical transforming stage is where I currently locate myself but using Freire's (1987) definition of critical consciousness, when consciousness is informed by in depth questioning, interpretation and analysis.

This research project is part of the critical consciousness as I search for answers by questioning, and then interpreting and analysing the information. This process is designed to raise my consciousness and result in transformative action, as it is only by understanding the social reality that one knows how to transform that reality. This process is also designed to raise the consciousness of the nurses who will participate in the focus group discussion. This research process and links to consciousness raising have been considered and will be discussed in Chapter five.

\section{Conclusion}

As stated in the introduction to this chapter, Critical Social Theory informs and shapes this research, not only what I research, but also the process I use for 
researching the topic. In particular the work of Habermas and Freire guide how I undertake the research process. Empowerment is a key concept within my research and a key concept of the underlying critical social theoretical position, which informs this research project. The research process I use needs to be consistent with the concepts of empowerment. "Emancipatory, critical social science must be premised upon the development of research approaches which empower those involved to change as well as understand the world" (Lather, 1991, p.4). Opie (1998, p.189) suggests when researching issues of power and power relationships with mental health service users, it important to direct the attention to "those unexamined, taken for granted modes of behaviour and assumption that underpin the nature of their interaction" and that this requires "questioning behaviour from users". I would suggest that this apply to research in general when studying power relationships. I would also suggest that Critical Social Theory with its focus on examining the taken for granted modes of behaviour and assumptions that underpin the nature of interactions is an appropriate theoretical position to inform this particular research topic. Held (1980, p.182) identifies a good study using a critical perspective " is one that makes transparent the historically formed contradictions and thereby promotes emancipation and empowerment". In the next chapter, I will describe how I plan to promote emancipation and empowerment through the research method selected and the research process used. 


\section{Chapter Five: $\quad$ Research Method and Process}

\section{Introduction}

In the previous chapter, I discussed how the underlying assumptions of a Critical Social Theory perspective would inform the research process. The research question and aims of this research are related to nurses working in the mental health area. The aims of this research are to identify how nurses feel about participating at a decisionmaking level, and to identify what needs to change in the work environment for nurses to feel they can participate and therefore have control over the content and the context of their practice and thus feel empowered. It is important to select a research method and process that fits with the question and aims, and, the underlying theoretical and philosophical position. The research question is: What can nurse leaders do to encourage an empowering environment for nurses working in the mental health area? Therefore, I have chosen a qualitative research method for this project and to answer the research question I will be using a focus group to gather data from the mental health nurse participants.

This method has been selected for two reasons. First, the critical social theoretical position supports a dialogic and dialectical approach to research. This is where the researcher interacts with the research subjects to gain knowledge (dialogic approach) and through this process of interaction and discussion (dialectical approach) the participants increase their understanding and consciousness of their situation (Guba, 1990; Held, 1980). Morgan (1993) suggests that a dialogical approach to research leads to greater empowerment for the research subjects. Longres and McLeod (1980) also identify discussion within a group setting as the best way to raise consciousness. As consciousness raising is an aim of Critical Social Theory, a focus group of nurses facilitated by me as the researcher seemed a logical method to collect data. Second, as the research topic is about nurse leaders creating an empowering environment for nurses practising within mental health services, the choice of a focus group as a data collection tool is significant as the only people who can describe how they perceive reality are the participants themselves and this aspect will be further explored in this chapter. 
Initially I discuss the characteristics and origin of using focus groups as a research method, their strengths and weaknesses as a data collection tool, and elaborate on why I selected the focus group as my method of choice. I also describe how I analysed the data from the focus group discussion. I discuss the process I used to gain ethical approval for this project as any research using human subjects can raise ethical issues for consideration. I identify ethical issues that arose as a result of the use of focus groups and also from choosing to use participants from within the service where I hold a management position. I conclude by discussing how I promote rigour throughout the research process using the criteria of credibility, transferability and dependability as measures of trustworthiness.

The authors who I cite frequently to inform my understanding on focus groups are David Morgan and Richard Krueger who produced 'The Focus Group Kit' in 1998. I also cite research studies that use focus groups as a data collection method as well as texts on general research methods and more specifically research methods consistent with a Critical Social Theory position.

\section{Focus Groups}

Focus groups originate from the discipline of sociology. They are a common method of data generation in market research to identify consumer opinion on specified products, and in politics to identify voter reactions to issues (Denzin \& Lincoln, 1994; Morgan, 1988). They can be used by themselves as a qualitative data collection tool or as one of a number of data collection tools in a piece of research (Denzin \& Lincoln, 1994; Morgan, 1988). Other data collection tools that may be used in combination with focus groups are questionnaires/surveys and one-to-one interviews (Morgan, 1993).

The focus group can be considered similar to a group interview. However, a significant difference is that the discussion is generated from the group interaction in a focus group as a response to the researcher's topics or prompts, whereas in group interviews the researcher is more likely to ask questions which the group responds to rather than interacting with each other. Morgan $(1988$, p.12) describes the hallmark 
of the focus group as "the explicit use of the group interaction to produce data and insights that would be less accessible without the interaction found in the group". One of the aims of focus groups identified by Argirides $(2000$, p.9) is "to encourage participants to engage in deep dialogue in order to explore and develop their own understanding and analysis of common experiences". Longres and McLeod (1980) identify that the group setting is the best way to raise consciousness, as it is through group discussion that the full implications of social experiences are explored.

\section{Advantages of Focus Groups}

The advantages of using focus groups as a data collection tool are identified by Argirides (2000), Denzin and Lincoln (1994), Krueger (1998), and Morgan (1988). Some of the advantages of using focus groups include: they are relatively simple to organise and cost little to run; they identify the experiences and perceptions of a number of participants in a short period of time; and, they produce useful data with little input from the researcher.

Focus groups provide an opportunity to collect data from group interaction, as it is the group interaction that generates data unique to that group, which will not be produced from one-to-one interviews. Focus groups are useful when it comes to investigating what participants think, as they excel at uncovering why participants think as they do. Focus groups are also identified as a useful way to get the experiences of a group of people who experience limited power and influence. The amount and complexity of the data collected from the focus group interaction can be an advantage as a large amount of complex data is collected within a short period of time. The complexity of data relates to the group interaction and the depth of analysis that can be used. There are also disadvantages associated with collecting a large amount of complex data and I will expand on these difficulties in the next section.

\section{Disadvantages of Focus Groups}

There are several disadvantages when using focus groups as they are an organised event and therefore the data is not collected in the natural setting (Argirides, 2000; 
Denzin \& Lincoln, 1994; Krueger, 1998; Morgan, 1988). The researcher has minimal control over the data that is generated as researcher input is minimal because the data is produced from the group interaction. The group setting itself may produce a bias, as the group interaction may not reflect the perceived reality, but the expected reality in which participants may only share what they think they should say within the group setting. If the topics discussed are highly emotive or controversial, people may not participate as they may not feel confident enough to state their opinion within the group environment. Conflict may also be produced within the group as discussion highlights differing opinions. The emerging culture of the group may significantly influence an individual's response within the group setting and domination of the group by one participant with forthright opinions may inhibit group discussion. Focus groups also produce a large amount of complex data, collected from the discussion generated from the interaction of focus group participants. The complexity of the data needs to be considered in terms of the scope of the research project and the method of data analysis that will be undertaken. For example, aspects that could be considered are the number of focus groups and the number of participants in each group.

The disadvantages identified are most likely to occur when the focus group is not the most appropriate data collection method (Morgan, 1998). For instance, focus groups would not be an appropriate data collection method if participants did not feel comfortable discussing the topic, and/or the participants had no knowledge of the topic under discussion. If statistical data or data that could be generalised to the wider population was required, alternative data collection methods such as questionnaires would be more appropriate than focus groups.

\section{Rationale for Selecting the Focus Group Method}

Having considered the advantages and disadvantages I then selected the focus group method to generate the data. My rationale for this was firstly, the discussion emerges from the interaction of participants within the group in response to the researcher's questions (Morgan, 1988). This approach to data gathering would offer participants an opportunity to discuss empowerment and reflect on what empowerment means for 
them within the workplace. Secondly, the reason why I selected the focus group is related to the theoretical and philosophical underpinning of this research, Critical Social Theory. Focus groups are consistent with the emancipatory aims of Critical Social Theory. Throughout the focus group process I anticipated that the participants would gain an increased understanding of the concept of empowerment. This increased understanding or consciousness raising is itself emancipatory, as it is through greater understanding that participants are assisted toward transforming action (Held, 1980). It is the sharing of experiences and identifying with the opinions of others that gives the group participants the strength to act as change agents (Ward \& Mullender, 1991). As Rapp et al. (1993, p.729) suggest in their discussions on research into consumer perspectives within mental health services "Inquiry must not only reflect good science, it must also contribute to the empowerment of those who seek help".

The identified advantages of using the focus group as a data collection method fits well with both the subject, size and scope of this research project. The nurses are engaged in morning and afternoon shifts over a seven-day period, within different mental health practice settings, and the group setting generated data over a short time frame. This was important, as interviewing this number of nurses individually would have been difficult to organise within the work environment and within the time available for completion of the project.

The disadvantages have been considered and mainly relate to the group process. I did not anticipate the topic being unfamiliar or controversial to the group participants and considered that my facilitation skills would be adequate to manage the situation if one or more participants attempted to dominate the group. If nurses were going to feel uncomfortable about sharing their opinions within the group environment then I anticipated that they would decline to participate in the research. However, I also realise that one can never predict how the discussion will go and how people will experience the group process until it actually occurs. 


\section{Analysing and Interpreting the Focus Group Data}

"Given the qualitative nature of data gathered by focus group methodology, a considerable amount of subjective judgement is necessarily involved in the interpretation and analysis" (Morgan, 1993, p.43). According to the Critical Social Theory perspective, all data analysis is value laden rather than value free. It is not possible to be totally objective when analysing data, as some form of subjective interpretation always exists (Held, 1980; Morgan, 1993). Australian narrative therapist Michael White (1989) provides an excellent example of 'how we can know the world' which he shared in a plenary address at a family therapy conference:

What we know of the world we know only through our experience of it; our experience of the world is all we have, and this is all we can know. We cannot even know another experience of the world. All we can do is interpret the experience of others; that is the expressions of their experience as they go about the business of interpreting it for themselves $(1989$, p.6).

Therefore, the data analysis will be influenced by my personal and professional life experiences. The knowledge I have developed around the concept of empowerment, nursing, and experiences I have as a manager (and prior to that as a nurse within the organisation), will influence the way in which I interpret the data generated from the focus group discussion.

Morgan (1993) suggests that the most challenging aspect of all research is the analysis of the data collected. Krueger (1998) expands on this point by identifying that in the analysis of focus group data the amount and complexity of the data make analysis a challenge. The complexity occurs because of the interactive nature of the discussion. Examples of the complexity may include: the amount of data collected; a number of participants speaking at the same time; participants using a number of different words to indicate the same meaning; participants changing their opinions and using non-verbal language to clarify their verbal statements (Krueger, 1998). 
The amount and complexity of focus group data generated from the interaction of focus group participants meant that I had to make a decision about the complexity of the data analysis process I used. First, as suggested by Krueger (1998) I returned to the aims of this research - to identify how nurses feel about participating at a decision-making level, and to identify what needs to change in the work environment for nurses to feel they can participate and therefore have control over the content and the context of their practice and thus feel empowered. Second, I considered the scope of my research, and this is where Krueger (1998) assisted in clarifying the data analysis process. He suggests that;

The researcher's task is to prepare a statement about what was found, a statement that emerges from and is supported by available evidence. In preparing the statement, the researcher seeks primarily to identify evidence that repeats and is common to several participants $(1998$, p.6).

Considering the complexity of the data collected, and Krueger's (1998) ideas about returning to the aims of the research and identifying ideas that are repeated by participants within the focus group setting, I decided on a relatively straightforward data analysis procedure.

As previously mentioned in Chapter one (p.5), Morgan (1993) describes a mechanical stage and an interpretive stage to analysis of focus group data. Although I have kept the data analysis process relatively straightforward I found the two stages helpful in guiding the analysis. In the mechanical stage the raw data from the focus group transcripts is examined until the key ideas emerge. Krueger (1998) suggests that as the researcher examines the data, labels are attached to similar ideas or phenomena. I will use the term 'key ideas' rather than 'labels' to represent the associated words, similar ideas or phenomena. These key ideas are presented and discussed in Chapter seven. Following the mechanical stage, the interpretive stage ascribes meaning to the data. Morgan (1993, p.43) contends that "Interpretation is facilitated by the fact that statements can be examined within the context of the broader discussion and in light of information available for other sources". The key ideas that emerge from the 
mechanical stage of the data analysis will be examined within the broader context of the mental health nursing practice environment. This broader context will be informed by the key assumptions of Critical Social Theory and the literature I have reviewed in relation to empowerment, power, the history of nursing in relation to women's role in society, oppression and resistance. It is from the integration of the key ideas from both the focus group discussion and the literature reviewed, that key themes around empowerment will be identificd. During the interpretive stage of analysis I will use direct quotations from the focus group discussion to aid and support the data analysis.

As stated in the introduction to this chapter, issues arising from research involving human subjects need to be considered irrespective of the type of research method used. The use of focus groups to collect data poses few ethical issues but when ethical issues do arise, they need to be considered carefully (Morgan, 1998). Ethical issues may include issues of informed consent, privacy and potential risks such as participation in the research potentially affecting the participant's employment.

\section{Ethical Considerations}

The major risk to the focus group participants in discussing their feelings about empowerment within the focus group setting, arose from my position as the researcher and as a manager within the employing service. The ethical issues I discuss are the issues of participation, confidentiality/identifiability, storage of information and informed consent. These issues needed to be considered and managed as part of the research process to ensure that the prospective participants were protected from harm.

The above issues were identified and considered prior to seeking approval to conduct the research from the Regional Ethics Committee in my area. I discussed the research project with the Ethics Committee secretary prior to submitting the application as I had identified that regional ethics committees around New Zealand had differing views on the process for obtaining ethical approval. A number of regional ethics committees did not expect to be involved if the research involved 
nurses using other nurses as research participants, as opposed to nurses using health service users/patients within a region as research participants. I required ethical approval for this research project and if I did not use the regional committee I would have to apply to the Victoria University of Wellington Human Ethics Committee. This conversation proved to be invaluable as it clarified the process that would be required and saved valuable time. I was required to submit an Application for Ethical Approval (Appendix 4) to the chairperson of the Regional Ethics Committee in the first instance. The chairperson would use his discretion in deciding if ethical approval would be granted or if the application had to be submitted to the Regional Ethics Committee. I received ethical approval (Appendix 5) via the Regional Ethics Committee chairperson. I understand that the research proposal was not circulated to other members of the Committee. The chairperson considered that I had provided appropriate information and conformed to the ethical guidelines outlined by the Regional Committee.

The ethical issues I identified (participation, confidentiality/identifiability, storage of information and informed consent) and planned for, were outlined in the Application for Ethical Approval (Appendix 4). The application included a copy of the Invitation to Participate (Appendix 1), Information Sheet (Appendix 2), and the Informed Consent Form (Appendix 3), which would be sent to the prospective participants. I will now expand on how I managed the ethical issues that arose from this research.

Participation in the research was voluntary. The participants were able to withdraw from the project at any time, or they were able to decline from responding to any of the questions asked within the focus group. An assurance was provided in the Information Sheet (Appendix 2) to participants that their work positions would not be jeopardised if they decided to withdraw. It was crucial that this was overtly stated considering my management position within the service. Conducting the research with nurses who worked in a service where I also held a management position was a potential risk to the participants. The measures taken to minimise this risk included: inviting nurses to participate in this research with whom I did not have a direct line management responsibility; providing a comprehensive Information Sheet (Appendix 
2) which clearly outlined why the research was being conducted, the aim of the research, my role within the focus group and a statement that participation is entirely voluntary; and, the use of an assistant during the focus group process. The assistant's role was to ensure equal relationships were maintained within the group, discussion remained focused around the questions asked of the group and to monitor the group facilitation.

Participants' names and associated information were kept confidential. No identifying information is included in this study. The focus group assistant and the audio tape transcriber are the only people (apart from myself) who know the names of the research participants and the information they shared within the focus group. The focus group assistant, and the typist transcribing the audio tapes were required to sign confidentiality agreements (Appendix 8) which requested that they did not disclose any information related to the participants or the discussion during or after the research process. Focus group participants were also asked to maintain confidentiality and this expectation was one of the group 'rules' identified by the focus group. No material that could personally identify the focus group participants or their location is used in any reports related to this research. Direct quotations are used to illustrate the key ideas/themes that emerge from the discussion. However, if any of the quotations seemed likely to identify the participants due to content or inflection, they were not used. The participants had the opportunity to delete any quotations that might have been used. They each received a copy of the key ideas I identified from the group discussion and a selection of quotes that I considered using to support or illustrate the data analysis and discussion.

Written records and the audio tapes were kept in a locked secure area at my home. Transcriptions of the focus group discussion were stored on the hard drive of my computer, which is password protected. I am keeping the audio tapes for up to five years as this information may be used for further articles or presentations arising from the original research. After this time the audio tapes will be erased.

Informed consent was obtained from prospective participants by providing an 
Invitation to Participate (Appendix 1), an Information Sheet (Appendix 2), which provided comprehensive details of what the research involved, and an Informed Consent Form (Appendix 3). Informed consent was assumed if the registered nurse returned the signed consent form.

Another risk to participants may have been if the sharing of opinions and feelings was uncomfortable for them within the group setting or if issues were raised in the group that caused psychological distress. As previously mentioned, participation was voluntary and therefore if sharing in a group setting was difficult for the prospective participants they had the choice of not being involved in the research. If during the course of the focus group session, psychologically distressing issues were raised for a participant, they had the choice of withdrawing from the research. If they wished to continue I had assured them that I would arrange a debriefing after the focus group session and follow-up counselling as required through an Employee Assistance Program. If the participant decided to withdraw they would have the same opportunity for debriefing. It was not envisaged that the topic and content of the focus group would cause distress but this needed to be planned for, as issues that cause distress are not always predictable.

As well as addressing the ethical issues that might arise for the participants of this research project - it is also imperative that I ensure there is rigour in the research process as a whole. I will address issues of rigour in the next section.

\section{Promoting Rigour in this Research Project}

There are a number of strategies I use to ensure rigour in the research process. Morgan (1993) and Krueger (1998) consider that validity and reliability are measures of methodological rigour. However, while I used the work of both authors extensively to inform my work with regard to the use of focus groups as a research method, I have not used validity and reliability as measures of rigour. Koch and Harrington (1998, p.884) suggest that researchers using a qualitative method are preoccupied with using quantitative or scientific measures and that "borrowing evaluation criteria from one paradigm and applying to another is problematic". 
In the health field, with its strong tradition of biomedical research and use of conventional quantitative methods, qualitative research is often criticised for lacking 'scientific' rigour. Until recently qualitative researchers have responded to these criticisms by claiming that the integrity of the research process can be protected by attending to the issues of objectivity and generalisability and their use of evaluation criteria. These evaluation criteria are often used to assess a piece of qualitative work and are often derived from conventional quantitative research practice (Koch \& Harrington, 1998, p.883).

I use credibility, transferability and dependability as the criteria to measure the trustworthiness of this research as outlined by Guba and Lincoln (1989). I will now discuss these criteria in relation to this project.

\section{Credibility}

Credibility is the match between the realities of the participants and the reality as interpreted by the researcher (Guba \& Lincoln, 1989). Credibility will be enhanced in this research in two ways. First, through my own self-awareness as a researcher, which includes acknowledging the potential impact of the position I hold within the healthcare organisation, and the influence my knowledge and experiences have on the selection of the topic, and second through the process I have selected to research the topic. I use a reflective process throughout this research to enhance the credibility of the research and to maintain consistency with the theoretical and philosophical underpinnings of Critical Social Theory. Self-reflection or reflexivity is central to critical theory as it is a person or groups' ability to reflect on their history and gain insight into their situation that may change the course of history (Skinner, 1985). Koch and Harrington (1998) encourage researchers to locate who they are as a person within the research. In Chapter two I have attempted to describe who I am and how I influence the research topic and process. I support Koch (1994, p.985) who says "I bring my pre-understandings and prejudices to this construction. No attempt is made 
to disguise these. I make my concerns and position clear". I also reflect on how I may have impacted on the focus group process and data analysis. Koch and Harrington (1998, p.887) say "The research product can be given shape by the politics of location and positioning and this is precisely what makes it a critical process". Credibility is therefore enhanced if the research is well 'signposted' and the reader is able to follow the path of the participants and the researcher and decide for themselves if the work is believable or plausible.

I enhance the credibility of this research by consulting with the focus group participants prior to the data analysis stage. I sent out a summary of the key ideas identified in the focus group discussion to the participants (Appendices $9 \& 10$ ) to ensure that $I$ had accurately reflected the discussion content. I also included a range of quotes from the discussion that I considered I might use in the research report to support or illustrate the data analysis and discussion. Participants were invited to comment on the key ideas and delete any quotes that they did not think were appropriate to use in terms of maintaining their confidentiality.

I consider that it is also important in establishing the credibility of the data, to reflect on the focus group discussion and identify the actions taken to ensure that the process was empowering for all involved. I use a focus group assistant to ensure equal relationships are maintained within the group; discussion remains focused around the questions; and, to monitor the group facilitation.

\section{Transferability}

Transferability is the second criteria used to establish trustworthiness. It was never my intention to generalise the finding of this research to the wider population or to use a method, which enabled other researchers to replicate the study. Guba and Lincoln (1989, p.241) state, "Transferability is always relative and depends on the degree to which salient conditions overlap or match". The method used may be transferable to another situation and the findings may be similar but as stated this was not my intention with this research. The focus group interaction will be unique to this group and generate data that is also unique to this combination of participants. 
Guba and Lincoln (1989) identify that it is important to describe the research context, as it is the similarity of research contexts upon which transferability is dependent. This research will use a group of nurses practising within mental health. Mental health services and the nurses practising within them do not exist in isolation and therefore this is why I have identified the research context in relation to the wider nursing, healthcare and socio-political environment. I have provided the research context to enhance transferability but also to support the underpinning critical approach to this research.

\section{Dependability}

Dependability is the third criteria used to establish trustworthiness. Dependability is defined as "the stability of the data over time" (Guba \& Lincoln, 1989, p.243) Dependability can be enhanced by "leaving a decision trail (which) entails discussing explicitly decisions taken about the theoretical, methodological and analytical choices through the study" (Koch, 1994, p.978). I have attempted to identify (or signpost) the reasons why I chose; a critical theoretical approach; the focus group as a data collection method; and, the analytical process used. It was essential that there was consistency in the approach taken, as empowerment is central to a critical approach and all aspects of the research required consideration and reflection to ensure people were not disempowered by the research process.

The involvement of the researcher within the research and with the research participants is also central to a critical approach (Gilboe et al., 1995). In critical theory, knowledge is gained by interaction between the researcher and the participants. A dialogic approach is essential in a critical methodology and is the term used to describe the interactions that occur between the researcher and the participants. The advantages of being present during the focus group discussion are related to getting 'a feel' for the situation. The written transcriptions provide the words that are spoken but not necessarily the facial expression or body posture that adds meaning to the spoken word. Rapp et al. (1993) suggest that for researchers who are concerned with empowerment it is important that the researcher has an understanding of the participants, their concerns and desires and the language they 
use to describe their experiences. Language is identified as central to the formation of subjectivity as it is through language that people develop and share meaning (Habermas, 1972).

Gilboe et al. (1995, p.24) also suggests when examining rigour within the research process that "in the critical paradigm, the degree of change brought about as part of the research process is of primary importance" and that change may be at the systems or individual level. Lather (1991) advances this idea by suggesting that it is the degree to which participants gain self-understanding and ultimately selfdetermination that is important. As the researcher I am also a participant in the research process. In Chapter eight in the section entitled 'Benefits of Participating in this Research Project' I will reflect on whether I have gained a greater selfunderstanding and/or bought about change at an individual and/or systems level.

\section{Conclusion}

In this chapter I have outlined the research method and process. I have justified the choice of the focus group research method. The characteristics, origin, advantages and disadvantages of focus groups have been outlined including the method of data analysis to be used. I have described the process used to obtain ethical approval for this research project and discussed the ethical considerations that arose and how these were managed. I conclude this chapter by discussing the strategies I used to promote rigour throughout the research process.

The appendices relevant to this section and other sections as well are attached to this research project. All identifying information (names and locations) has been removed. The next chapter discusses in more detail the planning and implementation of the focus group process used in this research project. 


\section{Chapter Six: The Focus Group}

\section{Introduction}

In this chapter, I discuss the focus group process used in this research project specifically the planning, which includes facilitation and the selection of participants, the implementation of the focus group process, and my reflections on the group content and process. I will start this chapter by revisiting the original research question and aims before providing a brief review on how I plan to answer the research question.

The research question is 'What can nurse leaders do to encourage an empowering environment for nurses working in the mental health area?' The aims of this research are to identify how nurses feel about participating at a decision-making level, and to identify what needs to change in the work environment for nurses to feel they can participate and therefore have control over the content and the context of their practice and thus feel empowered. As part of exploring the research question further, I planned to seek the views of a number of nurses practising in mental health as it is only by seeking their views that the aims of this research could be achieved. The questions asked of the group were designed to stimulate discussion, explore the concept of empowerment and identify what it takes for nurses to feel empowered or disempowered within the workplace. The research project is therefore qualitative, and uses an exploratory descriptive research method as I can not identify what nurses' experience in clinical practice is without talking to the nurses themselves.

The research data was gathered from a focus group of registered nurses working within the mental health service. The planning stage of the focus group was the starting point of the data collection process. It commenced during the process of obtaining ethical approval. As well as producing the Application for Ethical Approval (Appendix 4), I produced the package that would be sent to prospective participants. This package included the Invitation to Participate (Appendix 1), an Information Sheet (Appendix 2), and a Consent Form (Appendix 3). I will now discuss the planning stage. 


\section{Planning the Focus Group}

Planning the focus group is identified as important because the quality of the data collected is dependent on the quality of the focus group preparation (Beyea \& Nicoll, 2000; Morgan, 1988). The Invitation to Participate (Appendix 1) was sent to the registered nurses working within the mental health setting two weeks prior to the focus group date. The focus group assistant was in agreement with the time and date and the room was booked and refreshments arranged. I ensured that I had all the equipment required for the focus group implementation and that it was in working order. The equipment included an audio tape recorder, audio tapes, flip charts, whiteboard pens and a whiteboard. The Information Sheet (Appendix 2) contained the time and date of the focus group to ensure prospective participants were available. Immediately on receipt of the Consent Forms (Appendix 3), I contacted the registered nurses to thank them for agreeing to participate, confirmed the time and date and informed them of the venue for the focus group.

I made the decision to use a single focus group as the data would be representative of this one group at a single point in time. Morgan (1988) suggests that one group is never enough as observations may reflect the dynamics of a unique group of participants. However, I was seeking this group's experiences and opinions. The group interaction would be unique to this group and generate data that was unique to this combination of participants. An advantage of using a group of registered nurses is that the more homogeneous the group members' characteristics, the fewer the number of groups required (Morgan, 1988).

I considered the size of the focus group and sought to understand the advantages and disadvantages related to group size. My aim was to stimulate discussion within the group about empowerment in the workplace. The interaction of the group was pivotal to the data collection and I considered that the participants needed to be able to fully explore each question. The group also needed to be small enough to ensure all members of the group had the opportunity to express their opinion. As mentioned in Chapter five, one advantage of a smaller group is the opportunity for increased input from each participant which is useful when the participants reaction to the topic 
is required. Morgan (1998) cautions that small groups are more prone to be influenced by friendships or experts within the group, which may influence the ability of others to participate. Being aware of the group dynamic that was emerging from the group would be important and would determine my input as a facilitator. If one or more group members were dominating the discussion, I planned to use minimal prompts to encourage other group members to speak. I would also remind the group that one of the rules the group had set at the beginning was that one person would speak at a time and that we would respect the opinion of others. I was confident that the rules the group would set would be the customary group rules that were familiar to the participants as many of them facilitated groups within the mental health setting.

I had identified that the focus group participants would require up to two hours to discuss the questions. As this was the first focus group I had facilitated, I considered Morgan's (1988) time recommendation of between one and two hours and allowed the maximum recommended time to encourage a full discussion.

\section{Facilitating the Focus Group Process}

I planned to act as the focus group facilitator and to use an experienced facilitator and colleague as an assistant. I chose to use an assistant for two reasons. First, (as mentioned in Chapter five) due to an ethical consideration which related to my management position within the mental health service. One of the strategies for managing this issue was the use of an assistant within the focus group to ensure an equitable process for discussion was maintained. Second, the assistant was chosen to monitor and assist with the group facilitation. Even though I was comfortable with my group facilitation skills within the work environment, as a novice researcher I considered Beyea and Nicoll's (2000) suggestion of having an assistant facilitator to assist with the facilitation of the group, take notes and observe the group process. As Denzin and Lincoln (1994) point out, using a focus group discussion to generate data does present some challenges for the facilitator, ensuring one or two people do not dominate with their opinions, encouraging quieter group members to participate and monitoring the generation of discussion while also monitoring the group dynamics. 
In selecting a focus group assistant I considered the following factors; their experience facilitating groups; their knowledge of the focus group process; their relationship to the focus group participants; and, their credibility with the focus group participants. An important consideration was that the focus group participants felt 'safe' in discussing their ideas and opinions in the focus group. The focus group participants would most likely know the focus group assistant but not from working within the mental health service. The participants would also be informed that the focus group assistant had signed a confidentiality agreement.

I have chosen to use the term 'facilitator' rather than the term 'moderator', which is the terminology consistent with focus group literature. This is partly because I consider 'facilitation' rather than 'direction' is more consistent with a Critical Social Theory position and where the aim is to explore the participant's views and to create an environment where participants feel able to share their experiences and opinions (Morgan, 1988). 'To facilitate' is defined as 'to assist', whereas 'to moderate', is defined as 'to preside over' (Collins Concise Dictionary, 1999). Preside is further defined as 'to hold a position of authority', (as in over a meeting), or 'to exercise authority or control' (Collins Concise Dictionary, 1999). Facilitating a group to discuss empowerment and describing myself as the moderator of the group, which is defined as sitting in a position of authority, is a contradiction that would not be acceptable. The subject (empowerment) and underlying critical approach of this research, support the facilitator assisting with a process rather than having authority over the group. Longres and McLeod (1980, p.269) identify that "Consciousness raising can only be done within the context of a non-authoritarian practice...".

I had planned the focus group, organised the facilitation and focus group assistant. The selection of the focus group participants also needed to be planned and well organised to ensure the focus group was successful and participants were adequately informed about the research and had adequate advance notice of the date and time. 


\section{Selecting the Focus Group Participants}

I invited 12 registered nurses from the mental health service to participate, as the typical focus group size is between 6 to 10 people (Morgan, 1988). Ultimately the number of registered nurses who consented to participate determined the size of the group. If all the nurses invited had consented to participate the group would still have been of a manageable size. Morgan (1988) recommends over-recruiting by $20 \%$ as people may not turn up or they may withdraw from the research. I anticipated a number of the nurses would not consent, that some may not turn up, or that some may withdraw. Therefore, I planned for more participants than I required.

I invited participants who I knew were likely to have some knowledge of the topic and who were likely to feel comfortable expressing their opinion and discussing the topic within the group setting. This knowledge came from either working with the nurses in previous roles or participating in ongoing education courses with them. As I manage the majority of inpatient beds, most of the nurses practising within the inpatient setting were excluded from participating in the research project. The nurses invited to participate were mainly from community mental health services and although there were a number from inpatient services I did not have line management responsibility for them. One the characteristics of the prospective participants was that they were all registered nurses who had been working full time within mental health for a minimum period of one year. Another characteristic was that their professional background was similar but their experiences and opinions differed which was advantageous to the group discussion (Morgan, 1988). As Denzin and Lincoln (1994) identify, the selection of participants who are observant and knowledgeable may produce more valuable insights than a representative sample. I was seeking the experience of registered nurses working within mental health and considered that the data generated would reflect the discussion from this group and would not be reflective of any other group in any other setting. Although as discussed in Chapter five in the section on promoting rigour, there may be aspects of the discussion that are pertinent to other nursing contexts. The criteria of working full-time for at least one year was used to exclude nurses who were new to the service and those who worked part-time or casually. I wanted the opinions of nurses who 
were an established part of a practice environment, as the factors that they identified as important about empowerment, would not be related to being a new member of the team, or not being a full-time member of the team.

From the twelve invitations I sent out, five nurses consented to participate, one nurse e-mailed me to say the time did not suit, and the other six invitations were not acknowledged. Four of the nurses who consented to participate were from community settings and one nurse was from an inpatient setting. I telephoned the nurses who had consented to participate mainly to confirm the date, time and location of the focus group, but also to make contact so that I could answer last minute questions or provide any other information they required. The nurses did ask questions, mainly related to the focus group date, time and venue, but no questions were asked about the focus group process.

\section{Implementing the Focus Group Process}

After welcoming the group and ensuring they all knew each other and the focus group assistant, I introduced my research by title and gave a brief description of how the focus group was planned. Issues of confidentiality/identifiability were discussed with the focus group participants. As Morgan (1998) identifies, material shared by participants with the researcher is also shared with the other participants of the group - therefore it is important to seek confidentiality assurances within the group setting. Ground rules were identified and agreed on by the group members. Groups can be involved in deciding on the ground rules by identifying how the group will 'selfmanage'. The ground rules included; the content of the discussion remaining within the group, respecting the opinion of others, and one person speaking at a time. Group discussions are familiar to nurses working in mental health settings, as is the setting of ground rules within groups. I did not anticipate or experience any difficulty with the group identifying these ground rules, as they are standard for group settings. Ground rules are also important as the focus group had been set up to have minimal involvement from the researcher in order to enable discussion between the participants. 
I asked four open-ended questions to stimulate discussion within a two-hour time frame. These questions were:

1. Describe what the term empowerment means to you as a mental health nurse within your current practice environment?

2. Describe the aspects of your present working environment, which encourage you to feel empowered?

3. Describe the barriers in your working environment, which discourage you from feeling empowered?

4. Describe the changes you would like to see in your working environment that would assist in increasing your own feelings of empowerment?

The questions were developed in line with Morgan's (1988) description of moderately structured interviews, where the researcher starts with a broad question and moves to more specific questions. He suggests encouraging interaction that moves the group away from generalisations to specific examples. I started with a discussion about the concept of empowerment and moved through to what changes would be required in the work environment to increase feelings of empowerment. I moved from the general to the specific, focusing in on the topic as the group discussion progressed.

I planned to use minimal prompts during the focus group because I had read widely on the topic of empowerment. I had my own views on empowerment including: likely barriers to feelings of empowerment and how barriers are likely to effect decision-making and participation in service development; and, how individuals and groups might achieve feelings of empowerment. I did not want to influence the group discussion any more than I already had with the setting of the questions and selection of participants. Beyea and Nicoll (2000, p.1068) identify that the facilitator should "appear neutral toward the topic and participants' responses".

As stated earlier, I had planned to use minimal prompts to encourage discussion; not leading the discussion, but encouraging extensive discussion until saturation point had been reached for each question. Saturation point was to be determined when the group was silent for a period of approximately 10 seconds and agreed when asked if 
they were ready to move onto the next question. During the process I did not need to use many prompts as the group interaction kept the conversation going. I did need to pause the group to summarise the discussion on a number of occasions, particularly when they veered off the topic. I found that by checking with the group that I was accurately summarising the content of the discussion, or by asking the focus group assistant to summarise, the opportunity arose for me to ask the next question. I had also written the questions up on a whiteboard for the group's reference during the discussion. I thought the discussion would revolve around the question being asked at the time, but the reality was that as people talked about their experiences, barriers were often identified along with what it would take to enhance feelings of empowerment. I had planned to seek a definition of empowerment reached by group consensus before proceeding with the remaining questions, but after two attempts at this the group decided that the concept was too complex to define. The group was warming to the topic; the group dynamic was working as people extended each other's ideas.

Toward the end of the two-hour time frame, I started feeling slightly anxious about how I would conclude the group, as the participants were fully involved in the discussion. Again I verbally summarised the discussion and checked with the group that I had identified the key points. The four questions I had asked had been discussed extensively and although the group could have spent longer exploring the topic, I knew that a number of the participants had other commitments at the conclusion of the session. The focus group assistant helped at this point by identifying that the group was close to finishing and directing the group back to the overall research question: 'So what can nurse leaders do to encourage an empowering environment for nurses working in the mental health area?' The group responded with a number of specific strategies that had been identified during the discussion. At this point I reminded the group that the next step in the research was the process of data analysis. I would send them the key ideas that emerged from the discussion for their verification and clarification. I thanked the group for their participation and the discussion came to a close. 


\section{Reflecting on the Focus Group Process}

The group did not proceed exactly as I had planned. The questions I had developed to stimulate discussion were in reality too structured for the group participants. On reflection I over-structured the group as part of the pre-planning, probably due to anxiety about facilitating my first focus group as part of a research process.

One of the aims of the research was to identify how nurses feel about participating at a decision-making level. The questions I had developed to stimulate the discussion did not include asking nurses directly how they felt about participating at a decisionmaking level. However, participation at a decision-making level was discussed frequently in response to questions two and three, related to aspects of the environment which encouraged or discouraged feelings of empowerment. As stated, I did not ask the group specifically about participating at a decision-making level. I made the assumption that participation at all levels of the service would be discussed, as participation is a profession issue often discussed within the practice environment.

An aspect of the research project that differed from the original plan outlined in the Application for Ethical Approval (Appendix four) related to the focus group. I had planned that the focus group participants would define empowerment by group consensus, and prioritise the key themes to emerge from the focus group discussion. A common definition of empowerment was not achieved and I did not ask the focus group participants to prioritise the key themes from the discussion. The predetermined plan required adapting to ensure that the process remained empowering for the research participants.

A tension I experienced throughout the process was whether I should be directive in my facilitation style to enable the group process to follow my predetermined plan or whether the group itself determined the level of interaction and ultimately the process. I was also very aware that the group process needed to be empowering rather than oppressive for the group participants. Therefore, I had to set aside some of the planning to ensure that the group determined the level of interaction while still attempting to maintain the focus on the topic. This was achieved by summarising the 
content of the discussion at appropriate points, prior to moving the group onto the next question.

The other difficulty I experienced during the group process was limiting my participation to facilitation rather than participant. I have read widely on the topic of empowerment and formed my own views which I would have liked to contribute to the discussion, but had to remind myself of the purpose of the group and that it was the group's views and interaction that I was seeking.

An interesting pattern that emerged during the group discussion was that the participants tended to discuss empowerment in terms of their work with patients of the mental health service and what empowerment meant for the patient, rather than what empowerment meant for them as nurses. Both the focus group assistant and myself had to encourage the direction of the conversation on several occasions toward what empowerment meant to them as nurses.

An unexpected insight I gained during the group was how prepared the participants were to share their opinions and feelings about the topic with the other group members and myself as the researcher. I had heard other researchers talk about their commitment to maintaining the integrity of their participants' views. The willingness of the participants to share their opinions and feelings reinforced my commitment to ensuring that their experiences were reflected accurately and portrayed in a way that validated their experiences.

Data is recorded from the discussion that occurs within the focus group. The group interaction influences the participants' opinions and insights and therefore the discussion. There was an initial reluctance to start the discussion but this quickly abated. Once the first person started talking in response to the first question, the other participants contributed. I was aware of the issues that could arise from the group interaction after reading about focus groups. These issues mainly related to the level of individual participation, domination by individuals within the group, and bias as participants share what they think they should say rather than what they believe 
(Argirides, 2000; Denzin \& Lincoln, 1994; Morgan, 1988). All members of the group contributed and I did not detect group members attempting to dominate or unduly influence the opinions of other group members. I sought feedback from the focus group assistant immediately after the group process and she confirmed my assessment of the group interaction.

I also considered the issues of power within the group and whether my role as a manager within the mental health services impacted on the views expressed by the participants. On a number of occasions it was the actions of the participants' managers that were identified as barriers to feelings of empowerment, and as these managers were my peers I wondered if the group participants were also thinking along the same lines about my position. I also checked this out with the focus group assistant at the end of the session, and her view was that the group environment had reflected equal relationships and that any imbalances of power were not overt.

\section{Conclusion}

I have discussed and reflected on the focus group process and identified the preplanning which also included discussion around facilitation and the selection of participants. I was pleased that I had planned well for the focus group and thought through the potential issues identified in the literature on focus groups that could arise and how I would manage these. I would support Beyea and Nicoll (2000) and Morgan (1988) who suggest that planning is an important ingredient if quality data is to be obtained. I was satisfied with the group size and duration. The amount of discussion generated around the topic surprised me. I was glad that I only had a group of five participants, and even though the group could have continued with the discussion after the allocated time, I considered all group members had participated fully and the topic had been discussed extensively within the two-hour timeframe.

The next step in the research process was analysing the data. The data was transcribed from the audio tape to the written word by a typist who had experience in transcribing for research purposes. In the next chapter, I will describe the process I used to ascribe meaning to the raw data. 


\section{Chapter Seven: Analysing and Interpreting the Data from the Focus Group}

\section{Introduction}

The audio tape recording of the focus group discussion yielded approximately 14,000 words; the two audio tapes were transcribed to assist with the data analysis process. In Chapter five, the amount and complexity of focus group data was identified as both an advantage and a disadvantage of focus groups as a data collection method. I will use a relatively simple method of data analysis, consisting of a mechanical and interpretive stage as identified by Morgan (1993) and previously outlined in the data analysis section of Chapter five. The key ideas identified in the mechanical stage will be explored further in the interpretive stage. They will be discussed in relation to the literature reviewed (Chapter three), to assist in ascribing meaning to the data. This literature review included; empowerment, power, and the history of nursing in relation to women's role in society, oppression and resistance. The integration of the key ideas from the focus group discussion and the literature reviewed will identify the key themes around the topic of empowerment. To assist in organising the analysis section I will use the headings of mechanical stage and interpretive stage.

\section{Data Analysis - Mechanical Stage}

In the mechanical stage, the raw data from the focus group transcripts is examined until the key ideas emerge. I read the transcripts and listened to the tapes several times before attempting to analyse the content. I started the sorting process by identifying a number of words that were repeated several times throughout the transcript. I then identified variations of these words, and words or short phrases of similar meaning that were used repeatedly to assist in the identification of the key ideas. Table one on the following page identifies the key ideas that emerged and examples of the associated words/phrases of similar meaning. 
Table One. Key ideas that emerged and examples of the associated words/phrases of similar meaning

\begin{tabular}{|l|l|}
\hline Key Ideas & Examples of Associated Words/Phrases of Similar Meaning \\
\hline Power & $\begin{array}{l}\text { Empower, empowering, empowerment, disempower, power } \\
\text { relationships, balance of power }\end{array}$ \\
\hline Leadership & Leaders, professional and clinical leadership \\
\hline Management & Managers, bosses \\
\hline Support & $\begin{array}{l}\text { Supporting, 'I support what you are saying', supporting each other, } \\
\text { support within the team, support from management, support from } \\
\text { our colleagues, advocate, help, be there for, }\end{array}$ \\
\hline Systems & Political systems, organisational systems, management systems, \\
\hline Responsibility & $\begin{array}{l}\text { Responsibility for, responsible to, responsibility, accountable, } \\
\text { accountability }\end{array}$ \\
\hline Time & No time for, time available \\
\hline Doctors & Medical staff, clinicians, medical profession \\
\hline $\begin{array}{l}\text { Nurses as a } \\
\text { Professional } \\
\text { Group }\end{array}$ & $\begin{array}{l}\text { Health professional, nursing as a profession, nursing, nurse/s, 'us } \\
\text { as a group', colleagues, clinicians, the profession }\end{array}$ \\
\hline
\end{tabular}

I will now expand on these key ideas and associated words/phrases (in italics) that emerged from the focus group discussion.

\section{Power}

The word power and associated words/phrases were used frequently in relation to the presence or absence of power, balance of power, and power relationships. This is not unexpected, as to understand the concept of empowerment, the concept of power must first be explored (Ekeberg et al., 1997).

\section{Leadership}

The word leadership and the associated word leader appeared frequently throughout the discussion but their meaning may cause some confusion without additional context. Throughout the discussion these words were used interchangeably and referred specifically to nurse/team leaders or leadership in general, which is consistent with the UK literature where the terms 'nursing leadership' and 'nursing management' are used interchangeably (Cook, 2001). The healthcare organisation in which the mental health nurse's work promotes leadership through multidisciplinary teams as opposed to professional leadership, therefore the terms 'leader' and 
'manager' are often used interchangeably. For the purposes of this analysis I have made a judgement about the intended meaning of the words leader or leadership from the context of the discussion. The words will either denote leadership within nursing or leadership within the healthcare organisation.

\section{Management}

When the words management and the associated word manager were used, they clearly related to hierarchical positions within the organisational management structure, with line management responsibility attached.

\section{Support}

The word support appeared frequently and requires further clarification. The main use of this word was in relation to support for nurses and nursing from within the professional group, management and multidisciplinary teams. The other meanings related to the supporting work nurses do with patients of the mental health service and support of statements made by other focus group participants.

\section{Systems}

The word systems was used frequently in a generic way. It was the context of the discussion that indicated if the system referred to was the healthcare organisation, or system as in 'the political system'.

\section{Responsibility}

The word responsibility was consistently used in relation to the responsibility nurses have within the healthcare team for clinical decision-making but without the authority to effect change within the healthcare system. It was also used in relation to power relationships being a shared responsibility.

\section{Time and Doctors}

Two words mentioned frequently were time, as in 'too little time available' and doctors as in the medical profession. 


\section{Nurses as a Professional Group}

The word nurse was mentioned frequently mainly is relation to nurses as a professional group. This key idea was expressed in a number of ways throughout the discussion as indicated by the associated words and phrases.

Identifying words and associated words/phrases of similar meaning which were used repeatedly throughout the focus group discussion proved to be a useful starting point in the mechanical stage of the data analysis and assisted in the process of identifying the key ideas from the focus group discussion (Krueger, 1998). In summary the key ideas to emerge from the focus group discussion were: power; leadership; management; support; organisational or political systems; responsibility; time; doctors; and, nurses as a professional group.

I sent out a summary of the key ideas from the focus group discussion to the participants (Appendices $9 \& 10$ ) to ensure that I had accurately reflected the discussion content. I also included a range of quotes from the discussion that I might use in the research report to support or illustrate the data analysis and discussion. Participants were invited to comment on the key ideas and delete any quotes that they did not think were appropriate to use in terms of maintaining their confidentiality. If I received no comments I made the assumption that the focus group participants were in agreement with the key ideas I had identified.

I will now discuss the interpretive stage of the data analysis process.

\section{Data Analysis - Interpretive Stage}

Following on from the mechanical stage where I have identified the key ideas (summarised in Table one, p.74); the interpretive stage ascribes meaning to the data. I have used the four questions asked during the focus group session (refer to p.69) as a way of organising the interpretive stage of the data analysis. The key ideas that emerged from the mechanical stage of the data analysis will be examined within the broader context of the mental health nursing practice environment. This broader context will be informed by the key assumptions of Critical Social Theory and the 
literature I have reviewed in relation to empowerment, power, the history of nursing in relation to women's role in society, oppression and resistance. It is from the integration of the key ideas from both the focus group discussion and the literature reviewed that key themes around empowerment will be identified.

I have used quotes from the focus group discussion to assist in describing, clarifying and supporting the range of views within both the interpretive and discussion sections of this research (refer Chapter eight). All quotes will be in italics, and additional information required to assist in clarifying the spoken word will be in parenthesis in plain type.

Question 1: Describe what the term empowerment means to you as a mental health nurse within your current practice environment?

This first question of the participants attempted to gain an understanding of what empowerment means for nurses practising in mental health. As already identified in Chapter six, a clear definition of empowerment did not emerge from the focus group discussion. Although I had expected a common definition of empowerment to emerge, this outcome should not have been unexpected as popular phrases or 'catch words' have so many meanings to different people that they have come to mean little (Chamberlin, 1997; Walker, 1998). Empowerment is a popular term within health services and obviously the focus group participants did not have a shared understanding of what the term meant.

The key ideas of power and nurses as a professional group that emerged from the mechanical stage of the data analysis will be further explored and related to the literature on empowerment and nurses as a professional group. More specifically the key ideas were around power relationships and how nursing was perceived within the profession, within the organisation, and by the wider community. The nursing literature specifically used, focused on how nursing is viewed from within the profession and from a societal and historical viewpoint. 
Empowerment is about power and where power resides within a relationship. The participants discussed power in terms of what it means to have it or as the case may be, to not have it. Situations in which power exists and does not exist were discussed along with the responsibility of having power and not abusing it. The necessity of understanding what having power means and how power is gained was acknowledged as essential in understanding the relationship between empowerment and disempowerment. There was no consensus reached within the group about whether power was something that could be shared, or whether power could only come from within an individual or group. On reflection this is not an unexpected outcome as this debate is evident throughout the empowerment literature (Barker \& Ritter, 1996; Kanter, 1977; Turrell, 1996). The participants' views ranged from;

My own personal authority is what gives me power,

to

I am uncomfortable about having power - because you get to choose whether you empower others - you've got to remember all the time that you (as the nurse) are holding all of the power.

Nurses as a professional group were also discussed in relation to; how the organisation and wider society view nurses as a group, how nurses view themselves as a group, and how these views impact on feelings of empowerment. The perception of nursing as a profession was also linked with the historical evolution of nursing. The history of nursing was familiar to the group and identified as significant in the discussion about nurses feeling empowered. As one participant suggests;

There is something about nursing and its historical context that it's women's work - a caring profession - within society's structure it's not something that has a lot of status.

The significance and importance of understanding the historical, social and political position of nurses within the healthcare system to assist in understanding the issues of empowerment within nursing is supported by McEldowney (1995) and Speedy (1987). 
At this point the group was eager to move onto discussing what made them feel empowered or disempowered in their practice environment rather than attempting to further define the concept of empowerment.

\section{Question 2: Describe the aspects of your present working environment, which encourage you to feel empowered?}

The second question was related to feelings of empowerment. Overall, the group found it easier to identify barriers to feelings of empowerment rather than what made them feel empowered. The key ideas that emerged from the mechanical stage of the data analysis which will be expanded upon in this question are nurses as a professional group, organisational systems, management, and, support.

Professional relationships, access to peer and clinical supervision, and education were all identified as important. Highlights from the discussion included the following;

What makes me feel empowered is, good working relationships with other nurses, peer supervision as well as individual supervision because that makes me feel as though I am on the right track.

Peer supervision, clinical supervision, education ...Yes, that would be the three things that would make me feel empowered, particularly education, I know whenever I have been to a course or a study day or whatever you actually feel good about what you do.

This supports the findings of Laschinger and Havens (1996) in their study on staff nurse work empowerment and perceived control over nursing practice, that power stems from access to opportunity, information, support and resources in the workplace. The opportunities to access supervision and education were valued by the focus group participants. Having access to information to assist in making a meaningful contribution was also one of the organisational factors identified as important in experiencing feelings of empowerment. One of the participants revealed;

I feel good about where I work now, like I've got good information, I feel like I have an input to where the service goes. 
Organisationally a number of other points were raised. The valuing of nursing knowledge and expertise was considered essential as well as having a manager who had an understanding of, and valued the nursing role within the team. The following comment supports this;

Having a manager that has some kind of concept about where nursing is, who values nurses and the nursing role is important.

There have been a number of research studies undertaken to identify what empowerment means to nurses and their findings support the focus group discussion (Fulton, 1997; Laschinger et al., 1997; Morrison et al., 1997). They found that for nurses to feel empowered they need to feel their jobs are relevant, flexible and visible.

Remuneration was identified as a barrier but I have included it in this section as the group linked remuneration with valuing nursing as a profession. As one of the participants commented;

A policeman is worth more than a staff nurse is, first year out of Police College.

Being consulted and having input into team decision-making and service development was also discussed;

By consultation with your staff you are empowering them, (talking about managers) everyone will make a joint decision which they will embrace and move along with.

Having good management at a direct level was identified as important — specifically in relation to getting feedback on performance; autonomy in practice; and, time to do the job well. One of the participants commented;

I feel that I have got good management at a direct level, I also have autonomy to do what I want to a degree, like I can get out there and do some stuff and work individually and I get that feedback, I feel empowered because of this.

Management styles have been researched by Laschinger et al. (1997) who found that positive relationships with management and peers influenced feelings of workplace empowerment for nurses. One of the words that arose frequently in the focus group discussion was support. Support is not actually defined by the group but is discussed 
in terms of support for nurses and nursing from within nursing, management and from within the multidisciplinary team. Two examples include;

Support from the organisation with clinical decision-making.

Nurses not supporting each other.

The key themes to emerge from the integration of the key ideas from the focus group discussion and the literature reviewed were that aspects of the organisational and professional environment enhance feelings of empowerment.

The literature reviewed related to empowerment, suggests that for nurses to perceive that they have control over the content and the context of their practice they need to: feel valued; have opportunities for development and input into decision-making; and, have access to resources, support and information (Barker \& Ritter, 1996; Cahill, 1997; Gaitskell, 1998; Jenkins, 1997; Laschinger \& Havens, 1996; Rodwell 1996; Yarling \& McElmurry, 1986). The factors in the environment that made the nurses feel empowered support the findings of the literature reviewed.

\section{Question 3: Describe the barriers in your working environment, which discourage you from feeling empowered?}

When it came to identifying barriers in the working environment, which discouraged feelings of empowerment the discussion flowed. Barriers were not only identified during the response to this question, but throughout the entire discussion. The key ideas that emerged from the mechanical stage of the data analysis and that will be further explored in response to this question are; organisational and political systems; doctors; nurses as a professional group; time; responsibility; and, support.

At a political and organisational level medical staff were identified as historically powerful. The participants suggested that this power is supported at a political and organisational level;

Having power right from the top - the health system is funded according to diagnosis.

Some of the participants also identified that it was very easy for medical staff to dismiss what nurses' think; 
When I can't say what I really believe in for a patient, I tend to put them (medical staff) up there on a pedestal - It's that authoritarian kind of thing, what I feel is that what I say doesn't have much validity.

There's something historically (powerful) about the medical model and things like that, its very easy for them to dismiss what we think.

Historically, nurses have been dominated by the medical profession who have been identified as having prestige, power and status which largely goes unchallenged and can dominate healthcare settings and hierarchies (Street, 1992).

At a political level, legal requirements were identified as a barrier, both in terms of how nurses could work with patients and what they could be responsible for. Working as a nurse within mental health services, the most influential legislation is the Mental Health (Compulsory Assessment and Treatment) Act 1992. This Act specifies under what conditions people must accept treatment. As one participant says;

(The) Mental Health Act - enforcing treatment is disempowering.

Crowe (1996) also discusses the Mental Health (Compulsory Assessment and Treatment) Act 1992 and suggests that it supports the dominant thinking, and because medical staff are authorised to diagnose, they are identified as a dominant group within healthcare. At an organisational level it is medical staff who also have the authority to admit and discharge into the various services and this point was raised within the focus group as it also determined how nurses could work with patients and what they could be responsible for;

Medical staff are responsible for admitting and discharging patients.

Gaitskell (1998) agrees that legislation and organisational and professional systems are barriers to empowerment. She suggests that professional accountability and scope of practice for nurses are defined by codes of conduct, resource limitation and internal/external policies or legislation. It is the healthcare organisation that produces the codes of conduct, determines how resources will be distributed and produces 
operational policies. External policies and legislation are determined from outside of the organisational system and as identified by the focus group participants, impact on professional accountability and the nurse's scope of practice.

The fear of litigation and practising defensively was identified as a political and organisational barrier. Comments from the participants included;

The defensible culture we practice within makes it really hard for us to sit down with our colleagues and to actually learn from mistakes.

We are not able to take the risks that we need to take with clients due to the defensive nature of our practice.

This issue was raised a number of times throughout the group discussion in relation to nurses feeling they practice in a trusting environment. Although this issue is not specifically discussed within the nursing or health related literature, Horsfall (1997) identifies that trust is an important aspect of the environment for users of mental health services. She suggests that if the environment created by the organisation is trusting, supportive and caring, the nurse in turn will recreate this environment for the service user.

Another political and organisational barrier identified was the funding of health services. There are so few nurses to meet the demand for care that time management becomes a real issue;

Not being able to work with people to the full potential due to time constraints and competing priorities limits what we can do as nurses.

The demands made of the nurses' time featured frequently and not only in relation to direct patient care;

Being expected to be involved in service development with no reduction in caseload.

Management expectations of the extent nurses will work on 'good will'.

Organisational culture reflects this value - nurses are expected to work harder and harder, managing higher caseloads of higher acuity, leaving little time for input into 
developing policies which impact on nursing practice (McEldowney, 1995). The expectation that nurses manage higher caseloads was reflected in the group discussion, particularly in relation to other disciplines within the healthcare team. The relationships the nurses had with other members of the team also impacted on feelings of empowerment. Comments include;

There is lack of equality of professional groups within the teams, it is OK for some disciplines to say their caseload is full and they can't take any more.

Nurses aren't allowed to say 'no', 'no I can't take anymore patients' - we aren't given choices about being able to say 'no'.

Standing up for yourself can make you really unpopular with your manager and with your colleagues.

In the literature I reviewed, there is mention of the higher nursing workloads but not specifically in relation to the workloads of other professionals, however the consequences of nurses standing up for themselves are discussed. Yarling and McElmurry (1986) identify the consequences of nurses openly challenging authority in terms of risking their employment, their economic welfare, and their professional careers.

The final organisational barrier identified was the difficulties encountered by nurses in having responsibility without authority;

You have a whole lot of responsibility but perhaps not the authority to do anything with it. It can actually leave you feeling disempowered - so while you have a lot of responsibility it would be good to have the ability to process it further cause it's like you can't do anything without somebody's approval.

The statement about not being able to do anything without approval is reflective of oppressed groups who are controlled by outside forces (Freire, 1970).

Professional barriers were identified, both in terms of professional structures and how nurses treat each other; fragmentation within nursing was also identified as 
contributing to the professional barriers to empowerment. Several participants spoke about the issues;

Nurses disempower themselves and the nursing model all the time.

Horizontal violence amongst nurses - disempowering our own - we eat our young.

Nurses not valuing nursing or supporting each other.

No clinical structure or career pathway for nurses.

We have crisis clinicians, nurse counsellors and we are all under different contracts.

The fragmentation, lack of valuing and horizontal violence discussed is reflective of the literature reviewed on oppressed group behaviour in nursing. The fragmentation of nursing is supported by Hedin (1986) who found that nurses were divided into many groups and fought amongst themselves when she explored oppressed group behaviour of nurses in West Germany. The lack of valuing of nursing from within the profession and the existence of horizontal violence is supported by Roberts (1983) who suggests that nurses as a group have poor self esteem and do not value their own input.

The key themes to emerge in relation to barriers to empowerment within the workplace were around systems issues related to the political, professional and organisational environment. These barriers to empowerment are well documented within the reviewed literature. Barker and Ritter (1996) identify political barriers; Gaitskell (1998), Morrison et al., (1997) and Opie (1998) identify professional barriers; and Laschinger et al., (1997 \& 2000), Laschinger and Havens (1996), Laschinger and Wong (1999), and Rodwell (1996) all discuss organisational barriers to empowerment.

Question 4: Describe the changes you would like to see in your working environment that would assist in increasing your own feelings of empowerment? When it came to identifying the changes the nurses would like to see in their working environment to increase feelings of empowerment, the key ideas that emerged from 
the mechanical stage of the data analysis were organisational and political systems; leadership; management; nurses as a professional group; time, and, support. The political, professional, and organisational themes evident from the previous questions again emerge.

The political theme related to how services were funded according to diagnosis, and was again linked to medical domination of services;

We should ditch DSM-IV (diagnostic tool used by medical staff to classify mental illness) and work from a nursing model.

The medical model on which diagnosis is based reinforces the dominant model of care provided within healthcare settings, and dominant models within institutions are maintained by dominant disciplines (Crowe, 1996). The degree of power of the medical profession is linked to the body of knowledge that people have, and the value society places on the type of knowledge (Foucault, 1980; McHoul \& Grace, 1998).

The changes the participants would like to see within the profession included: the development of a professional structure to promote and support nursing; valuing and respecting each other; and what nursing has to offer in the healthcare setting. Participants expressed this as;

Nurse leaders need to promote some unity amongst us as a professional group.

Nurses need to respect and value each other.

Nursing leadership - being taken away from management and put into a professional leadership structure.

There is discussion evident in the literature about nurses not respecting and valuing each other; most of the discussion relates to the characteristics nurses display which indicates they are an oppressed group. These characteristics include, horizontal violence, acting individually rather than collectively, and valuing the technical rather than the caring aspects of their role (Hedin, 1986; Horsfall, 1997; McEldowney, 1995; Roberts, 1983; Street, 1992). The suggestion that nursing leadership is taken 
away from management and put into a professional leadership structure to increase feelings of empowerment is not supported by Gaitskell (1998) who found professional nursing structures encourage hierarchical leadership which is a point I will discuss further in Chapter eight.

Changes suggested by the participants within the organisation included the organisation supporting clinical decision-making despite the 'defensive' health environment; and, nurses having the ability to say 'no' when caseloads were becoming unmanageable;

Support from the organisation with clinical decision-making. I think my practice could be empowered by actually not feeling insecure or that I won't be supported from management when making the best clinical decision I can.

Being supported in setting boundaries around what and how much nurses can do.

Having the time to be to do a good job with patients.

Time not only featured at a clinical level but also at a service development level. Nurses were expected to contribute, but no allowance was made for the time it takes to be involved in service development activities. As a participant suggests;

Having time to be involved in service development activities and being recognised for the work $I$ do...(is important for feeling empowered).

Finally at an organisational level as one participant expressed her feelings;

A caring environment - from the top down.

A number of the ideas have already been discussed in response to earlier questions, specifically the defensive healthcare environment, the lack of time available, and finally a caring environment. I have also discussed these ideas in relation to the literature and they will again be explored further in Chapter eight.

\section{Conclusion}

I have examined the key ideas that emerged during the mechanical stage and linked these ideas to the literature reviewed. Identifying words and associated 
words/phrases of similar meaning which were used repeatedly throughout the focus group discussion proved to be a useful starting point in the mechanical stage of the data analysis. The four questions asked within the focus group were used as a framework for organising the interpretive stage of the data analysis. The discussion around each of the focus group questions reflected the key ideas that had emerged during the mechanical stage of the data analysis and were discussed in relation to the literature. It was Morgan (1993) who suggested that a statement examined within the context of the broader discussion and in light of information available from other sources, assists in the interpretive stage of data analysis.

Two key themes emerged from the mechanical and interpetive stages of the analysis. In summary the key themes to emerge from the data analysis process include; power is an important component of empowerment and power relationships; and at a systems level, how professional, organisational, and, political influences impact on feelings of empowerment and/or disempowerment. These themes will form the basis of the discussion in Chapter eight. The discussion will be informed by the literature reviewed in Chapter three on empowerment, power, the history of nursing in relation to women's role in society, oppression and resistance to identify the historically formed contradictions which exist to facilitate the process of emancipation and empowerment (Held, 1980). 


\section{Chapter Eight: Discussion}

\section{Introduction}

In this chapter, I return to the original question and aims of this research and reflect on other questions or issues that have arisen as part of reflecting on my own experiences, the research process, or as part of exploring the literature. The research question was: What can nurse leaders do to encourage an empowering environment for nurses working in the mental health area? The aims of the research were, to identify how nurses feel about participating at a decision-making level, and to identify what needs to change in the work environment for nurses to feel they can participate, and therefore have control over the content and the context of their practice and thus feel empowered. I also consider the key themes that emerged from the data analysis process outlined in Chapter seven in relation to the literature reviewed in Chapter three on empowerment, power, the history of nursing in relation to women's role in society, oppression and resistance to identify the historically formed contradictions that exist within the broader social and cultural context. The key themes identified were power is an important component of empowerment and power relationships; and at a systems level, how professional, organisational, and political influences impact on feelings of empowerment and/or disempowerment.

I also identify that nurses might not participate at a policy development level for different reasons and suggest a framework for assessing where nurses are positioned on the analysis of social consciousness continuum (Freire, 1987). The analysis might assist in understanding the reasons why nurses might not participate and why nurses might behave in ways which suggest they are an oppressed group.

The starting point in deciding on this research topic was considering the reasons why nurses seemed reluctant to participate at a policy development level and I had asked myself the following questions: Is it because they think their input will not be valued or be ignored and therefore they do not bother? Is it that they are quite happy for other people to tell them what to do and to define how they practice? Or is their reluctance to participate related to feelings of disempowerment? In an attempt to 
answer these questions I will reflect on and discuss the themes that emerged from the data analysis. I initially discuss how the nurses who participated in the focus group felt about participating at a decision-making level, as this was one of the aims of the research.

\section{Nursing Participation at a Decision-Making Level}

One of the aims of this research was to identify how nurses feel about participating at a decision-making level. The nurses who participated in the focus group were positive about contributing at a decision-making level and believed their contribution was valuable. However, a number of factors limited their ability to participate. The main factor identified was a lack of time available for a meaningful contribution to be made. The lack of time was related to clinical needs consuming the majority of the nurses' time and also the inability for nurses within the healthcare organisation to say 'no, I can not take on any more work' when other professions had this ability. One of the responses included;

There is lack of equality of professional groups within the teams, it is OK for some disciplines to say their caseload is full and they can't take any more.

The other factor identified which limited their ability to participate was other members of the healthcare team (both within nursing and other professional groups) dismissing what the nurse had to offer. The focus group discussion did not support Roberts (1983) who suggests that nurses are an oppressed group who do not participate in change because they fear change or moving away from the status quo, and that as a group they have poor self esteem and do not value their own input. The nurses within the focus group clearly valued their own input and gave no indication that they feared change or moving away from the status quo. There is support for the suggestion by Lange and Cheek (1997) that lack of participation may be related to political or organisational structures discouraging the involvement of nurses. Du Plat-Jones (1999) suggest that it is the powerful groups within society that have the power to shape what questions are asked and who is included in the discussion. Crowe (2000) identifies that in the current health care environment, the powerful groups are the medical profession because of their 'authoritative/expert' knowledge, and healthcare management because of the political ideology of a market driven 
economy. The reasons given for lack of participation by the focus group participants related to time and other health professionals not valuing their input. Considering nurses are the majority of the healthcare workforce $(\mathrm{MOH}, 1998)$ there may be an advantage to silencing the 'nursing voice' if the power of the powerful groups in healthcare is to be maintained. The dominant groups may feel at risk if nurses did have the time to discuss and reflect on their position within the healthcare setting, as consciousness raising may lead to dissatisfaction and a change to the existing power structures within healthcare settings.

One of the questions I raised was related to nurses not participating in policy development - more specifically, is it because the nurses think their input will not be valued or be ignored and therefore they do not bother. Considering the focus group discussion and the literature, I conclude that nurses' consider their input is not valued by other health professionals and by the organisation but this is not the main reason for their reluctance to participate. The main reason for their reluctance is related to time, that is, having sufficient time to make a meaningful contribution. The focus group participants did make a number of suggestions that relate to making time for input into policy development. I discuss their suggestions at the conclusion of this chapter when responding to the research question about what needs to change in the working environment to increase feelings of empowerment.

Another set of questions I had asked related to more specific reasons why nurses may be reluctant to participate in service development: Is it that nurses are quite happy for other people to tell them what to do and to define how they practice? Or is their reluctance to participate related to feelings of disempowerment? If nurses are quite happy for other people to tell them what to do and to define how they practice it would mean that they do not have control over their own practice. Speedy (1987) identifies that it is the lack of autonomy, accountability and control over their profession that indicates nurses are an oppressed group and Laschinger et al. (1997) found that for nurses' empowerment means having control over the context and content of their practice. McEldowney (1995) links oppression and empowerment when discussing nurses as an oppressed group. To respond to these questions I will 
discuss the key themes that emerged from the data analysis in relation to the literature on empowerment and oppression. I will respond to these questions by referring to the first key theme that emerged from the mechanical and interpretive stages of the data analysis, that is, power is an important component of empowerment and power relationships.

\section{Power is an Important Component of Empowerment and Power Relationships}

It is not surprising that the theme, power is an important component of empowerment and power relationships emerged from the data analysis, because empowerment is about power (Ekeberg et al., 1997). Within the literature, 'locus of control', 'agency' (Weary et al., 1993) and 'power within' and 'power over' (Starhawk, 1987) are all terms used to describe the location of power. No consensus was reached within the group about whether power was a commodity that could be shared, or whether power could only come from within an individual or group. Again the lack of consensus around this issue is not surprising, as there is considerable debate evident in the literature about the location of power, that is, whether power was something that could be shared, or whether power could only come from within an individual or group (Barker \& Ritter, 1996; Kanter, 1977; Turrell, 1996).

There was discussion about the impact of power relationships within the healthcare setting and within nursing. Historically nurses have been dominated by the medical profession who have been identified as having prestige, power and status which largely goes unchallenged and dominates in healthcare settings and hierarchies (Crowe, 1996; Street, 1992). Political processes support medical domination as suggested by the focus group participants. The healthcare system is funded according to medical diagnosis and healthcare providers organise services according to diagnosis or medical speciality, for example, mental illness, cardiac disease, renal disease (Crowe, 1996). Nurses have been described as an oppressed group because they are "controlled by forces outside themselves that have greater prestige, power, and status" (Roberts, 1983, p.21). Medical staff have been identified as having greater prestige, power, and status (Street, 1992) and by association the medical model is the dominating scientific paradigm. Medicine, as the dominant discipline 
and model of care, impacts on nurses and nursing practice. Medical staff are not the only dominant group that assists in maintaining the oppression of nurses. The political trend toward managerialism within the healthcare setting and the fragmentation and horizontal violence within nursing, also contribute. These contributing factors are explored as part of this discussion on the characteristics of oppressed groups and related to the focus group discussion.

Characteristic behaviours of oppressed groups include the fear of freedom; individual rather than collective action; adopting the values of the dominating group in order to become more like them; housing the oppressor within; horizontal violence; and, lack of autonomy, accountability and control over their destiny (Freire, 1970; Hedin, 1986; Roberts, 1983; Street 1992). Examples of oppressed group behaviour were evident throughout the focus group discussion (examples below) and also identified as oppressed group behaviours by the participants.

Fear of freedom was a characteristic that was not identified during the focus group discussion although it is well documented in the literature on oppression (Freire, 1970).

Nurses' taking individual rather than collective action was identified when the participants spoke about the different divisions within the mental health service and the different titles nurses call themselves. Examples given were 'crisis clinician', 'nurse counsellor' and 'nurse therapist'. As one nurse said;

We have become quite fragmented and that leaves us without a stable footing.

The title 'nurse' was not enough for some nurses, they had to add the word 'therapist' onto it, or change it altogether as in 'crisis clinician'. By not valuing the title of 'nurse' the group considered that the nurses were saying nursing on its own is not good enough. To have power and prestige, something additional to the title 'nurse' was required. Another indicator of oppressed group behaviour identified by Roberts (1983) is that nurses as a group have poor self-esteem and do not value their own input. The example of the title 'nurse' not being enough for some nurses is an 
example of this indicator identified by the participants, although the participants themselves did not indicate that they had poor self-esteem or that they did not value their own input.

Horizontal violence among nurses was discussed at length and how as a profession we maintain our own oppression by fighting with each other;

There is this real theme of horizontal violence amongst nurses, we disempower ourselves and we eat our young (new nurses).

Speedy (1987) identifies that nurses as an oppressed group lack autonomy, accountability and control over their profession and the participants also explored this issue. The participants identified barriers to working autonomously in terms of having to work within a medical model, restrictive legislation (the Mental Health (Compulsory Assessment and Treatment) Act 1992) and organisational regulations. One participant discussed her starting time;

I would like to be able to choose the time I start work, which really does sound trivial but nobody (patients) wants to see me before 11 o'clock anyway but I still have to turn up at 8 o'clock.

Organisational routines do not necessarily reflect the most efficient way to meet clinical needs, but all staff having the same starting and finishing times makes it easy for the organisation to keep track of the nurse's timetable. This example also sends the paternalistic message that as a nurse you are not to be trusted, not able to take responsibility/accountability for monitoring your own time keeping. The participants also identified that they were expected to take responsibility but did not have the authority to make decisions. As one participant suggested;

You have a whole lot of responsibility but perhaps not the authority to do anything with it. It can actually leave you feeling disempowered - so while you have a lot of responsibility it would be good to have the ability to process it further cause its like you can't do anything without somebody's approval.

This example suggests that nurses may lack the autonomy and control over their profession, but retain the accountability. 
The issue of remuneration was raised in terms of how nurses are valued by the organisation and by society in general. The wage of a nurse was compared to the wage of policemen first year out of Police College and the discussion centred around the value society places on different professions. The nursing workforce is the largest group in the health sector and any increase to wages has significant financial implications for healthcare providers. This may suggest that there is a political, economic and organisational advantage in maintaining nurses as a disempowered group and not encouraging nurses to unite as a profession.

Housing the oppressor within, another characteristic of oppressed group behaviour is also found within nursing. The belief that nurses were powerless to change their situation can be maintained through socialisation and education (Freire, 1970). Socialisation of new staff within an environment is a powerful way to influence a person's behaviour. The focus group participants did not overtly discuss this characteristic but powerlessness was expressed in terms of;

Working continually within the constraints of the system, and

Being told what to do rather than negotiated with.

Positive reinforcement is given to nurses for behaviour preferred by the oppressor (Roberts, 1983). Positive reinforcement may be in terms of promotion, additional salary or better conditions. During the discussion around manager's roles within the service there was discussion around the perception that current management structure does not allow nurses who are managers to promote nursing leadership. One participant identified what was important for them;

Having a manager that has some kind of concept about where nursing is and who values nurses and the nursing role.

There was also discussion around managers who participated in business management courses and did not develop their nursing knowledge. The focus group participants identified this action by managers as nurses assuming the values of management rather than nursing. Roberts (1983) identified that rewards given for behaviour preferred by the dominant group is one way of maintaining and reinforcing 
an oppressive structure. Nurses working in management positions may feel they have to identify with the values of management to retain their positions, therefore denying their nursing backgrounds and not identifying with nurses or further developing their nursing knowledge.

At this point I reflect on my own experience as a manager within a healthcare organisation in relation to this example. I have no interest in studying management at this time as I have been actively developing my nursing knowledge over the past nine years. There has never been an expectation by the healthcare organisation that $\mathrm{I}$ complete management papers only that I participate in ongoing education. My own experience suggests that within the employing organisation it is the nurse manager rather than the organisation that chooses the type of ongoing education.

A suggestion that nursing leadership is taken away from management and put into a professional leadership structure to increase feelings of empowerment was raised. Professional support and leadership are important but care needs to be taken that one oppressive structure is not replaced by another. Gaitskell (1998) studied barriers to empowerment and found that professional nursing structures encouraged hierarchical leadership rather than promoting empowerment. Hierarchical leadership may encourage maintenance of oppressive structures as one oppressive structure is replaced by another.

The history of nursing has influenced the profession as it currently exists and individual nurses who work within the profession (Crowe, 2000). The focus group participants discussed examples of oppressed group behaviours within their practice setting. There is also evidence of resistance to this domination, through nonparticipation and acts that have been described by Hutchinson (1990) as 'responsible subversion' (acting in the best interests of the patient and going against the dominating force). An example of resistance through acts of responsible subversion was described by one of the nurses within the focus group. She discussed her work with a patient who has a major mental illness but who also met the criteria set by the organisation for discharge from the service. By working with the patient over a 
longer period, the nurse considered a relapse could be prevented, but because the patient met the criteria for discharge, relapse was a likely outcome. It was at this point in the discussion that nurses talked about how they often delayed discharge in 'creative ways' in the best interest of the patient. It was Freire (1970) who suggested that as people or groups become aware of oppressive forces they will test the waters with rebellious acts. Acts of resistance as described in the example about discharge could be considered a rebellious act. There was also evidence within the focus group that nurses are fully aware of the dominating cultural, social and political forces within their practice environment;

Medical staff - historically powerful.

(Nursing) - within societies structure it is not something that has a lots of status.

I agree that historical, political, social and economic influences have all contributed to the development and maintenance of nurses as an oppressed group (McEldowney, 1995; Roberts, 1983; Speedy, 1987). I would however suggest that nurses are moving on from being identified and identifying themselves as an oppressed group. From my experiences in practice I acknowledge that there are nurses who do participate in policy development but also find that the majority of nurses are reluctant. However, to make a generalisation that all nurses are reluctant would be incorrect, just as it would be incorrect to say that all nurses are disempowered or oppressed.

\section{Analysis of Social Consciousness}

I suggest the four levels identified by Freire (1987) in the analysis of social consciousness are used as a starting point in identifying where nurses are positioned on the continuum. The first level intransitive consciousness, is the starting point on the continuum where people are preoccupied with basic survival and have little interest in asking questions about their life situations. The next level semiintrasitivity, occurs when there is an absence of critical questioning about 'the way things are', a culture of dependency exists, as people do not have the confidence or ability to be self-sufficient. The next level naive or semi-transitive consciousness occurs when people start to question 'the way things are' and to look for answers to 
their questions. The final level on the continuum, critical consciousness, is when consciousness is informed by in depth questioning, interpretation and analysis.

There will be nurses who are positioned within each of the four levels but from the literature I have reviewed, the focus group discussion and my experiences within mental health, I consider that there are a minority of nurses at the most fundamental level, intransitive consciousness. There were no examples given within the focus group discussion and even when nurses do discuss the difficulties of 'surviving' in the practice environment, they are not talking about surviving to maintain life but surviving at a professional level. I also consider there are very few nurses within the next level of semi-intrasitivity. There were examples given within the focus group discussion which indicated a time in the history of nursing when a culture of dependency existed, nurses as a group lacked confidence and the ability to be selfsufficient, and the subsequent impact this has had on the nursing practice environment today. This is represented in the comment;

There is something about nursing and its historical context that it's women's work - a caring profession - within society's structure it's not something that has a lot of status.

These features of semi-intrasitivity are well documented in the nursing literature which identifies nurses acting in ways which indicate they are an oppressed group (Speedy, 1987; Roberts, 1983). The next level, naive or semi-transitive consciousness is where I consider the majority of nurses working in mental health are positioned. There was ample evidence within the focus group that the nurses questioned 'the way things are' and looked for answers to their questions. One example was the nurse who questions why she has to be at work at 8 o'clock when she will not be visiting any patients until at least 11 o'clock. It is within this level that people start to discuss empowerment or disempowerment as it is only when inequality is identified that discussion around power imbalances occurs;

You have a whole lot of responsibility but perhaps not the authority to do anything with it. It can actually leave you feeling disempowered - so while you a lot of responsibility it would be good to have the ability to process it further cause its like you can't do anything without somebody's approval. 
I consider there are nurses who are positioned within the final level of critical consciousness where in-depth questioning, interpretation and analysis inform consciousness. The nurses within the focus group provided evidence of in-depth questioning, interpretation and analysis - they identified and named aspects of their own oppression, they could identify the dominant groups and systems and why they were dominant. Examples from the discussion include;

Having power right from the top - the health system is funded according to diagnosis.

There's something historically (powerful) about the medical model.

Susan Roberts writes extensively on nurses as an oppressed group. In one of her more recent articles she supports the idea that consciousness is enhanced through understanding. She suggests that "the first step in liberation from oppression is understanding its dynamics" (1999, p.1).

The focus group participants clearly identified the dominant groups and systems as they responded to the final question asked within the focus group. The question was: Describe the changes you would like to see in your working environment that would assist in increasing your own feelings of empowerment? The dominant groups and systems were reflected in the second key theme that emerged from the mechanical and interpretive stages of the data analysis. The theme was that professional, organisational, and political influences impact on feelings of empowerment and/or disempowerment. I will use these headings to identify the changes the focus group participants identified were required in order to increase feelings of empowerment in the working environment.

\section{Professional, Organisational, and Political Empowerment}

Political empowerment related to the funding of healthcare services, particularly in terms of how services were funded according to diagnosis, (i.e. mental illness, cardiac disease, renal disease) and the expectation that increasingly more health services will be provided with no change to the funding provided. How services were funded was linked to the medical domination of services raised in the focus group discussion and 
within the literature reviewed. The expectation that more services are provided without an increase in funding impacts on nursing. It is often the nursing budgets that are reduced when cost cutting occurs. Although in this section, the nurses did not identify solutions they did identify the underlying issues related to political systems maintaining medical and organisational domination of health services.

Professional empowerment related to the nursing profession itself and included organisational support for the development of a professional structure to promote and support nursing, the valuing of what nurses have to offer within the healthcare team; and, valuing and respecting each other as nurses. The terms 'horizontal violence', 'tall poppies' and 'nurses eating their young' were used by the focus group participants to describe the infighting between nurses and the subsequent fragmentation that occurs. The group acknowledged the need for nurses to unite as a group and value what they have to offer, as opposed to the fragmentation and infighting that currently exists.

Organisational empowerment relates to the healthcare organisation supporting clinical decision-making despite the defensive mental health environment. Nurses having the right to say when their caseloads are becoming too large as other professions have the right to; valuing the input of nurses by acknowledging their participation in policy development; and enabling the nurse to identify what their priorities and needs are in relation to managing their time.

\section{Conclusion}

I have returned to the original question and aims of this research and have discussed other questions or issues that have arisen as part of reflecting on my own experiences, the research process or as part of exploring the literature. From the focus group discussion and the literature reviewed related to empowerment, power, the history of nursing in relation to women's role in society, oppression and resistance, I have

discussed how nurses feel about participating at a decision-making level. I have discussed the themes that emerged from the data analysis (outlined in chapter seven) in relation to the broader social and cultural context, and identified historically 
formed contradictions, which exist in the nursing practice environment and impact on feeling of empowerment. I discussed these key themes in relation to the reasons why nurses may be reluctant to participate at a policy development level in relation to issues of power. I discussed what the focus group participants considered needed to change in the work environment for nurses to feel they can participate, and therefore have control over the content and the context of their practice. I have identified that nurses may not participate for different reasons and suggested that assessing where nurses are positioned on the analysis of social consciousness continuum might assist in understanding the reasons why nurses may not participate and why nurses might behave in ways which suggest they are an oppressed group (Freire, 1987).

In the next chapter I respond to the research question by making a number of recommendations for nurse leaders who aim to encourage an empowering environment for nurses practising in mental health while reflecting on the aspects of the practice environment the focus group participants identified needed to change for nurses to feel empowered. 


\section{Chapter Nine: Conclusion to the Research}

In this concluding chapter I make a number of recommendations for nurse leaders who aim to encourage an empowering environment for nurses practising in mental health in response to the original research question: What can nurse leaders do to encourage an empowering environment for nurses working in the mental health area?

To conclude this research project I briefly discuss the research process, reflecting on whether or not I have answered the research question. I also reflect on the importance of the topic and the contribution this research may make for nurses practising in the area of mental health. I identify how I have benefited from participating as a researcher and also how the participants may have benefited from the process as well. I outline the limitations of the research and identify areas that may be worthy of further investigation. I identify how the research report will be disseminated and specifically how the focus group participants will receive the final research report.

I make the following general recommendations to nurse leaders who aim to encourage an empowering environment for nurses practising in mental health. I provide a number of specific examples arising from the focus group and the literature under each recommendation, to assist nurse leaders in the process of turning the recommendations into positive actions within the practice environment.

\section{Recommendations for Nurse Leaders}

\section{Recommendation One}

Acknowledge that nurses make up the majority of the healthcare workforce and promote and value their expertise and input in terms of clinical care and in terms of what they have to offer at a policy development level.

\section{Examples}

- Identify that nurses make up the majority of the mental health workforce in multidisciplinary and management forums and therefore need to be involved in policy development. 
- Identify specific nurses to be involved and participate in policy development and provide the nurses with feedback on their involvement.

- Provide training for nurses to ensure they have the appropriate knowledge and skills to participate in policy development.

- Ensure nurses have the time to contribute in a meaningful way.

- Ensure access to adequate resources and information.

\section{Recommendation Two}

Ensure that nurses have access to support at a professional level.

\section{Examples}

- Ensure access and time for ongoing education, clinical and peer supervision.

- Ensure access to a professional structure that encourages nursing leadership and supports nurses having control over the context and content of their practice.

\section{Recommendation Three}

Provide flexibility to enable nurses to manage their own caseload.

\section{Examples}

- Nurses deciding when they start and finish their day in relation to the needs of their patient caseload.

- Nurses having the ability to set the level of their patient caseloads, as other disciplines do - while ensuring mechanisms exist for providing the required services.

\section{Recommendation Four}

Ensure that authority matches responsibility and that nurses have the authority to make decisions within their scope of practice.

\section{Examples}

- Ensure appropriate training and support to provide nurses with the knowledge, skills, confidence and ability to make decisions.

- Develop clear psychiatric nursing models, with nurses practising in mental health. 


\section{Recommendation Five}

Encourage forums where nurses can explore the 'taken for granted' aspects of the practice environment, and use in-depth questioning, interpretation and analysis to increase their understanding of the practice environment.

\section{Examples}

- Ensure time is set aside for the forums to occur.

- Ensure access to appropriate facilitation if required.

\section{Recommendation Six}

Ensuring a 'caring environment from the top down' - the environment created for nurses will be reflected in the environment that nurses create for patients.

\section{Examples}

- Systems and personnel reflect a caring environment, which involves respect, valuing one another, supporting clinical decision-making and trust.

- Identify the impacts of horizontal violence within the nursing profession.

\section{Recommendation Seven}

Consider how nursing leaders can influence the organisational and management systems to encourage an empowering practice environment for nurses.

\section{Examples}

- Nurse leaders in key organisational and management positions, who insist on nursing participation at all levels of policy development.

- Ensure nurses apply for these key positions and that nurses in these positions are supported by other nurses at the clinical and management level.

\section{Recommendation Eight}

Advocate for nurses and nursing at a political and organisation systems level. Lobbying at this level will influence policy development/direction and provide role modelling in terms of nurses being political and influencing change.

\section{Examples}

- Participate and/or submit names of nurses to participate in national and local policy development forums. 
- Organise and provide submissions on national and local discussion documents.

\section{Reflections: Answering the Research Question/Importance and Contribution of this Research to Nursing}

As I continue to reflect on the research process I ask myself: Have I answered the question and what have I contributed to the development of nursing knowledge by completing this project? I have made a number of recommendations in order to answer the research question: What can nurse leaders do to encourage an empowering environment for nurses working in the mental health area? I consider this contribution important for two reasons.

First, Lange and Cheek (1997), and the Ministry of Health (1996, 1998) have identified the importance of nurses participating at a policy development level. They also identify that there is a lack of nursing involvement in policy development. Lange and Cheek (1997) suggest that if nurses want more autonomy and control over their practice, want to be involved in decision-making and want equality with other professionals in the healthcare setting, then they need to be involved in developing health policy. The MOH (1996) identified that it is nursing leaders that have a responsibility to ensure nurses have access to relevant information and the resources to make a meaningful contribution.

Second, within the mental health service an empowering environment is particularly important. To support this statement I refer back to Horsfall (1997, p.61) who describes the impact of the disempowering organisational systems;

People who experience psychiatric disturbances require trust, support, and care. None of these will be inevitably forthcoming if the nurse is rendered powerless by organisational practices and medical epistemologies and is therapeutically (along with the consumer) at the mercy of unpredictable medication. A cycle of impotence is perpetuated whereby the agency of both the client and the nurse is diminished, and the service user, as the more vulnerable and least powerful of the two, is likely to remain in a desperate state. 
As a nurse it is important to me that the users of mental health services feel supported in a caring and trusting environment. I would suggest that if nurses feel supported in a caring and trusting practice environment, they in turn will create this environment for the users of mental health services.

This research links a lack of participation in policy development to feelings of disempowerment. I provide a number of recommendations for nursing leaders that are aimed at encouraging an empowering mental health practice environment which in turn is aimed at facilitating nursing participation at a policy development level. There are a number of ideas that emerged throughout the research process and more specifically in the recommendation section. Nurses and others within the healthcare setting should consider these recommendations as nurses have a valuable contribution to make to the healthcare setting and make up the majority of the workforce. Nursing leaders need to be clear that there are strategies they can use to encourage an empowering environment but also that they can not make nurses feel empowered, only nurses can do this - feelings of empowerment come from within. I offer a quote from Freire (1983, p.10/11) in which he refers to the education system but there are parallels for nurse leaders and nurses;

The educator (nurse leader) must constantly discover and rediscover these paths that make it easier for the learner (nurse) to see the object to be revealed, and finally learned, as a problem. The educator's (nurse leader's) task is not to use these means and these paths to uncover the object himself (herself) and to offer it, paternalistically, to the learner, thus denying him (her) the effort of searching that is so indispensable to the act of knowing.

The process I used for this project needed to be consistent with the topic of empowerment and the underlying theoretical and philosophical position of Critical Social Theory. Horsfall (1997, p.63) writes specifically about the mental health practice environment and states that "it is essential that psychiatric nurses explore and critique hegemonic psychiatric beliefs and critically reflect on their own 
practice". I have endeavoured to use a critical approach to explore the reality of the nursing practice environment within mental health.

Acting as a change agent is an important concept in Critical Social Theory. I considered a statement by (Lather, 1991, p.4) that "Emancipatory, critical social science must be premised upon the development of research approaches which empower those involved to change as well as understand the world". I selected the focus group as the data collection tool for this reason as the focus group process is consistent with the emancipatory aims of critical social theory. I anticipated that throughout the focus group process the participants would gain an increased understanding of the concept of empowerment. It is the sharing of experiences and identifying with the opinions of others that gives the group participants the strength to act as change agents (Ward \& Mullender, 1991).

\section{Benefits of Participating in the Research Project}

As the researcher I am also a participant in the research process. Have I gained a greater self-understanding and/or bought about change at an individual and/or systems level?

I have reviewed literature on empowerment, critical social theory, and the history of nursing in relation to women's role in society, oppression and resistance. I have sought and gained the opinions of a group of nurses practising within mental health on the topic of empowerment. I started by thinking about all these issues/concepts independently but as I have moved through the research process they have become integrated. It has been difficult to try and separate the issues or concepts into chapters because they are all intertwined. I can not think about empowerment without thinking about critical social theory. I can not think about critical social theory without thinking about oppression because power relationships are central to a critical approach. I can not think about oppression without thinking about nursing the characteristics of oppressed group are evident within my everyday nursing practice as are actions indicative of the four levels in the analysis of social consciousness described by Freire (1987). I can not think about nursing without 
thinking about nursing history; or that most nurses work for large healthcare organisations; and that the social, political and economic environment influences healthcare organisations and the nurses that practice within.

So have I gained greater self-awareness and bought about change? I can answer yes to the fact that I have developed a greater awareness of the issues in general and a greater self-awareness. Through the research process I have increased my understanding of the complexity of the healthcare environment and therefore the complexity of the issues for nurses practising within mental health. The understanding has been achieved by examining the environment from an historical, social and political perspective. I have also increased my understanding of the issues by listening to the five nurses as they discussed their experiences related to empowerment within the practice environment. I have considered what the nurses discussed in relation to the literature reviewed and found consistent themes. These themes include; power is an important component of empowerment and power relationships and that at a systems level, professional, organisational, and political influences impact on feelings of empowerment and/or disempowerment. I have also benefited from the opportunity to make a contribution to nurses working in the mental health field by identifying strategies nursing leaders could use to encourage an empowering practice environment.

I can not answer for the participants in the focus group, but the research process was designed to be empowering, with discussion of the topic facilitating greater selfawareness and understanding which in turn facilitates emancipatory change. The benefits of being together as a group and having the opportunity to discuss issues and share experiences is identified by Longres and McLeod (1980) as the best way to raise consciousness, as it is through group discussion that the full implications of social experiences are explored.

\section{Limitations of the Research Project}

One of the limitations with this type of research that may be identified by people with positivist leanings, is the inability to generalise the research findings to the wider 
population. The conclusions I have drawn from the focus group discussion are relevant to this group of nurses at this one point in time.

One of the reasons I embarked on this research was to provide direction for my style of leadership to assist in creating a more empowering environment for the nurses who work in the inpatient areas which I manage. The most appropriate people to use as research participants would have been nurses within these inpatient areas but because of my management relationship with the nurses, there would have been ethical issues related to power imbalances. As stated in Chapter five, the participants in the research were mostly from community mental health services. The major difference between inpatient and outpatient services (apart from clinical differences) is that the inpatient nurses work the full range of shifts and have the patient group in residence 24 hours a day. This has an impact in terms of the time available to participate in policy development and also in terms of the time the entire team has together. I suspect that these factors are major contributors to the level of participation from nurses within mental health inpatient services but this was unable to be explored within this research project.

Familiarity with the topic, the participants and the organisation may have been a limitation within this study. Krueger (1998) describes familiarity as both an asset and a liability. Familiarity can assist in developing meaning from the focus group discussion but it can also limit one's thinking, as assumptions that are made may not be correct.

The size and scope of this project limited me to what I consider only a basic analysis of the focus group data. The willingness of the focus group participants to share their thoughts and feelings within the group was appreciated. However, I do not feel that the basic analysis and subsequent interpretation has done justice to, or honoured their contribution adequately. This topic was interesting and important for nurses and there was so much valuable data collected from the nurses who participated in the focus groups that I may have to reconsider how I can develop the ideas more fully in the future. 
As part of promoting rigour within the research process I sent out the key ideas I had identified from the focus group discussion with a range of quotes from the discussion to the participants (Appendices $9 \& 10$ ). On reflection I sent this information to the participants too early in the data analysis process. The initial key themes I identified form the focus group discussion were further developed and refined as the mechanical stage of the data analysis progressed. In retrospect it would have been better to complete the mechanical stage of the data analysis prior to sending out this information.

\section{Suggestions for Further Research}

There are a number of areas that arose from the focus group discussion, which I have mentioned only briefly. I suggest that these areas may be considered as worthy of further exploration.

One of the areas identified by the focus group participants was the impact of practising in a defensive healthcare environment. I have not supported this statement with literature or discussed this issue in depth. The defensive nature of the mental health care environment and the impact on feelings of empowerment and clinical decision-making are issues often discussed within the mental health service. Further exploration would be valuable in terms of nursing practice and changing the current environment.

Another area I have not explored is the impact of education and subsequent socialisation on nursing practice. Do newly graduated nurses have the skills to question, interpret and analyse their practice environment, and if they do what impact does the practice environment have on these skills in terms of socialisation?

The focus group participants practised in mental health, yet the issue of participation in policy development is not limited to nurses practising in mental health. A similar type of study in other areas of nursing may result in similar outcomes or may identify other strategies, which could be used by nursing leaders to create an empowering environment. 
The starting point of this research began with the idea that what I role modelled as a nurse leader was in turn role modelled by nurses within the practice environment. Sines (1994) identified that nurses dominated by managers may in turn dominate the patients requiring care and Horsfall (1997) identified that the agency of the nurse and the patient may be diminished in disempowering environments. The impact of the healthcare organisational culture on the culture of patient care to identify parallels would be an interesting research project and valuable in terms of the strategies required to change the culture of care throughout the organisation.

\section{Dissemination of Findings/Feedback to Participants}

The findings of this research will be available to the Victoria University of Wellington Graduate School of Nursing and Midwifery, and the healthcare organisation that supported the research. The participants in the research will have the opportunity to see a copy of the final research report. Articles arising from the research report may be submitted to international and national refereed nursing journals, and work in progress may also be presented at conferences. The research will be reported in a thesis and lodged in the library at Victoria University of Wellington. Continuing on with the empowerment perspective, Rapp et al. (1993, p.733) identify that "If knowledge is power then the results of research must be placed in the hands of those we seek to empower". By providing a copy for the supporting organisation, the participants in this research and other nurses within the organisation will have access to the findings of this research.

\section{Concluding Statement}

I have discussed the historical, social and political position of nurses within the healthcare system and the issues around empowerment. There is evidence in the literature that nurses are an oppressed group and that as part of this oppression, dominant groups will tell nurses what to do, define how they practice and that nurses will feel disempowered (Freire, 1970; McEldowney, 1995; Roberts, 1983; Speedy, 1987). The nurses who participated in the focus group discussion valued what they had to contribute as nurses at a clinical and service development level and were very clear about the reasons why they may appear reluctant to participate at a policy 
development level. They did not indicate that they were happy for others in the healthcare setting to tell them what to do, or to define their practice. They could identify that feelings of disempowerment existed and identify the professional, organisational, and political barriers to empowerment. I have offered a number of recommendations for nurse leaders in response to the research question; What can nurse leaders do to encourage an empowering environment for nurses working in the mental health area? To promote in depth questioning, interpretation and analysis within the nursing practice environment I have suggested a framework for assessing where nurses are positioned on the analysis of social consciousness continuum (Freire, 1987). The analysis might assist in understanding the reasons why nurses may not participate and why nurses might behave in ways which suggest they are an oppressed group.

As Starhawk (1987) suggests, it is only by uncovering how reality is shaped that we can begin to become shapers ourselves. 


\section{Appendix 1: Letter: Invitation to Participate in a Research Project}

\section{Address}

Date

Name

Address

Dear

\section{Invitation to participate in a research project}

The title of the research is: Empowerment: What can nursing leaders do to encourage an empowering environment for nurses working in the mental health area?

I am researching this area as part of the requirements for a Masters of Arts (Applied) Degree at the Department of Nursing and Midwifery, Victoria University of Wellington.

You are invited to participate in a focus group with other registered nurses who are interested in exploring the concept of empowerment.

Attached to this invitation is an information sheet, which will tell you more about the research project and what your participation would involve.

Participation in this research is voluntary and if you do not wish to participate in this research project you do not have to take any action.

If you would like to participate in this research project please read the consent form (attached) carefully before signing and once signed return in the self addressed envelope by the (date)

Thank you for taking the time to read this information

Yours sincerely

Heather Casey 


\section{Appendix 2: Participant Information Sheet}

\section{Participant Information Sheet}

\section{The title of the research is:}

Empowerment: What can nursing leaders do to encourage an empowering environment for nurses working in the mental health area?

I am currently enrolled in the Master of Arts (Applied) Degree in the Department of Nursing and Midwifery at Victoria University of Wellington. This research project is being undertaken as part of the requirements for this degree.

I have chosen to undertake a research project, which explores mental health nurses' perceptions of empowerment in relation to their practice environment and their participation at a decision making/service development level.

The aims of this research are to identify how nurses define empowerment and if feelings of disempowerment are the barrier to participation in service development activities, particularly related to nursing practice. A specific objective is to identify what needs to change in the work environment for nurses to feel they can participate and have control over the content and the context of their practice.

The findings of this research will provide direction with my style of leadership and assist in creating an environment, which allows for greater participation by mental health nurses in activities which impact on nursing practice.

I am inviting registered nurses working within the mental health service to participate in the research focus groups. The invitations to participate will be sent to a number of registered nurses who are employed on a full time basis and have practised in the mental health area for a minimum of one year.

If you are interested in participating in this project, approximately two hours of your time will be required in July to discuss the concept of empowerment in a focus group setting (with between 6 to 12 other nurses). Light refreshments will be available.

I will act as the focus group facilitator asking four questions of the group participants related to the concept of empowerment. I anticipate that the group will discuss the questions at length and that minimal prompting will be required from me. (Name, role and employing organisation) will also be in the group in the role of assistant facilitator. (Name) is also acting in the role as "critical friend" during this academic year.

The focus group discussion will be audio taped to record the data generated and to assist with the analysis of the data. 
Prior to analysing the data, the key themes identified within the focus group discussion will be circulated to the focus group participants for verification, to ensure the themes identified accurately reflect the group discussion

No material that could personally identify the focus group participants will be used in any reports related to this research. Direct quotations will be used to illustrate the main themes that emerge from the discussion. However, if the quotations are likely to identify the group member related to content or inflection, the quotations will not be used.

Written records and the audio tapes will be kept in a locked secure area at my home address. Transcriptions of the focus group discussion will be stored on the hard drive of my computer, which is password protected. The research supervisor will be the only other person who will have access to the audio tapes and the transcripts. The audio tapes may be kept for up to five years as this information may be used for further articles or presentations arising from the original research. After this time the audio tapes will be erased.

There are some potential risks associated with being a participant in this research project. The major risk to participants relates to my decision to conduct this research with nurses who work in a service where I also have a management position. The measures taken to minimise this risk are:

- inviting to participate in this research only nurses with whom I do not have a direct line management responsibility

- ensuring participants are fully informed about all aspects of the research

- using an assistant during the focus group to ensure equal relationships are maintained within the group, to ensure discussion remains focused around questions asked of the group and to monitor the group facilitation.

- involving the research supervisor in all aspects of this research

Another risk to participants may be if sharing opinions and feeling is uncomfortable for them within the group setting, or if issues are raised within the group setting which cause psychological distress. Participation is voluntary and therefore if sharing in a group setting is difficult for the prospective participant they have the choice of not being involved in the research. If during the course of the focus group session, psychologically distressing issues are raised for the participant, the participant has the choice of withdrawing from the research. If they wish to continue the facilitator will arrange a debriefing after the focus group session and follow up counselling as required through the (Healthcare Organisation) Employee Assistance Program. If the participant decides to withdraw they will have the same opportunity for debriefing. It is not envisaged that the topic and content of the research focus groups will cause distress but this needs to be planned for, as issues which cause distress, are not always predictable.

There may also be some potential benefits to the participants. The benefits may include increased feelings of empowerment in the nursing practice environment if the findings of the research are incorporated the workplace. There also may be a benefit in discussing the empowerment concept within a group setting as this may increase the participants understanding of the concept. 
Participation in this research is entirely voluntary. If you decide not to participate in this research take no further action. If you do decide to participate in this research, please read, sign and return the written consent form in the addressed envelope. Should you choose to withdraw you can do so at any time without having to give a reason, or you can decline to respond to any of the questions asked. Choosing not to participate or withdrawing after agreeing to participate will not jeopardise your work position in any way.

Confidentiality of participant names and information has been considered. The focus group assistant and research supervisor will be the only people apart from myself who will know the names of the research participants and the information they share within the group. The assistant and the typist transcribing the audio tapes, will be required to sign a confidentiality form which requests that they do not disclose any information related to the participants or the content of the discussion either during or after the research process.

This research has received ethical approval from the (Region) Ethics Committee. The secretary of this committee can be contacted on (number).

As a student in the Masters of Arts (Applied) Degree at Victoria University of Wellington the research process and content will be supervised at all stages. Rose McEldowney, Senior Lecturer at the Department of Nursing and Midwifery, Victoria University of Wellington, is supervising this study.

The findings of this research will be available to the Department of Nursing and Midwifery, Victoria University of Wellington and (Healthcare Organisation) as the organisations supporting the research. The participants in the research will have the opportunity to see a copy of the final research report. Articles arising from the research report may be submitted to international and national refereed nursing journals, and work in progress may also be presented at conferences. The research will be reported in a thesis and lodged in the library at Victoria University of Wellington.

If you have any questions or would like to receive further information about the project I can be contacted via phone (number). Ms McEldowney can be contacted at work on (number) if you have any queries about the research, which you can not address with me.

Thank you for taking the time to read this information

Heather Casey 


\section{Appendix 3: Consent Form to Participate in a Research Project}

\section{Consent Form to Participate in the Research Project}

I have been given and understood the information sheet which explains this research project. I understand that participation in the research project is entirely voluntary. I have had the opportunity to ask questions and I am satisfied with the answers I have been given.

\section{I also understand that:}

- if I do agree to participate and then choose to withdraw at any time I can do so without having to give a reason, or that I can decline to respond to any of the questions asked within the focus group

- choosing not to participate, or withdrawing after agreeing to participate, will not jeopardise my work position in any way

- confidentiality will be maintained as the participant names and group discussion will only be accessible to the researcher, the focus group assistant and the research supervisor

- the audio tapes used to record the group discussion will be available to the typist for transcribing. The assistant and the typist will be required to sign a confidentiality form which requests that they do not disclose any information related to the participants either during or after the research process

- the audio tapes will be stored in a locked cabinet for a period of up to five years after which time they will be erased

- although direct quotations may be used to support the main themes that emerge from the group discussion, no material which could be used to identify me, will be used in the research report.

I understand the potential risks of being involved as a participant in this research may include

- the researcher's decision to conduct the research with nurses who work in the same service where the researcher holds a management position.

- sharing opinions and feelings of discomfort within the group setting, or if issues are raised in the group, which cause psychological distress.

I also understand that

- the findings of this research will be available to the Department of Nursing and Midwifery, Victoria University of Wellington and (Healthcare Organisation) as the organisations supporting the research.

- I will have the opportunity to see a copy of the final research report.

- articles arising from the research report may be submitted to international and national refereed nursing journals, and work in progress may also be presented at conferences.

- the research will be reported in a thesis and lodged in the library at Victoria University of Wellington.

I agree to participate in this research project.

Signed:

Name of Participant:

Date: 


\section{Appendix 4: Application for Ethical Approval to Undertake a Research Project with Registered Nurse Employees of the Healthcare Organisation}

\section{APPLICATION FOR ETHICAL APPROVAL TO UNDERTAKE A RESEARCH PROJECT WITH REGISTERED NURSE EMPLOYEES OF (HEALTHCARE ORGANISATION)}

\section{Title of the Research}

Empowerment: What can nurse leaders do to encourage an empowering environment for nurses working in the mental health area?

\section{Background}

I am currently enrolled in the Master of Arts (Applied) Degree in the Department of Nursing and Midwifery at Victoria University of Wellington. This research project is being undertaken to meet the requirements for this degree.

I have worked as a registered nurse in Mental Health for the past eight years. My current position involves working as a nurse leader at (Healthcare Organisation). Service development activities I am involved in include; setting and maintaining standards of nursing practice, developing policies and procedures to support nursing practice, and providing leadership and direction in professional development activities.

I often ask myself why nurses are often reluctant to participate in service development activities. Is it because they think their input will be ignored and therefore they do not bother, or is it that they are quite happy for other people to tell them what to do and to define how they practice? Is the lack of participation related to feelings of disempowerment?

If nurses are to feel empowered within a practice setting they need to feel able to make choices and decisions about their work life. Several factors are identified in the literature related to issues of empowerment for nurses. These factors contribute to nurses perceiving that they have control over the content and the context of their practice and include: feeling valued; having opportunities for development and input into decision-making; and, having access to resources, support and information (Barker \& Ritter, 1996; Cahill, 1997; 1996; Gaitskell, 1998; Jenkins, 1997; Laschinger \& Havens, 1998; Rodwells 1996; Yarling \& McElmurry, 1986;). However, the lack of input by nurses into decision making or setting practice guidelines, and their willingness to have the structure of nursing practice dictated by others, suggests the work environment may not be empowering, but rather an environment that supports oppressed group behaviours (Speedy, 1987).

\section{Research Aim}

The aim of this research is to identify how mental health nurses define empowerment and if feelings of disempowerment are the barrier to participation in service development activities, particularly related to nursing practice. A specific objective is to identify what needs to change in the work environment for mental health nurses to feel they can participate and have control over the content and the context of their practice. 
The findings of this research will provide direction for my style of leadership and assist in creating an environment, which allows for greater participation by mental health nurses in activities which impact on nursing practice.

\section{Research Design}

This is an exploratory descriptive qualitative research project. The mental health nurses participating in the study will be identifying, describing and sharing their experiences of clinical practice in relation to the factors they believe are necessary to create an empowering environment - an environment in which they feel they have control over the content and the context of their practice.

Empowerment is about power, at an individual, organisational or societal level. The use of critical social theory as a theoretical base and as a methodology is consistent with research related to empowerment. Reality as it exists is related to "power relations that are socially and historically constructed" (Guba, 1990, p.139). Critical social theory identifies that knowledge can only be understood by examining the social and cultural conditions that exist, from an historical perspective (Held, 1980). Nursing has a long history and the structure of nursing today cannot be understood without reference to that history. Historical influences on nursing incorporate the values society has placed on gender, occupation, class, and types of knowledge. Nursing has developed as predominantly a woman's profession with women classified as having a duty to care for others (Reverby, 1987). The status of nursing within an occupational and class hierarchy was also significant as medical training and scientific knowledge were viewed as superior (Davis \& George, 1993).

A focus group of registered nurses will be used to generate the data. This approach to data gathering will offer participants an opportunity to respond to questions related to empowerment and reflect on what empowerment means for them within the workplace.

Throughout the focus group process, it is anticipated that the participants will gain an increased understanding of the concept of empowerment. This consciousness raising or greater understanding, is emancipatory, energising, and assists the participants toward transforming action (Held, 1980). Held (1980, p.242) suggests that "Critical knowledge enlightens an audience by revealing the structural conditions of their existence, specifically how these conditions came about and what distortions or injustices they currently represent". Therefore, it is through the raising of consciousness within the group that the 'status quo' may be examined and challenged, the power relationships and oppressive structures within nursing may be explored and reflected upon (Cheek \& Rudge, 1994).

\section{Research Process}

The research data will be gathered from a focus group of registered nurses working within the mental health service at (Healthcare Organisation). Focus groups are similar to a group interview; the significant difference being the discussion is generated from the interaction of participants within the group in response to the researcher's questions. Morgan (1988, p.12), describes the hallmark of focus groups as "the explicit use of the group interaction to produce data and insights that would be less accessible without the interaction found in the group". 
The size of the group will be determined by the number of registered nurses consenting to participate. I will invite 12 registered nurses to participate as the typical focus group size is between 6 to10 people (Morgan 1988). If all the nurses invited consent to participate the group will still be a workable size.

I will act as the focus group facilitator and (name, role and employing organisation) will fulfil the assistant role. (Name) is also acting as my "critical friend" for the duration of the research project which involves giving me feedback on my draft writing. She will also monitor my role as focus group facilitator.

Issues of confidentiality will be discussed with the focus group participants at the start of the session. Ground rules will be identified and agreed on by the group members. It is anticipated that the following will be identified:

- content of the discussion remaining within the group;

- respecting the opinion of others; and,

- one person at a time speaking.

Group settings are familiar to nurses working in mental health settings, as is the setting of ground rules within groups. I do not anticipate any difficulty with the group agreeing to these ground rules, as they are standard for group settings.

A semi-structured interview technique will be used in the focus group to stimulate the discussion. The researcher will ask four open-ended questions within a two-hour time frame. These questions are:

1. Describe what the term empowerment means to you as a mental health nurse within your current practice environment?

2. Describe the aspects of your working environment, which encourage you to feel empowered?

3. Describe the barriers in your working environment, which discourage you from feeling gonnpyered?.

4. Describe the changes you would like to see in your working environment that would assist in increasing your feelings of empowerment?

The researcher will use minimal prompts to encourage discussion; not leading the discussion but encouraging extensive discussion until saturation point has been reached for each question. Saturation point will be determined when the group is silent for a period of 10 seconds and agree when asked if they are ready to move onto the next question. The questions will be written up on a whiteboard for the group members' reference during the discussion. The next question will be read out after saturation point has been reached with the previous question. The definition of empowerment reached by group consensus will be written on the whiteboard before proceeding with the next three questions. Key themes generated from the focus group discussion will also be identified and prioritised by group consensus.

The focus group discussion will be audio taped on two tape recorders and the tapes transcribed by a typist.

Analysis of Data

Prior to analyzing the data, the key themes identified within the focus group discussion will be circulated to the focus group participants to ensure the themes 
identified accurately reflect the group discussion. Seeking feedback from the focus group assists with the trustworthiness and validity of the data analysis (Krueger, 1998).

The data will be analysed by examining the ranked key themes that emerge from the discussion. Direct quotations from the group discussion will be used to support the key themes identified.

The key themes will be examined within the broader context of the mental health nursing practice environment and will be informed by a critical social theory perspective. That is, the social and cultural conditions that underlie nursing practice will be examined from an historical perspective and will inform the discussion about feelings of empowerment and disempowerment within the nursing practice environment.

\section{Selection of Participants}

A group of 12 registered nurses working within the mental health service of (Healthcare Organisation) will be sent an Invitation to Participate Sheet (refer Appendix 1), an Information Sheet (refer Appendix 2), and an Informed Consent Form (refer Appendix 3). Criteria for selection will be that the nurses are employed on a full time basis and have practised in the mental health area for a minimum of one year. The nurses invited to participate will be employed within inpatient wards and community services where I do not have a line management responsibility.

\section{Participation in the Research Project}

Participation in the research is entirely voluntary. A participant can withdraw from the project at any time without having to give a reason, or they can decline to respond to any of the questions asked within the focus group. An assurance will be provided in the information sheet to participants that their work positions will not be jeopardised if they decide to withdraw. It is crucial that this is overtly stated considering my management position within the service. I will not have line management responsibility for the nurses who will be sent invitations to participate.

Participation in the focus group will take approximately two hours and light refreshments will be made available.

\section{Maintaining Confidentiality}

Confidentiality of participants' names and information has been considered. The focus group assistant and the research supervisor will be the only people apart from myself who know the names of the research participants and the information they share within the focus group. The focus group assistant, (name), and the typist transcribing the audio tapes will be required to sign a confidentiality form which requests that they do not disclose any information related to the participants or the discussion, either during or after the research process. The research supervisor will have access to the audio tape and transcripts during the research process. Focus group participants will also be requested to maintain confidentiality. This expectation will be one of the group 'rules'.

No material that could personally identify the focus group participants will be used in any reports related to this research. Direct quotations will be used to illustrate the 
main themes that emerge from the discussion. However, if the quotations are likely to identify the group member related to content or inflection, the quotations will not be used.

\section{Storage of Information}

Written records and the audio tapes will be kept in a locked secure area at my home address. Transcriptions of the focus group discussion will be stored on the hard drive of my computer, which is password protected. The audio tapes may be kept for up to five years as this information may be used for further articles or presentations arising from the original research. After this time the audio tapes will be erased.

\section{Informed Consent}

Informed consent will be obtained from prospective participants by providing an Invitation to Participate (refer Appendix 1) which will be accompanied by an Information Sheet (refer Appendix 2) which will provide comprehensive details of what the research involves and an Informed Consent Form (refer Appendix 3). Informed consent will be assumed if the registered nurse returns the signed consent form.

\section{Potential Risks to Participants}

The major risk to participants relates to my decision to conduct this research with nurses who work in a service where I also have a management position. The measures taken to minimise this risk are:

- Inviting to participate in this research only nurses with whom I do not have a direct line management responsibility

- Providing a comprehensive information sheet which clearly outlines why the research is being conducted, the aim of the research, my role within the focus group and a statement that participation is entirely voluntary

- Using an assistant during the focus group. The assistant's role will be to ensure equal relationships are maintained within the group, discussion remains focused around the questions asked of the group and to monitor the group facilitation.

- Involving the research supervisor in all aspects of this research.

Another risk to participants may be if sharing opinions and feelings is uncomfortable for them within the group setting or if issues are raised in the group, which cause psychological distress. Participation is voluntary and therefore if sharing in a group setting is difficult for the prospective participant they have the choice of not being involved in the research. If during the course of the focus group session, psychologically distressing issues are raised for the participant, the participant has the choice of withdrawing from the research. If they wish to continue the facilitator will arrange a debriefing after the focus group session and follow-up counselling as required through the (Healthcare Organisation) Employee Assistance Program. If the participant decides to withdraw they will have the same opportunity for debriefing. It is not envisaged that the topic and content of the research focus groups will cause distress but this needs to be planned for, as issues which cause distress, are not always predictable. 


\section{Benefits of Participating in this Research Project}

Benefits to the participants may include increased feelings of empowerment in the nursing practice environment if the findings of the research are incorporated in the workplace. There also may be a benefit in discussing the empowerment concept within a group setting as this may increase their understanding of the concept. Other positive aspects may include the benefit of being together as a group and having the opportunity to discuss issues and share experiences. As the researcher, I will also benefit from this experience, my understanding of the concept of empowerment will be enhanced as well as experiencing the satisfaction of making a contribution to nurses working in the mental health field.

\section{Research Supervision}

As a student in the Masters of Arts (Applied) Degree at Victoria University of Wellington, the research process and content will be supervised at all stages.

Rose McEldowney, Senior Lecturer at the Department of Nursing and Midwifery, Victoria University of Wellington, is supervising this study. If you wish to discuss any aspects of the project with my supervisor she can be contacted at work on (telephone numbers).

\section{Dissemination of Findings/Feedback to Participants}

The findings of this research will be available to the Department of Nursing and Midwifery, Victoria University of Wellington and (Healthcare Organisation), as the organisations supporting the research. The participants in the research will have the opportunity to see a copy of the final research report. Articles arising from the research report may be submitted to international and national refereed nursing journals, and work in progress may also be presented at conferences. The research will be reported in a thesis and lodged in the library at Victoria University of Wellington.

(If ethical approval is granted a formal letter to (Healthcare Organisation) requesting permission to conduct the research will be submitted.)

Attached:

Appendix 1: Invitation to participate

Appendix 2 Participant information sheet

Appendix 3 Consent form to participate in the research project 


\section{References}

Barker, P., \& Ritter, S. (1996). Editors commentary. Journal of Psychiatric and Mental Health Nursing, 3, 141 - 144.

Cahill, A. (1997). Guest editorial: empowerment, answering the white phone first. Journal of Nursing Administration, 27(7/8). 5-6.

Cheek, J., \& Rudge, T. (1994). Been there, done that? consciousness raising, critical theory and nurses. Contemporary Nurse, (3).

Davis, A., \& George, J. (1993). A profession of nursing. Chapter 7. States of Health. Australia: Harper Educational

Gaitskell, S. (1998). Professional accountability and service user empowerment: issues in community mental health. British Journal of Occupational Therapy, 61(5). 221-222.

Guba, E. G. (Ed). (1990). The paradigm dialog. California: Sage Publications

Held, D. (1980). Introduction to critical social theory: Horkheimer to Habermas. Hutchinson: London.

Jenkins, R. (1997). Issues of empowerment for nurses and clients. Nursing Standard, 11(46). 44-46.

Krueger, R. A. (1998). Analysing \& reporting focus group results: Focus group kit 6. London: Sage Publications.

Laschinger, H., \& Havens, D. (1998). Testing Kanter's theory with workplace empowerment and occupational stress. Research in Nursing, 5, 28-36.

Morgan, D. L. (1988). Focus groups as qualitative research. California: Sage Publications.

Reverby, S. (1987). A caring dilemma: womanhood and nursing in historical perspective. Nursing Research 36(1).

Rodwell, C. (1996). An analysis of the concept of empowerment. Journal of Advanced Nursing, (23). 305-313.

Speedy, S. (1987). Feminism and the profession of nursing. The Australian Journal of Advanced Nursing, 4(2). 20-29.

Yarling, R., \& McElmurry, B. (1986). The moral foundation of nursing. Advances in Nursing Science, 8(2). 63-73. 
14 July 2000

Heather Casey

Dear Heather

Research project with registered nurse employees of Healthcare Otago Investigator:

Ethics Reference: $\quad$ CPD 00/22

I acknowledge receipt of your fax of 7 July enclosing this application which was referred to (name) i, Chairperson of this committee for his consideration. (name) is happy to give full ethical approval for this project.

Approvals granted to protocols are for 12 months. If, after 12 months the study is not completed, it will be necessary to forward to the Committee a brief report on progress made to date and a request for an extension.

It should be noted that Ethics Committee approval does not imply any resource commitment or administrative facilitation by any healthcare provider within whose facility the research is to be carried out. Where applicable, authority for this must be obtained separately from the appropriate manager within the organisation.

Please advise the Committee on the completion of the study or if, for any reason, you decide not to complete it. On completion of the study a brief report should be forwarded to the Committee.

Please quote the above protocol number in all correspondence relating to this study.

Yours sincerely

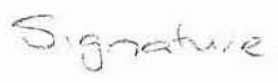

Ethics Committee Administrator 


\section{Appendix 6: Letter: Request for Access to Registered Nurse Employees of the Healthcare Organisation}

Address

$21^{\text {st }}$ July 2000

Name and address

Dear (Name)

\section{Re: Research project with registered nurse employees of (Healthcare Organisation)}

I am currently enrolled in the Master of Arts (Applied) Degree in the Department of Nursing and Midwifery at Victoria University of Wellington. As part of the final year of study I am undertaking a research project to meet the requirements for this degree.

The research project is titled:

Empowerment: What can nurse leaders do to encourage an empowering environment for nurses working in the mental health area?

The aim of this research is to identify how mental health nurses define empowerment and if feelings of disempowerment are the barrier to participation in service development activities, particularly related to nursing practice. A specific objective is to identify what needs to change in the work environment for mental health nurses to feel they can participate and have control over the content and the context of their practice.

The findings of this research will provide direction for my style of leadership and assist in creating an environment, which allows for greater participation by mental health nurses in activities which impact on nursing practice.

I am seeking your permission to approach 12 registered nurses from the Mental Health Service to participate in a focus group. The focus group will be held in August and will take approximately two hours. To maximise participation I would like to arrange the focus group between $3 \mathrm{pm}$ and $5 \mathrm{pm}$, which may mean two hours off during work time for a number of the nurses.

The registered nurses will be asked to discuss the concept of empowerment within the group setting.

The nurses invited to participate will be employed within inpatient wards and community services where I do not have a line management responsibility.

Rose McEldowney, Senior Lecturer at the Department of Nursing and Midwifery, Victoria University of Wellington, is supervising this study. If you wish to discuss any aspect of the project with my supervisor she can be contacted at work on (number). 
The findings of this research will be available to the Department of Nursing and Midwifery, Victoria University of Wellington and (Healthcare Organisation), as the organisations supporting the research. The participants in the research will have the opportunity to see a copy of the final research report. Articles arising from the research report may be submitted to international and national refereed nursing journals, and work in progress may also be presented at conferences. The research will be reported in a thesis and lodged in the library at Victoria University of Wellington.

I enclose a copy of the letter from the (Region) Ethics Committee granting full ethical approval.

Yours sincerely

Heather Casey 
Heather Casey

Dear Heather

Thank you for your letter requesting approval to undertake your research project with registered nurses employed by organisation I am pleased to support your project and therefore confirm my approval for you to approach 12 Registered Nurses from within the Mental Health Clinical Practice Group to participate in a focus group. I have discussed this with the Team Leaders who will be involved (! names)

You will need to contact these team leaders prior to approaching staff to introduce your project and to coordinate times of when staff would be able to be released. Please note that some staff finish duty at $4.30 \mathrm{pm}$, your suggestion was for the focus group to be between $3 \mathrm{pm}-5 \mathrm{pm}$.

Empowerment is a particularly interesting topic. I wish you all the very best with your research and I look forward to seeing your thesis.

Regards

Yourgsincerely<smiles>C=C=[13C][As]=S</smiles> 
Appendix 8: $\quad$ Letter: Confidentiality Agreement - Focus Group Assistant.

VICTORIA UNIVERSITY OF WELLINGTON

$T e$ Whare Wananga o te Upoko o te Ika a Mani

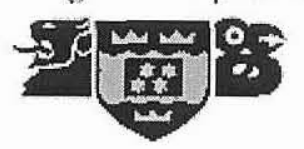

$1^{\text {st }}$ September 2000

(Name and Address)

Dear (Name)

Thank you for agreeing to undertake the assistant facilitator role within the focus group. As you are aware the group is part of a research project I am undertaking to meet the requirements of the Master of Arts (Applied) Degree in the Department of Nursing and Midwifery at Victoria University of Wellington.

The identities of the participants in this research and the content of the discussion are to remain confidential. There is a strong possibility that you will know the participants and/or relate the content of the discussion to services or people you are familiar with in (Local Area).

I seek your assurance that you will protect the confidentiality of the participants and the contents of their discussion. If you are willing to provide this assurance could you please sign the section at the end of this letter and return the letter.

Yours sincerely

Heather Casey

I will maintain confidentiality related to the identity of the participants and the contents of their discussion.

Signed

Date 


\title{
Appendix 8: $\quad$ Letter: Confidentiality Agreement - Transcriber
}

\author{
VICTORIA UNIVERSITY OF WELLINGTON \\ Te Whare Wananga o te Upoko o te Ika a Mati
}

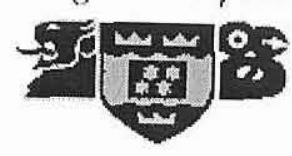

$1^{\text {st }}$ October 2000

(Name and Address)

\section{Dear (Name)}

Thank you for agreeing to undertake the transcription from the audiotapes. The tapes are part of a research project I am undertaking to meet the requirements of the Master of Arts (Applied) Degree in the Department of Nursing and Midwifery at Victoria University of Wellington.

The identities of the participants in this research and the content of the discussion recorded on the audiotapes are confidential. There is possibility that you may recognise the participants or relate the content of the discussion to services or people you are familiar with.

I seek your assurance that you will protect the confidentiality of the participants and the contents of their discussion while you are transcribing the audiotapes. If you are willing to provide this assurance could you please sign and return the section at the end of this letter.

Thank you for your assistance with the transcriptions

Yours sincerely

Heather Casey

I will maintain confidentiality related to the identity of the participants and the contents of their discussion.

Signed

Date 


\section{Appendix 9:Letter: Thank You for Participating in the Focus Group and Accuracy Check with Focus Group Participants}

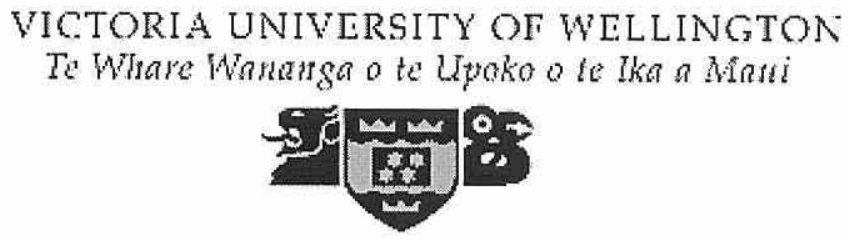

$28^{\text {th }}$ October 2000

(Name and Address)

Dear (Name)

Thank you so much for participating in the focus group and for being so willing to discuss the concept of empowerment. (Focus Group assistant - Name) was correct when she said that the two weeks I initially suggested for getting this information to you might have been a bit hasty. You may be interested to know that during the twohour period the discussion consisted of over 14,000 words, which have since been transcribed by a very patient typist.

Enclosed are the major themes I have identified from the focus group discussion about empowerment. I have also included supporting quotes from the discussion, which I may use to illustrate the themes.

If you consider that the themes I have identified accurately reflect the discussion which occurred and support the use of the identified quotes within the thesis then you do not need to take any further action.

If you do not consider that the themes discussed have been accurately identified please add or delete on the copy provided. If you do not support the use of any of the quotes within the thesis could you also please delete or amend on the copy provided. I would be grateful if you could return the amended copy to me through the internal mail by the $6^{\text {th }}$ November.

Again thank you for your participation, I will contact you again when this thesis is complete to ensure that you have the opportunity to read the completed research.

Yours sincerely

Heather Casey 
Appendix 10: Key Ideas to Emerge from the Focus Group Discussion with Supporting Quotes - (Sent to Participants with Appendix 9)

The initial key ideas to emerge from the focus group discussion with supporting quotes:

1. What the term empowerment means to you as a mental health nurse within your current practice environment?

Power relationships

- acknowledgement that the nurse has power in their relationships with clients

- unequal power with manager and within work environment

- equal power with manager

- having power but not abusing it

- having some understanding of power and power imbalance

- The clients of the service most probably feel disempowered - similar to how I feel within the hierarchical structure where I work

- My own personal authority is what gives me some power

- Being uncomfortable about having my own power - because you get to choose whether you empower others - you've got to remember all the time that you (as the nurse) are holding all of the power

- People create their own inner power - another person can only assist or guide

- It's not necessarily ours to give (power) but it could be very easily ours to take away.

- how we as nurses are and how we feel is hugely important in our work and how we relate to our clients - if I feel like I have nothing, then what do I have to give

Professional/Historical

- We (nurses) maybe large in numbers but we are not considered important (within the organisation).

- There is something about nursing and its historical context - that its women's work - a caring profession - within society's structure its not something that has had a huge lots of status

2. Describe the aspects of your present working environment, which encourage you to feel empowered?

Professional

- Good working relationships with other nurses

- Peer supervision

- Individual (clinical) supervision

- Education

Organizational

- Time (to do my job well).

- Being actively involved in the service I work for

- When nursing knowledge and nursing expertise are valued.

- Having a manager that has some kind of concept about where nursing is and who values nurses and the nursing role

- Good information provided

- Input to where the service is going

- Good management at a direct level, 
- Autonomy in how you work

- Getting feedback

- Being consulted with in a meaningful way about change

- Being part of joint decision making

3. Describe the barriers in your working environment, which discourage you from feeling empowered?

Medical staff

- its very easy for them to dismiss what we think

- historically powerful

- they have power, right from the top - because the whole system is funded according to diagnosis

- When I can't say what I really believe in for a patient, I tend to put them up there on a pedestal - Its that authoritarian kind of thing, what I feel is that what I say doesn't have much validity.

Remuneration

- A Policeman is worth more than a staff nurse is first year out of Police College.

Legislation

- Mental Health Act - enforcing treatment is disempowering

Political

- the fear of litigation

- Not being able to work with people to the full potential - (due to time constraints and competing priorities)

- The defensible culture we practice within makes it really hard for us to sit down with our colleagues and to actually learn from mistakes.

- not able to take the risks that we need to take with clients due to the defensive nature of our practice

Organizational

- Being told what to do rather than negotiated with - working in partnership

- Being expected to be involved in service development with no reduction in caseload

- Having to work set hours - nobody (patients) want to see me before 11 o'clock anyway but I still have to turn up at 8 o'clock and work to the work is finished.

- Responsibility without authority

- Management expectations of the extent nurses will work on "good will"

- Working continually within the constraints of the system

- Relationships with managers

- Evidence based or best practice is not supported by the organisation's rules

- Standing up for yourself can make you really unpopular

- Lack of equality of professional groups within the teams

Professional

- Nurses disempowering themselves and the nursing model all the time

- Horizontal violence amongst nurses, disempowering our own, we eat our young

- Nurses not valuing nursing

- No clinical structure for nurses

- No valuing of professional identity 
- Fragmentation of nursing (crisis clinicians, nurse counsellors - different contracts)

- Lack of career pathway

- Nurses aren't allowed to say no, "no I can't take anymore patients" - we aren't given choices about being able to say no.

- nurses not supporting each other

4. Describe the changes you would like to see in your working environment that would assist in increasing your own feelings of empowerment?

Professional

- To ditch DSMIV and ICD10 (diagnostic tools) and work from a nursing model

- Nurse leaders actually promoting some unity amongst us as a professional group.

- Nurses looking after each other

- Nurses respecting and valuing each other

- Nursing leadership being taken away from management and put into a professional leadership structure

Organizational

- Support from the organisation with clinical decision making. (I think my practice could be empowered by actually not feeling insecure or that I won't be supported from management when making the best clinical decision I can.)

- A caring environment - from the top down

- Being supported in setting boundaries around what and how much nurses can do.

- Having time to be to do a good job with patients

- Having time to be involved in service development actives and being recognised for the work I do

I return this copy with the identified amendments and/or deletions, which will assist in ensuring the discussion from the focus group is accurately interpreted/recorded. 


\section{References}

Allen, D., Benner, P., \& Diekelmann, N. (1986). Three paradigms for nursing research: methodological implications. In M. Chin (Ed.), Nursing research methodology: issues and implementation, (pp.190-198). Rockwelle, MD: Aspen Publications.

Alschuler, A. S. (1986). Creating a world where it is easier to love: counselling applications of Paulo Freire's theory. Journal of Counselling and Development, 64(8), 341-345.

Argirides, A. (2000). Why are focus groups not group interviews. Qualitative Research Journal, 1(1), 8-10.

Barker, P., \& Ritter, S. (1996). Editors commentary. Journal of Psychiatric and Mental Health Nursing, 3, 141-144.

Beyea, S. C., \& Nicoll, L. H. (2000). Methods to conduct focus groups and the moderator's role. AORN Journal, 71(5), 1067-1068.

Cahill, A. (1997). Guest editorial: empowerment, answering the white phone first. Journal of Nursing Administration, 27(7/8), 5-6.

Campbell, J. C., \& Bunting, S. (1991). Voices and paradigms: perspectives on critical and feminist theory in nursing. Advances in Nursing Science, 13(3), 1-15.

Chamberlin, J. (1997). A working definition of empowerment. Psychiatric Rehabilitation Journal, 20(4), 43-46.

Chopoorian, T. J. (1986). Reconceptualisation of the environment. In P. Moccia (Ed.), New approaches to theory development, New York: National League for Nursing.

Collins concise dictionary (4 ${ }^{\text {th }}$ Ed.). (1999). Glasgow: Harper-Collins.

Cook, M. J. (2001). The renaissance of clinical leadership. International Nursing Review, 48, 38-46.

Crowe, M. (1996). Cutting up: signifying the unspeakable. Australian and New Zealand Journal of Mental Health Nursing, 5, 103-111.

Crowe, M. (1997). An analysis of the socio-political context of mental health nursing practice. Australian and New Zealand Journal of Mental Health Nursing, 6, 59-65.

Crowe, M. (2000). The nurse-patient relationship: a consideration of its discursive context. Journal of Advanced Nursing, 31(4), 962 - 967. 
Denzin, N. K., \& Lincoln, Y. S. (1994). Handbook of qualitative research. California: Sage Publications.

Du Plat-Jones, J. (1999). Power and representation in nursing: a literature review. Nursing Standard, 13(49), 39-42.

Ekeberg, C., Lagerstrom, M., \& Lutzen, K. (1997). Empowerment and occupational health nursing. AAOHN Journal, 45(7), 342-347.

Foucault, M. (1980). Power/Knowledge: selected interviews and other writings, 1972-1977. New York: Pantheon Books.

Freire, P. (1970). Pedagogy of the oppressed. New York: Continuum.

Freire, P. (1983). Pedagogy in progress. New York: Continuum.

Freire, P. (1987). Education for critical consciousness. New York: Continuum.

Fulton, Y. (1997). Nurses views on empowerment: a critical social theory perspective. Journal of Advanced Nursing, 26, 529-536.

Gaitskell, S. (1998). Professional accountability and service user empowerment: Issues in community mental health. British Journal of Occupational Therapy, 61(5), 221-222.

Gilbert, T. (1995). Nursing: empowerment and the problems of power. Journal of Advanced Nursing. 21, 865-871.

Gilboe, M., Campbell, J., \& Berman, H. (1995). Stories and numbers: coexistence without compromise. Advances in Nursing Science, 18(1), 1426.

Gramsci, A. (1971). Selections from the prison notebooks. New York: International Publishers.

Guba, E. G. (Ed.). (1990). The paradigm dialog. California: Sage Publications.

Guba, E. G., \& Lincoln, Y. S. (1989). Fourth generation evaluation. Newbury Park: Sage Publications.

Habermas, J. (1972). Knowledge and human interests. Boston: Beacon Press.

Hedin, B. A. (1986). A case study of oppressed group behaviour in nurses. IMAGE: Journal of Nursing Scholarship, 18(2), 53-57.

Held, D. (1980). Introduction to critical social theory: Horkheimer to Habermas. London: Hutchinson. 
Holter, I. M. (1988). Critical theory: a foundation for the development of nursing theory. Scholarly Inquiry for Nursing Practice: An International Journal, 2(3), 233236.

Horsfall, J. (1997). Psychiatric nursing: epistemological contradictions. Advances in Nursing Science, 20(1), 56-65.

Hubbard, A. (1994). Why I blew the whistle. Listener. May, 16-22.

Hutchinson, S. (1990). Responsible subversion: a study of rule bending among nurses. Scholarly Inquiry for Nursing Practice: An International Journal, 4(1), 3-22.

Jenkins, R. (1997). Issues of empowerment for nurses and clients. Nursing Standard, 11(46), 44-46.

Kanter, R. M. (1977). Men and woman of the corporation. New York: Basic Books.

Koch, T. (1994). Establishing rigour in qualitative research: the decision trail. Journal of Advanced Nursing, 19, 976 - 986.

Koch, T., \& Harrington, A (1998). Reconceptualising rigour: the case for reflexivity. Journal of Advanced Nursing, 28(4), $882-890$.

Krueger, R. A. (1998). The focus groups kit. California: Sage Publications.

Kuokkanen, L., \& Leino-Kilpi, H. (2000). Power and empowerment in nursing: three theoretical approaches. Journal of Advanced Nursing, 31(1), 235-241.

Lange, A., \& Cheek, J. (1997). Health policy and the nursing profession: a deafening silence. International Journal of Nursing Practice, 3, 2-9.

Lather, P. (1991). Getting smart: feminist research pedagogy with/in the post modern. New York: Routledge.

Laschinger, H., Finegan, J., Shamian, J., \& Casier, S. (2000). Organisational trust and empowerment in restructured healthcare settings. Journal of Nursing Administration, 30(9), 413-425.

Laschinger, H., \& Havens, D. (1996). Staff nurse work empowerment and perceived control over nursing practice. Journal of Nursing Administration, 26(9), $177-186$.

Laschinger, H., Sabiston, J. A., \& Kutszcher, L. (1997). Empowerment and staff nurse decision involvement in nursing work environments: testing Kanter's theory of structural power in organisations. Research in Nursing, 20, 341-352. 
Laschinger, H., \& Wong, C. (1999). Staff nurse empowerment and collective accountability: effect on perceived productivity and self-rated work effectiveness. Nursing Economics, 17(6), 308-316.

Lewis, M. (1990). Interrupting patriarchy: politics, resistance, and transformation in the feminist classroom. Harvard Educational Review, 60(4), 467-488.

Longres, J. F., \& McLeod, E. (1980). Consciousness raising and social work practice. Social Casework, 61(5), 267-276.

Lythgoe, J. (1977). Paulo Freire: from radical reformer to revolutionary advocate. Learning, 3(2), 18-24.

McEldowney, R. (1995). Critical resistance in nursing education: a nurse educator's story. Unpublished Master of Education thesis, University of Waikato: New Zealand.

McHoul, A., \& Grace, W. (1998). A Foucault primer: discourse, power and the subject. New Zealand: University of Otago Press.

McNaught, D. (2001, July). What becomes of the broken hearted? A report from the front lines of mental health. Metro, 37-51.

Manias, E., \& Street, A. (2000). Legitimation of nurses' knowledge through policies and protocols in clinical practice. Journal of Advanced Nursing, 32(6), 1467 -1475 .

Mental Health Commission. (1998). Blueprint for mental health services in New Zealand. Wellington: Mental Health Commission.

Mental Health (Compulsory Assessment and Treatment) Act 1992. New Zealand Government Printers: Wellington.

Ministry of Health. (1996). Nursing leadership development. Wellington: Ministry of Health.

Ministry of Health. (1997). Moving forward: the national mental health plan for more and better services. Wellington: Ministry of Health.

Ministry of Health. (1998). Report of the ministerial taskforce on nursing: releasing the potential of nursing. Wellington: Ministry of Health.

The Mirriam - Webster Thesaurus. (1989). Massachusetts: Mirriam - Webster Inc.

Morgan, D. L. (1988). Focus groups as qualitative research. California: Sage Publications. 
Morgan, D. L. (Ed). (1993). Successful focus groups: advancing the state of the art. California: Sage Publications.

Morgan, D. L. (1998). The focus groups kit. California: Sage Publications.

Morrison, R., Jones, L., \& Fuller, B. (1997). The relationship between leadership style and empowerment on job satisfaction of nurses. Journal of Nursing Administration, 27(5), 27-34.

Opie, A. (1998). "Nobody asked me for my view": users' empowerment by multidisciplinary health teams. Qualitative Health Research, 8(2), 188-206.

Rapp, C. (1998). The strengths model. New York: Oxford Press.

Rapp, C. A., Shera, W., \& Kisthardt, W. (1993). Research strategies for consumer empowerment of people with severe mental illness. Social Work, 38(6), 727-735.

Reverby, S. (1987). A caring dilemma: womanhood and nursing in historical perspective. Nursing Research, 36(1), 5-11.

Reverby, S. (1987). Ordered to care. Cambridge: Cambridge University Press.

Roberts, S. J. (1983). Oppressed group behaviour: implications for nursing. Advances in Nursing Science, 5(4), 21-33.

Roberts, S. J. (1999). Power to the leaders. Nursing Spectrum (Online), 3 pages. Available:http://community.nursingspectrum.com/MagazineArtilces/artilce.cfm?AID $=1$. (November 29).

Robinson, J. (1991). Power, politics and policy analysis in nursing. In A. Perry \& M. Jolly, Nursing: A knowledge base for practice, (p. 271-307).

Rodwell, C. (1996). An analysis of the concept of empowerment. Journal of Advanced Nursing, 23, 305-313.

Sines, D. (1993). Balance of power. Nursing Times, 89(46), 52-55.

Sines, D. (1994). The arrogance of power: a reflection on contemporary mental health nursing practice. Journal of Advanced Nursing Practice, 20, 894 - 903.

Skinner, Q. (Ed.). (1985). The return of grand theory in the human sciences. Cambridge: Cambridge University Press.

Speedy, S. (1987). Feminism and the profession of nursing. The Australian Journal of Advanced Nursing, 4(2), 20-29.

Starhawk. (1982). Dreaming the dark: magic, sex and politics. New Edition, (1988). Boston: Beacon Press. 
Starhawk. (1987). Truth or dare: encounters with power, authority and mystery. San Francisco: Harper \& Row.

Stevens, P. E. (1989). A critical social reconceptualisation of environment in nursing: implications for methodology. Advances in Nursing Science, 11(4), 56-68.

Street, A. F. (1992). Inside nursing: a critical ethnography of clinical nursing practice. New York: State University of New York Press.

Turrell, E. (1996). Understanding the conflicts of patient empowerment. Nursing Standard, 10(45), 43-47.

Walker, R. (1998). Diabetes: reflecting on empowerment. Nursing Standard, 12(23), 49-52.

Ward, D., \& Mullender, A. (1991). Empowerment and oppression: an indissoluble pairing for contemporary social work. Critical Social Policy, 11(2), 21-30.

Weary, G., Gleicher, F., \& Marsh, K. (Eds.). (1993). Control motivation and social cognition. New York: Springer-Verlag.

White, M. (1989). Experience and narrative. Plenary Address: Australian and New Zealand Conference of Family Therapy, Christchurch: New Zealand.

Yarling, R., \& McElmurry, B. (1986). The moral foundation of nursing. Advances in Nursing Science, 8(2), 63-73. 